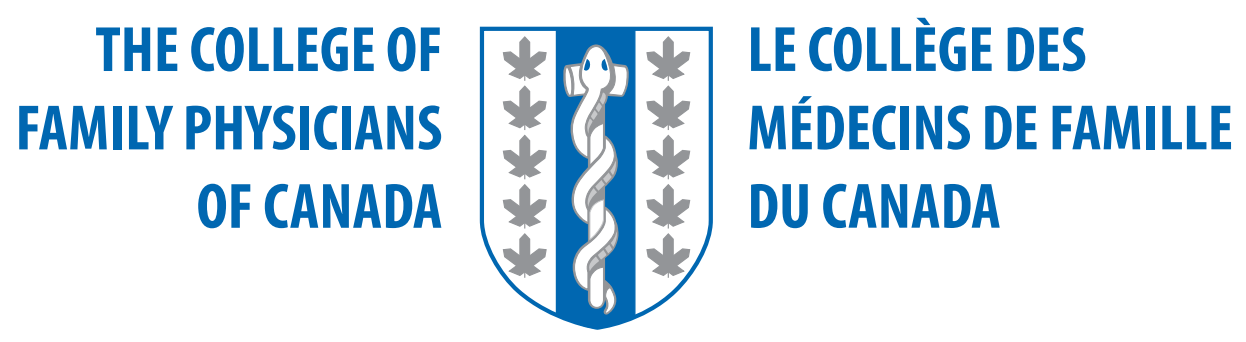

\title{
Triple C
}

Competency-based Curriculum

Report - Part 2

\section{Advancing Implementation}

\section{Canadian Family Medicine au Canada}


(C)The College of Family Physicians of Canada 2013 All rights reserved.

Suggested Citation:

Oandasan I, Saucier D, eds. Triple C Competency-based Curriculum Report - Part 2: Advancing Implementation. Mississauga, ON: College of Family Physicians of Canada; 2013.

Available from: www.cfpc.ca/uploadedFiles/Education/_PDFs/TripleC_Report_pt2.pdf. Accessed 2013 Jul 29.

ii Triple C Report - Part 2 


\section{Dear Colleagues:}

The Triple C Competency-based Curriculum (Triple C), the renewed approach to the delivery of family medicine education in Canada, was presented in 2011, with the publication of Triple C Competencybased Curriculum Report - Part 1. Many years in the making, it was launched under the leadership of the Working Group on Postgraduate Curriculum Review. The report engaged many members of the College and the 17 academic departments of family medicine throughout Canada. Collectively, they worked passionately to help better define what we do as family physicians and how to educate future family physicians.

The Triple C Competency-based Curriculum Report - Part 1 provided the direction for change. It defined the elements of a Triple C Competency-based Curriculum. It was based on a competency framework, entitled CanMEDS-Family Medicine (CanMEDS-FM), and presented recommendations for adoption of Triple C by the CFPC. Triple C Report - Part 1 has been positively received by learners and educators across the country and has been endorsed by the College of Family Physicians of Canada (CFPC).

Family medicine residency programs and educational College committees have actively been engaged in making the changes needed for Triple $\mathrm{C}$ to be implemented across the country. Triple C Competencybased Curriculum Report - Part 2 aims to assist in the full implementation of Triple $C$ by all stakeholders. It gathers expert opinions, resources, and tools developed by members of various CFPC educational committees. Triple C Report - Part 2 is intended to guide the change toward Triple C.

This report highlights CFPC's ongoing commitment to improve the health of Canadians by promoting high standards of medical education and care in family practice. As its editors, we have had the privilege of bringing the work of the different committees forward, weaving together an implementation road map that we hope is useful to all.

Sincerely,

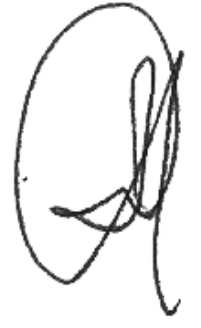

Ivy F. Oandasan MD MHSC CCFP FCFP Editor,

Triple C Competency-based Curriculum Report-Part 2

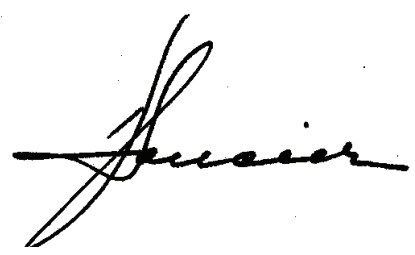

Danielle Saucier MD CCFP FCFP MA(Ed)

Editor,

Triple C Competency-based Curriculum

Report - Part 2 


\section{ACKNOWLEDGEMENTS}

The development of the Triple C Competency-based Curriculum has stemmed from the work of multiple committees of the College. Many of these committees have contributed to this report.

Committee members have written specific papers and are acknowledged as authors within the report. It is important to recognize the work of these family physician educators and learners, who voluntarily continue to give their time to advance family medicine education in Canada.

\author{
Working Group on \\ Postgraduate Curriculum Review \\ David Tannenbaum, Chair \\ Jonathan Kerr \\ Jill Konkin \\ Andrew Organek \\ Ean Parsons \\ Danielle Saucier \\ Liz Shaw \\ Allyn Walsh \\ Working Group on Certification Process \\ Tom Crichton, Chair \\ Tim Allen \\ Cheri Bethune \\ Carlos Brailovsky \\ Michel Donoff \\ Kathrine Lawrence \\ Tom Laughlin \\ Stephen Wetmore
}

\author{
Triple C Competency \\ Based Curriculum Task Force \\ Eric Wong, Chair \\ Elaine Blau \\ Fraser Brenneis \\ Teresa Cavett \\ Cathy Cervin \\ Tom Crichton \\ Nancy Fowler \\ Roger Ladouceur \\ David LaPierre \\ Cathy MacLean \\ Diane Clavet \\ Louise Nasmith \\ Danielle Saucier \\ Salvatore Spadafora \\ David Tannenbaum \\ Allyn Walsh
}

\author{
Alignment Sub-Committee \\ Danielle Saucier, Co-Chair \\ Ivy Oandasan, Co-Chair \\ Michel Donoff \\ Karl Iglar \\ Shirley Schipper \\ Eric Wong
}

The work of these committees is coordinated and supported by dedicated staff at the College of Family Physicians of Canada. Their commitment ensures the work is completed to a high-quality standard, with impeccable execution. This report would not have been possible if not for the leadership offered by Katherine Aldous, Kate Dehaas, Karen Dowsett, Lucie Hamelin, Heather Hepplewhite, Debby Lefebvre, Nadia Mangal, Heidi Plant, and Lynn Schellenberg. 


\section{TABLE OF CONTENTS}

Where We Started: Triple C Competency-based Curriculum Overview 001

Key Elements for a Triple C Competency-based Curriculum $\quad 011$

$\begin{array}{ll}\text { Introduction } & 011\end{array}$

The Scope of Training for Family Medicine Residency 013

Assessment of Learners in a Triple C Competency-based Curriculum 019

Template for In-training Assessment Process 031

Triple C: Linking Curriculum and Assessment 033

$\begin{array}{ll}\text { Implementing Competency-based Assessment Within Triple C } & 037\end{array}$

$\begin{array}{ll}\text { Introduction } & 037\end{array}$

The Evaluation Objectives: Relationship With the Other Triple C Frameworks 039

Field Notes: Assisting Achievement and Documenting Competence 059

$\begin{array}{ll}\text { A Road Map for Programs to Implement Triple C } & 063\end{array}$

$\begin{array}{ll}\text { Introduction } & 063\end{array}$

A Guide for Translating the Triple C Competency-based Recommendations Into a

Residency Curriculum

Implications of a Triple C Competency-based Curriculum

Introduction

Length of Training in the Core Family Medicine Residency

079

Triple C Implications for Enhanced Skills Training in Family Medicine Programs: A

Discussion Paper

Moving Toward a Triple C Competency-based Curriculum

Introduction

093

Facilitating Curriculum Change: Moving to a Triple C Competency-based Curriculum

095

Resource Implications for Departments of Family Medicine: A Discussion Paper

105

Potential Impact of Triple C on CFPC External Stakeholders: A Discussion Paper

Evaluating Impact of a Triple C Competency-based Curriculum

Introduction

A National Program Evaluation Approach to Study the Impact of Triple C

Triple C: Present and Future

Introduction

Transitioning to Triple C: Residency Program Perspectives From 2009 to 2010

Reflections From the Triple C Task Force

Triple C: Looking Ahead 


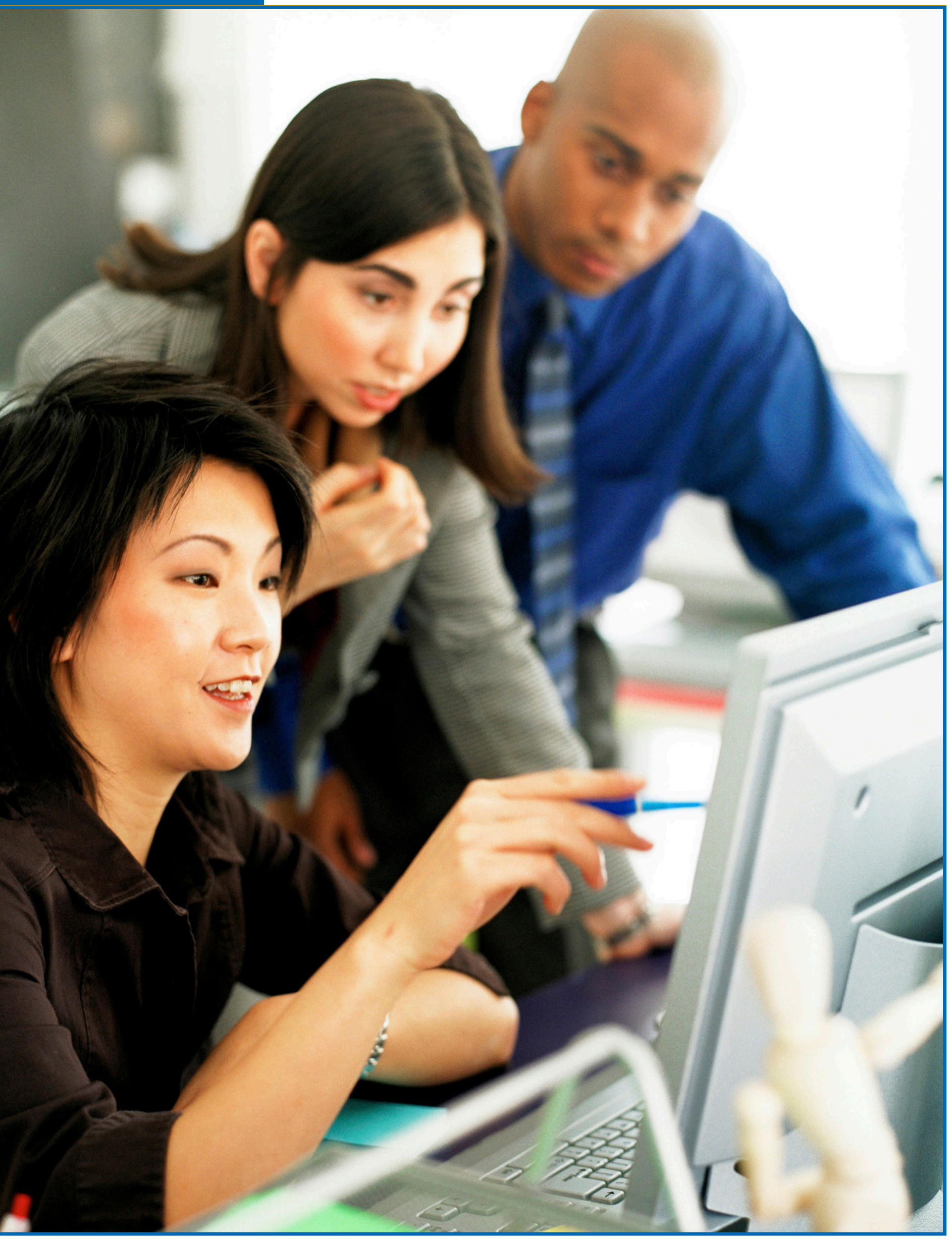

vi Triple C Report - Part 2 


\title{
Where We Started: \\ Triple C Competency-based Curriculum Overview
}

\author{
Authors \\ Ivy Oandasan and Danielle Saucier
}

\section{Suggested Citation:}

Oandasan I, Saucier D. Where we started: Triple C Competency-based Curriculum overview. In: Oandasan I, Saucier D, eds. Triple C Competency-based Curriculum Report-Part 2: Advancing Implementation. Mississauga, ON: College of Family Physicians of Canada; 2013. Available from: www.cfpc.ca/uploadedFiles/Education/_PDFs/TripleC_Report_pt2.pdf. Accessed 2013 Jul 29. 
The College of Family Physicians of Canada (CFPC) is the certifying and accrediting body for family physicians and family medicine residency programs in Canada. Established in 1954, it has a voluntary membership of over 28,000 family physicians worldwide with more than 1,000 members serving on committees, task forces, and working groups, which advocate for the discipline of family medicine through education, research, practice, and policy. ${ }^{1}$ An important mission of the CFPC is to improve the health of Canadians by promoting high standards of medical education and care in family practice.

Sensitive to the evolving needs of Canadians, in 2011 the CFPC approved a new approach to educating family medicine residents in Canada through the Triple C Competency-based Curriculum (Triple C). ${ }^{2}$ The curriculum was launched with the intent of ensuring graduates are equipped with competencies that respond to the changing health care needs of Canadians. Triple $C$ provides educators across the country with a competency-based approach to designing family medicine residency curriculum, providing relevant learning experiences, assessing graduates, and evaluating the residency program itself. The goal of Triple C, shared by CFPC and family medicine residency programs, is to ensure graduates are ready to begin the practice of comprehensive family medicine in any community in Canada. Triple $\mathrm{C}$ provides a guide for the 17 university-based family medicine programs to give residents learning experiences that 1) reflect the comprehensive nature of family medicine, 2) focus on continuity of care and education, and 3) centres training on the competencies most needed by family physicians.

Residency programs in partnership with the CFPC have embarked on a national change process to fully implement Triple C across Canada. Triple C Report - Part $1^{3}$ describes the stage that asks "what needs to be done?" Educators across the country are investing time and resources to understand Triple C, communicate its vision, and implement the curriculum in their own local contexts. CFPC educational committees, including the Board of Examiners and the Accreditation Committee, are aligning policies to enable coherence with the foundational concepts put forward by the Triple $\mathrm{C}$ curriculum. To support the academic community in adopting Triple C, the CFPC has provided many resources, such as workshops for both educational leaders and preceptors in the trenches. It also maintains a Triple C-dedicated website, with a toolkit ${ }^{4}$ containing PowerPoint presentations, videos, key reports produced by CFPC committees, and links to the series of papers describing different components of the Triple $\mathrm{C}$ published in Canadian Family Physician. A wealth of useful information has also been gathered through the ongoing dialogue with family medicine educators attuned to Triple $\mathrm{C}$ and the repeated sharing of local positive experiences.

\section{TRIPLE C REPORT - PART 2 AND ITS CONTRIBUTORS}

Triple C Report - Part 2 gathers materials arising from this very dynamic, multidirectional process. It includes the final work of the Working Group on Postgraduate Curriculum Review (WGCR), continued after the release of Triple C Report - Part 1, along with contributions from other educational committees of the CFPC, including the Working Group on Certification Process (WGCP), the Alignment Sub-Committee, and the Triple C Competency Based Curriculum Task Force (Triple C Task Force). Papers arising from these educational committees are shared in Triple C Report - Part 2. Triple C Report - Part 2 is aimed at helping the academic community address the issues related to implementation of Triple C. To highlight the committees who have authored significant papers in this second report, the following section provides a description of their roles and their valuable contributions to the ongoing enhancement of family medicine education through Triple C.

\section{The Working Group on Postgraduate Curriculum Review (WGCR)}

In 2006, the CFPC, through its Section of Teachers Council, formed the Working Group on Postgraduate Curriculum Review. Because of the evolving needs of Canadians, the CFPC felt it was 
time to review "what" and "how" family medicine education was being provided in collaboration with the 17 family medicine residency programs in Canada. The specific terms of reference for the working group were as follows ${ }^{3}$ :

- To review recent trends in medical education

- To incorporate recent initiatives of the CFPC into the curriculum

- To make recommendations for changes to the current standards, if necessary

- To recommend modifications, if necessary, to the Four Principles of Family Medicine, ${ }^{5}$ so that they would reflect changes to the current standards

The WGCR undertook a rigorous review process in order to provide recommendations for change within postgraduate family medicine education in Canada. The review and resulting recommendations were intended to do the following:

- Produce competent family physicians in a more efficient and effective way

- Ensure that graduating family physicians have a strong mix of competencies that enable them to practise in any Canadian community and context

- Attract more medical school graduates to family medicine

It was further hoped that achieving these three goals would increase the public's access to family physicians, enhance the health and safety of Canadians, and reduce overall costs to the health care system.

Rising to the challenge, the WGCR released its report entitled Triple C Competency-based Curriculum: A Report From the Working Group Curriculum Review Report - Part 1 (Triple C Report - Part 1). ${ }^{3}$ Through this report, the WGCR shared its synopsis of an extensive pedagogical literature review, its consultations with stakeholders, and its recommendations for the future of family medicine education. The WGCR's main recommendation was that family medicine residency programs across Canada implement a competency-based curriculum that is comprehensive, focused on continuity of care and education, and centred in family medicine. This enhanced approach to family medicine residency education is known as the Triple C Competency-based Curriculum (Triple C).

Eleven recommendations were approved by the Section of Teachers Council in 2010, as summarized in Box 1. These recommendations established an approach for the future of family medicine residency education and reflect the WGCR's best advice on how curriculum should be constructed, with intended outcomes in mind. The WGCR recommended that the CanMEDS-Family Medicine* (CanMEDS-FM) Roles ${ }^{6}$ be used as the national competency framework to guide curriculum design and evaluation of residency programs' performance. The WGCR emphasized that programs should provide learning experiences that are fully relevant to the needs of family medicine residents in terms of content, learning environment, and selection of teachers. Further, residents need to undergo ongoing competency-based workplace assessments to ensure that expected outcomes are achieved. In a competency-based curriculum, the shared responsibility between residency training programs and residents is emphasized, especially with respect to assessment approaches. The WGCR's last two recommendations address issues related to length of training and enhanced skills training. Both will be impacted by Triple $\mathrm{C}$, reflecting the spirit of competencybased medical education within the context of what is core to family medicine-comprehensiveness and continuity of care.

* Adapted from Frank JR, ed. The CanMEDS 2005 Physician Competency Framework. Better standards. Better physicians. Better care. Ottawa: The Royal College of Physicians and Surgeon of Canada; 2005. Available from: http://www.royalcollege.ca/portal/page/portal/rc/common/documents/canmeds/resources/publications/framework_full_e.pdf. Accessed 2013 Apr 15. 


\section{Box 1. 2010 recommendations from the $W G C^{3}$}

Eleven recommendations were endorsed for the implementation of the Triple C. These

recommendations will impact various levels of the College's work in education, practice, and policy

both internally and externally.

1. The goal of training should be to produce family physicians who are competent to practice comprehensive, continuing care.

2. Learning in family medicine should be comprehensive, and defined by a set of competencies organized under the seven professional Roles of the CanMEDS-FM framework.

3. Continuity should be an important principle in family medicine residency training:

i. Continuity of patient and family care

ii.Continuity of education

4. A competency-based approach should be used to guide curriculum development and planning. Expected learning outcomes should be derived from CanMEDS-FM and related documents. Learning experiences should be designed with the explicit intent of assisting residents in the acquisition and demonstration of these competencies.

5. Acquisition of specific competencies should be assessed regularly, and the assessment process should be embedded in the curriculum. Promotion should depend upon achievement of competency rather than upon time in training.

6. Family medicine program planners should maintain ownership over all aspects of the curriculum to ensure that family medicine and family medicine-relevant experiences form the curriculum.

7. Experienced and skilled family medicine teachers, providing comprehensive care individually or as a group, should form the core of the educational faculty.

8. Residents should take enhanced responsibility for their learning and for demonstrating the acquisition of competencies.

9. The final performance of residents should be a shared responsibility between residency training programs and the residents themselves. This implies that programs should offer the full range of learning opportunities, that learning outcomes should be properly assessed, and that flexible, individualized training should be available to permit residents to acquire the expected competencies.

10. Most residents should achieve the expected learning outcomes of the core family medicine program within a 24-month time frame; however, some will require a longer training period, which should be available when needed.

11. Enhanced skills training programs should be structured and operated in a manner that is consistent with the above recommendations. Skills in comprehensive, continuing care should be maintained during periods of extended training.

Tannenbaum D, et al. Triple C Competency-based Curriculum. Report - Part 1. CFPC; 2011

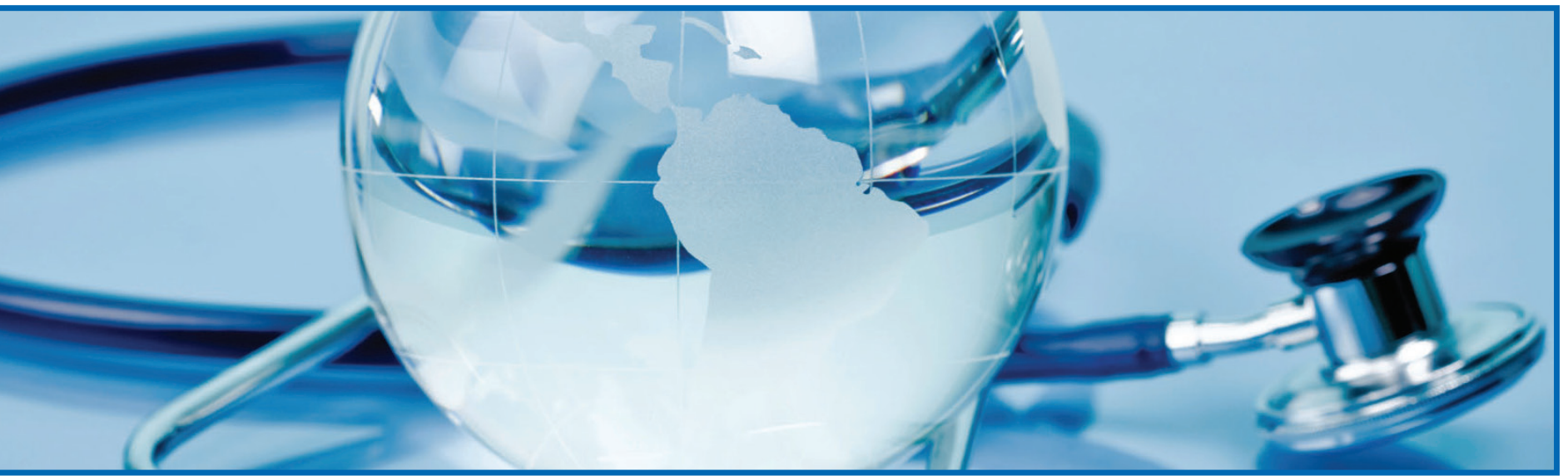


Although Triple C Report - Part 1 was officially released in March of 2011, many of the residency programs had already begun to adopt elements of Triple C. The WGCR continued its communication strategy and ongoing dialogue with the academic community, recognizing that further guidance related to the recommendations and strategies for implementation were being requested. The WGCR embarked on writing a series of papers to respond to these needs, based on their expert opinion and continuous scanning of ongoing competency-based experiences. Some of the papers were released earlier to CFPC members as PowerPoint presentations and position papers, and are readily available on the Triple $\mathrm{C}$ website. ${ }^{4}$ With the release of all of the WGCR papers in Triple C Report - Part 2, this committee has completed its work and the committee has parted.

\section{The Working Group on Certification Process}

While the WGCR was working on reviewing and making recommendations for change in residency curriculum, another working group within the CFPC had been charged with reviewing and making recommendations for enhancing the CFPC's Certification decisions. The Working Group on Certification Process (WGCP) began its work by actively reviewing the literature on assessment, and conducting focus groups and interviews with practising family physicians. The WGCP recommended that competency-based assessment be used to guide CFPC's Certification decisions, both during the Certification exams and throughout the in-training assessment process. ${ }^{7}$ The WGCP published its report entitled Defining Competence for the Purposes of Certification by the College of Family Physicians of Canada: The Evaluation Objectives in Family Medicine (Evaluation Objectives) in 2010.7 For the purposes of assessment, the Evaluation Objectives articulate the observable competencies expected of a resident at the end of the residency program. The WGCP recommended that the Evaluation Objectives be used by the Board of Examiners to guide the Certification process of the CFPC. This recommendation was approved by the Board of Examiners in 2004 and since then, the Evaluation Objectives have guided the structure and content of the Certification examinations. The WGCP recommended that competence attainment should also take into account ongoing competencybased assessment throughout residency "through a process of continuous sampling, observation of and reflection on resident performance," and to "guide sampling of observable behaviours across the Domains of Clinical Care." ${ }^{\prime}$ Therefore, it was decided that the Evaluation Objectives would be used to structure the development and implementation of the in-training assessment process leading to Certification.

Thus, the two CFPC working groups, WGCR and WGCP, one looking at curriculum and the other at assessment as starting points, came to the same conclusion-competency-based education is the direction for the future of family medicine education, with ongoing in-training competency-based assessment as a central component. The two groups reached agreement and shared support for Triple C.

\section{The Triple C Competency Based Curriculum Task Force}

With the introduction of Triple $\mathrm{C}$, many residency programs across the country began thinking about implementation. The CFPC was being looked to for guidance to help articulate the essence and impact of Triple C. Most of all, the academic community was asking for support to help facilitate a nationwide change process. The Section of Teachers Council responded by creating a task force that would be charged with developing and implementing a national implementation strategy to introduce and incorporate Triple C into postgraduate family medicine programs across the country. The Triple C Competency Based Curriculum Task Force (Triple C Task Force) includes broad representation of many stakeholders who are able to inform and influence issues facing the implementation of Triple C. ${ }^{9}$ 
The Triple C Task Force began in 2010 and was given a four-year mandate to:

- Implement a knowledge dissemination approach and communication strategy to ensure members and key stakeholders across the country are aware of Triple $\mathrm{C}$ and its implications

- Construct a faculty development process leveraging new and existing resources to facilitate system readiness for successful implementation of the Triple C

- Develop policy recommendations for Triple C within the College and external to the College

- Advance an evaluation plan that leverages scholarship and quality assurance processes to advance family medicine postgraduate curricular change in the country

- Cultivate a culture of academic excellence and collaboration in the process of developing and implementing Triple C

A plan has been put into place for each of the terms of reference. A sub-committee was created to address the first terms of reference related to knowledge dissemination and communications.

Its mandate ending by 2014, the Task Force has been charged with the responsibility of ensuring that there is a solid foundational start to the Triple $\mathrm{C}$ change process. At the time of publication of this report, the Task Force was in the middle of its mandate; it had put into progress a faculty development approach and a stakeholder communication strategy related to the impact of Triple $\mathrm{C}$, and was in discussion to establish policy alignment recommendations for both internal and external stakeholders. The Triple C Task Force also developed a plan for a national program evaluation of Triple C, which is now being implemented. Its approach leverages the Task Force's fifth term of reference, highlighting the need to "cultivate a culture of academic excellence and collaboration." Triple C Report - Part 2 is an example of how the CFPC is advancing this collective approach to implementing the changes needed for the success of Triple $\mathrm{C}$ and its goal of graduating family physicians ready to practise comprehensive family medicine in any community in Canada.

\section{The Alignment Sub-Committee}

At the start of the Triple C Task Force's work, the CFPC was hearing from residency programs a definite need for clarity. By 2010, the academic community had been introduced to new approaches to competency-based education. Two competency-based frameworks - the CanMEDS-FM Roles and the Evaluation Objectives-were shared without a clear understanding of how both competency frameworks were related. New responsibilities for preceptors were emerging related to competencybased assessment and new terms were being used without clear definitions (eg, comprehensive care, continuity of care and education, centred in family medicine). The academic community was faced with the challenge of making sense of these new frameworks, approaches, and terms. The Triple C Task Force recognized that there was an urgent need to develop a communication strategy that could help the community.

The Triple C Task Force created the Alignment Sub-Committee, with members from the WGCR, the WGCP, and three program directors. They were asked to develop communication tools that could be used by educational leaders to better understand concepts related to Triple C. The Alignment Sub-Committee decided to create a series of PowerPoint presentations and promotional materials in the form of videos, guides, and tools that could be used by the academic community. In order to disseminate these communication tools, the Alignment Sub-Committee created the Triple C Toolkitan online host for all of these resources. ${ }^{4}$ The Toolkit was launched in the spring of 2012 and is 
maintained as a living resource for program directors, educational leaders, preceptors, and learners. One of the most important contributions of the Alignment Sub-Committee was the clarity provided on the relationship between the CanMEDS-FM Roles, the Domains of Clinical Care for residency training, and the Evaluation Objectives. This description was shared in the CFP article "Triple C: Linking Curriculum and Assessment,"10 and has been reprinted as part of the Triple C Report - Part 2.

\section{MAKING THE CHANGE - THE ROLE OF TRIPLE C REPORT - PART 2}

Change takes time and effort. Change at a national level and in multiple institutions requires determination and coordination. The good news is that the changes being discussed have already been in process for years, so they are more often "tweaks" than radical changes within residency programs. Implementing Triple $\mathrm{C}$ across Canada will require a collaborative national effort. The 17 Canadian family medicine residency programs are actively engaged in this process, and the CFPC is playing a central role.

Implementation of Triple $\mathrm{C}$ is not meant to be prescriptive; rather, it is meant to be flexible, adapting to the realities of educational environments, the learning needs of residents, and the health care needs of the populations served. Implementing Triple $\mathrm{C}$ must take into account the medical education system, the health system, and the political systems of this country, along with their related multiple stakeholders, and then changes must be made in these areas accordingly. The section "Implementing Competency-based Assessment Within Triple C" aims to offer the academic family medicine community a way to find solutions to implementation challenges, highlight key considerations and strategic approaches, and guide local and national progress. It provides a systematic approach to change management that identifies issues that will need to be addressed as implementation moves forward. Many of the discussion papers will foster opportunities for early dialogue within the community and with stakeholders who are key partners with the academic family medicine community. These dialogues will help to build support, understanding, and buy-in for the years ahead.

Triple C Report - Part 2 addresses the practical issues and implications related to adoption of the Triple C curriculum. It is written in a way that assumes there is familiarity with the content of Triple $C$ Report - Part $1^{3}$ and the Evaluation Objectives. ${ }^{7}$ It complements and echos the PowerPoint presentations and documents already posted in the Triple C Toolkit. ${ }^{4}$ Within the report, readers will find a series of discussion papers. Each discussion paper is written as a stand-alone piece and can be accessed either on its own or with the other papers in the section. The report is provided in an electronic format so that readers can search for key areas of interest with ease.

The discussion papers included in the next two sections, "Key Elements for a Triple C Competencybased Curriculum" and "Implementing Competency-based Assessment Within Triple C," are seminal documents that add to Triple C Report - Part 1 (including the CanMEDS-FM competency framework) and the Evaluation Objectives. In particular, "The Scope of Training for Family Medicine Residency" describing the Domains of Clinical Care for residency training, "Assessment of Learners in a Triple C Competency-based Curriculum," "Template for In-training Assessment Process," "Triple C: Linking Curriculum and Assessment," and "The Evaluation Objectives: Relationship With the Other Triple C Frameworks," are important resources for educators. A road map for programs to implement Triple C, "A Guide for Translating the Triple C Competency-based Recommendations Into a Residency Curriculum," is then offered to help put theory into application when constructing or reviewing residency curriculum.

The second part of Triple C Report - Part 2 highlights potential implications and facilitation strategies that can be used. Two discussion papers are included in the section "Implications of a Triple C 
Competency-based Curriculum": "Length of Training in the Core Family Medicine Residency" and "Triple C Implications for Enhanced Skills Training in Family Medicine Programs: A Discussion Paper." The two papers aim to help the community reflect on Triple C policy implications, informing future direction. "Facilitating Curriculum Change: Moving to a Triple C Competency-based Curriculum" provides a broad review of ways to facilitate change within local contexts, including engagement and gaining buy-in from key players. It continues with "Resource Implications for Departments of Family Medicine: A Discussion Paper" and "Potential Impact of Triple C on CFPC External Stakeholders: A Discussion Paper."

The third part of this report moves from practical and immediate implications to a more long-term perspective. It includes a paper describing the CFPC's evaluation plan on residents, faculty, residency programs, the CFPC, and the discipline in general, in "A National Program Evaluation Approach to Study the Impact of Triple C."

This rigorous approach is characteristic of the scholarly approach already taken and shared in the section "Triple C: Present and Future" and particularly in the paper "Transitioning to Triple C: Residency Program Perspectives From 2009 to 2010," which provides evidence of the ongoing implementation of Triple C by programs to date. The paper entitled "Reflections From the Triple C Task Force" highlights the work already accomplished by the Triple C Task Force and its plans for the final two years of its mandate. The last paper, "Triple C: Looking Ahead," written as a reflective piece by the editors, describes the potential impact of Triple $\mathrm{C}$ on the medical education and the health care system, with critical next steps for the academic family medicine community to consider.

The academic family medicine community is encouraged to read and share the individual papers, sections, or whole report with key stakeholders, using the discussion papers to stimulate discussion and leverage opportunities for Triple $\mathrm{C}$ transformation within family medicine residency programs. Triple C Report - Part 2 is the product of the collaboration of numerous dedicated members of the CFPC: teachers in the pursuit of enhancing education and family physicians advocating for optimal patient care. Hosted on the Triple C Toolkit website, ${ }^{4}$ this report is hoped to be one of many resources used to guide implementation with tools that are practical, applicable, and useful. Visit the website often because updates will be provided periodically and future documents arising from the Triple $\mathrm{C}$ initiative will be posted regularly. Feedback is always welcome and can be sent to triplec@cfpc.ca. 


\section{References}

1. College of Family Physicians of Canada. About CFPC. 2013. www.cfpc.ca/AboutUs. Accessed 2013 Apr 15.

2. Kerr J, Walsh AE, Konkin J, Tannenbaum D, Organek AJ, Parsons E, et al. Renewing postgraduate family medicine education: the rationale for Triple C. Can Fam Physician 2011;57:963-964. Available from: www.cfp.ca/content/57/8/963.full.pdf+html. Accessed 2013 Apr 15.

3. Tannenbaum D, Kerr J, Konkin J, Organek A, Parsons E, Saucier D, et al. Triple C CompetencyBased Curriculum. Report of the Working Group on Postgraduate Curriculum Review - Part 1. Mississauga, ON: College of Family Physicians of Canada; 2011. Available from: www. cfpc.ca/uploadedFiles/Education/_PDFs/WGCR_TripleC_Report_English_Final_18Mar11.pdf. Accessed 2013 Apr 15.

4. College of Family Physicians of Canada. Triple C Competency-based Curriculum: Canada's family medicine curriculum. www.cfpc.ca/Triple_C/. Accessed 2013 Apr 15.

5. College of Family Physicians of Canada. Four principles of family medicine. College of Family Physicians of Canada. 2006. www.cfpc.ca/Principles/. Accessed 2013 Apr 15.

6. College of Family Physicians of Canada, Working Group on Curriculum Review. CanMEDSFamily Medicine: A Framework of Competencies in Family Medicine. Mississauga, ON: College of Family Physicians of Canada; October 2009. Available from: www.cfpc.ca/ uploadedFiles/Education/CanMeds\%20FM\%20Eng.pdf. Accessed 2013 Apr 13.

7. College of Family Physicians of Canada, Working Group on Certification Process. Defining Competence for the Purposes of Certification by the College of Family Physicians of Canada: The Evaluation Objectives in Family Medicine. Mississauga, ON: College of Family Physicians of Canada; 2010. Available from: www.cfpc.ca/uploadedFiles/Education/Definition\%20 of $\% 20$ Competence $\% 20$ Complete $\% 20$ Document $\% 2$ with $\% 20$ skills $\% 20$ and $\% 20$ phases $\% 20$ Jan\%202011.pdf. Accessed 2013 Apr 15.

8. Crichton T, Allen T, Bethune C, Brailovsky C, Donoff M, Laughlin T, et al. Evaluation objectives in family medicine: defining competence for the purposes of Certification [PowerPoint presentation]. Mississauga, ON: College of Family Physicians; 2011. Available from: www.cfpc.ca/TripleCToolkit/. Accessed Apr 15.

9. College of Family Physicians of Canada. Triple C Competency-based Curriculum Task Force. http://www.cfpc.ca/TripleC_Comm/. Accessed 2013 Apr 15.

10. Oandasan I, Wong E, Saucier D, Donoff M, Iglar K, Schipper S. Triple C: linking curriculum and assessment. Can Fam Physician 2012;58:1165-1167. Available from: http://www.cfp.ca/ content/58/10/1165.full.pdf+html. Accessed 2013 Apr 15. 

In the years prior to the implementation of the Triple C Competency-based Curriculum (Triple C), a number of reports authored by different educational committees of the College of Family Physicians of Canada (CFPC) provided crucial information that shaped the development of the curriculum. The CanMEDS-Family Medicine (FM) competency framework, developed by the Working Group on Curriculum Review, is detailed in the Triple C Report - Part 1 as playing a key role in designing a competency-based family medicine. At about the same time, the CFPC's Working Group on Certification Process wrote a report highlighting the competencies to be used for the purposes of assessing family medicine residents at the end of training. Approved by the Board of Examiners, Defining Competence for the Purposes of Certification by the College of Family Physicians of Canada: The Evaluation Objectives in Family Medicine is a second seminal paper, and, along with the CanMEDS-FM Roles, a key element of Triple C.

In this section of the Triple C Report - Part 2, readers will be formally introduced to a third formative report that helps to define the comprehensive scope of family medicine as a discipline. "The Scope of Training for Family Medicine Residency" describes the Domains of Clinical Care for residency training and provides a taxonomy for educators and practitioners to understand the full range of defined populations seen within the discipline of family medicine. It also outlines the contexts within which family physicians practise and the spectrum of illnesses and procedures managed within the full scope of family medicine. This document is a key reference for family medicine educators, and aims to better define the broad scope of comprehensive care and comprehensive education associated with Triple C.

This section also showcases the critical role of the discussion paper entitled "Assessment of Learners in a Triple C Competency-based Curriculum." Although seemingly new, competency-based assessment concepts were in existence within many of the family medicine programs prior to the introduction of Triple C. The competency-based assessment paper serves as another important document to help readers understand what is meant by competency-based assessments and processes within a Triple C Competency-based Curriculum.

Also in this section is a resource written by the Working Group on Certification Process entitled "Template for In-training Assessment Process," also known as the ITA (In-training Assessment) Table, which highlights key processes residency programs need to include when implementing a Triple C competency-based assessment system.

"Triple C: Linking Curriculum and Assessment" is the final paper in this section. It helps to highlight how the CanMEDS-FM competency framework, which was used to design the curriculum, is linked with the evaluation objectives defined for Certification purposes (Evaluation Objectives), and serves as the CFPC's approach to competency-based assessment. This article was originally published in Canadian Family Physician (2012) and again aims to assist medical educators wading through the new concepts, framework, terminology, and pedagogies.

These papers will be referenced several times in this report, as well as in upcoming reports and publications. Readers should keep these documents handy; they will be critical to gaining a full understanding during this time of innovation in family medicine education. 



\section{The Scope of Training for Family Medicine Residency}

Prepared by

The Working Group on Postgraduate Curriculum Review

David Tannenbaum, Chair

Jonathan Kerr

Jill Konkin

Andrew Organek

Ean Parsons

Danielle Saucier

Liz Shaw

Allyn Walsh 
(C) 2011 The College of Family Physicians of Canada. All Rights Reserved. Suggested Citation:

Tannenbaum D, Kerr J, Konkin J, Organek A, Parsons E, Saucier D, Shaw L, Walsh A. The Scope of Training for Family Medicine Residency: Report of the Working Group on Postgraduate Curriculum Review. Mississauga, ON: College of Family Physicians of Canada; 2011. 


\section{The Scope of Training for Family Medicine Residency}

\section{AN OUTLINE FOR TEACHING, LEARNING, AND ASSESSMENT}

\section{INTRODUCTION}

The goal of residency training in Family Medicine is to graduate family physicians who are ready to practise comprehensive continuing care at the level of a beginning family medicine specialist. Programs have the responsibility to provide training that exposes learners to the full scope of Family Medicine and —-through rigorous and ongoing assessment-to ensure that family medicine competencies are acquired and programmatic educational goals are met.

CanMEDS-Family Medicine (CanMEDS-FM)* offers a framework that describes competencies required of family physicians in the provision of comprehensive care. However, this framework does not fully describe the spectrum of clinical activities within which the CanMEDS-FM Roles are applied and that defines comprehensive care provided by family physicians in Canada.

This document is to serve as a supplement to the CanMEDS-FM document. It offers an outline of the professional activities that delineate the scope of comprehensive care in Family Medicine: the settings in which care is provided, the spectrum of clinical responsibilities managed by family physicians, the clinical procedures performed in practice, and the varied patient populations cared for. These Domains of Clinical Care form the base from which the learning experiences in Family Medicine residency are built and educational assessments are conducted. They also provide the context that gives the CanMEDS-FM Roles practical meaning in patient care.

This document organizes the professional activities into two areas:

\section{Domains of Clinical Care in Residency Training}

\section{Evolving Professional Competencies}

Further details regarding the scope of training in Family Medicine residency are found in the CanMEDS-FM document and the documents of the Working Group on the Certification Process, Priority Topics and Key Features for Assessment in Family Medicine. ${ }^{2}$ The article "Family medicine in 2018," authored by the Chairs of family medicine (http://www.cfp.ca/cgi/reprint/56/4/313), offers further insight into the required domains of learning. ${ }^{3}$

*The CanMEDS-Family Medicine framework was adapted from: Frank, JR, ed. The CanMEDS 2005 physician competency framework. Better standards. Better physicians. Better care. Ottawa: The Royal College of Physicians and Surgeons of Canada; 2005 [cited 2009 Dec 14]. Available from: http://www.royalcollege.ca/portal/page/portal/rc/canmeds/resources/publications. 


\section{DOMAINS OF CLINICAL CARE IN RESIDENCY TRAINING}

The Domains of Clinical Care are arranged for convenience as a reflection of the daily work in Family Medicine: life cycle of patients, clinical settings where care is provided, spectrum of clinical responsibilities, and procedural skills. An additional component, care of underserved patients, draws attention to our responsibility as family physicians to care for those most vulnerable in Canadian society. Specific clinical problems encountered in family practice can be organized under one or more headings using the following arrangement.

\begin{tabular}{|c|c|}
\hline Care of patients across the life cycle & $\begin{array}{l}\text { - Children and adolescents } \\
\text { - Adults: } \\
\text { o Women's health care, including maternity care } \\
\text { o Men's health care } \\
\text { o Care of the elderly } \\
\text { o End-of-life and palliative care }\end{array}$ \\
\hline $\begin{array}{l}\text { Care across clinical settings (Urban or } \\
\text { Rural): }\end{array}$ & $\begin{array}{l}\text { - Ambulatory/office practice } \\
\text { - Hospital } \\
\text { - Long-term care } \\
\text { - Emergency settings } \\
\text { - Care in the home } \\
\text { - Other community-based settings }\end{array}$ \\
\hline Spectrum of clinical responsibilities & $\begin{array}{l}\text { - Prevention and health promotion } \\
\text { - Diagnosis and management of presenting problems } \\
\text { (acute, subacute, and chronic) } \\
\text { - Chronic disease management } \\
\text { - Rehabilitation } \\
\text { - Supportive care } \\
\text { - Palliation }\end{array}$ \\
\hline Care of underserved patients & $\begin{array}{l}\text { Including but not limited to the following: } \\
\text { - Aboriginal patients } \\
\text { - Patients with mental illness or addiction } \\
\text { - Recent immigrants }\end{array}$ \\
\hline Procedural skills & $\begin{array}{l}\text { - As per CFPC list of core procedures: } \\
\text { http://www2.cfpc.ca/cfp/2005/oct/vol51-oct- } \\
\text { researh-2.asp }\end{array}$ \\
\hline
\end{tabular}




\section{EVOLVING PROFESSIONAL COMPETENCIES}

The Evolving Professional Competencies reflect selected competencies within the CanMEDS-FM Roles that will be increasingly required of family physicians in the future. These competencies must be emphasized in current training. They are presented in the following table in relation to their respective CanMEDS-FM Roles.

\section{Professional Competencies}

Information technology, including electronic medical records

Collaborative, team-based practice

Leadership

Patient safety initiatives, error disclosure

Quality improvement

Information retrieval and management

Social responsibility

Community responsiveness

Teaching skills

Research skills

Lifelong learning skills

Professionalism, including ethics, boundaries, and self-care

\section{Relevant CanMEDS-FM Role}

Communicator

Collaborator

Manager

Health Advocate

Scholar

Professional

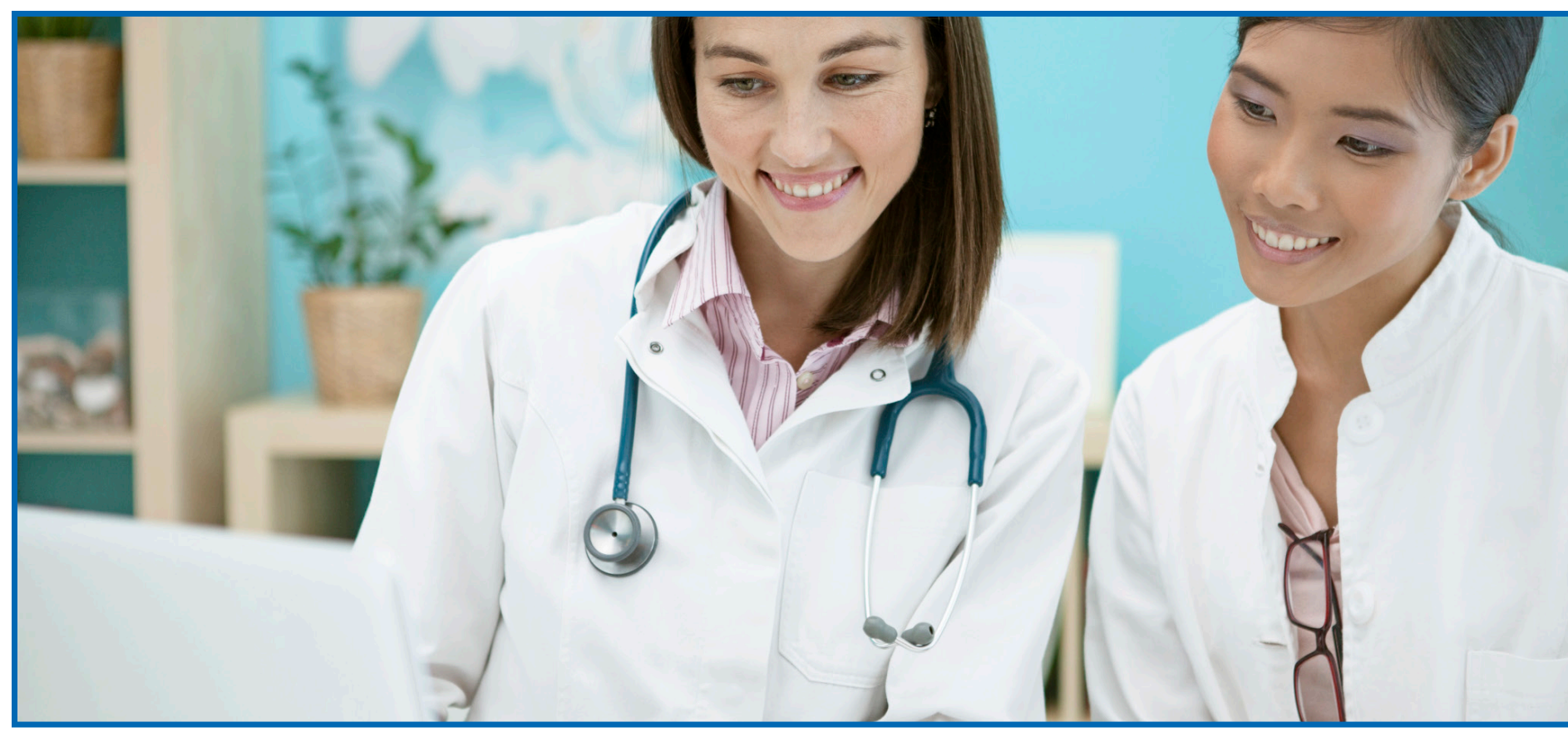




\section{References}

1. Frank, JR, ed. The CanMEDS 2005 physician competency framework. Better standards. Better physicians. Better care. Ottawa: The Royal College of Physicians and Surgeons of Canada; 2005 [cited 2009 Dec 14]. Available from: http://www.royalcollege.ca/portal/page/portal/rc/ canmeds/resources/publications.

2. Allen T, Bethune C, Brailovsky C, Crichton T, Donoff M, Laughlin T, Lawrence K, Wetmore S. Defining Competence in Family Medicine for the Purposes of Certification by the College of Family Physicians of Canada: The Evaluation objectives in Family Medicine. Priority Topics and Key Features for Assessment in Family Medicine. (updated December 2010).

3. Ogle KD, Boulé R, Boyd RJ, Brown G, Cervin C, Dawes M, et al. Family medicine in 2018 [Commentary]. Can Fam Physician 2010;56:313-5. 


\section{Assessment of Learners in a Triple C Competency- based Curriculum}

\section{Authors}

Danielle Saucier, Tim Allen, Tom Crichton, Cheri Bethune, Carlos Brailovsky, Michel Donoff, Jonathan Kerr, Jill Konkin, Tom Laughlin, Kathrine Lawrence, Andrew Organek, Ean Parsons, Liz Shaw, David Tannenbaum, Allyn Walsh

Suggested Citation:

Saucier D, Allen T, Crichton T, Bethune C, Brailovsky C, Donoff M, et al. Assessment of learners in a Triple C Competency-based Curriculum. In: Oandasan I, Saucier D, eds. Triple C Competencybased Curriculum Report - Part 2: Advancing Implementation. Mississauga, ON: College of Family Physicians of Canada; 2013. Available from: www.cfpc.ca/uploadedFiles/Education/_PDFs/ TripleC_Report_pt2.pdf. Accessed 2013 Jul 29. 
Learner assessment is a central component in a Triple C Competency-based Curriculum (Triple C). The goal of Triple $\mathrm{C}$ is for residents to achieve professional competence "to the level of a physician ready to begin practice in the specialty of family medicine."1 Residency programs must ensure that learners are provided relevant learning opportunities to enable them to gain competencies expected and to demonstrate they have achieved these competencies.

Competency-based assessment of learners represents a significant paradigm shift when compared with traditional assessment practices in postgraduate medical education. This shift involves a change in the focus of assessment from knowledge to competence-the ability to "do the right thing at the right time in the right way in complex situations, by using and integrating the right internal and external resources, in accordance to professional roles and responsibilities." ${ }^{2}$ It also implies a change of perspective on the role of assessment; a competency-based assessment system not only provides the evidence that a given resident has achieved specific competencies and demonstrates overall competence, but also involves ongoing, constructive, and formative assessment that helps residents develop these competencies. Thus, this shift in focus and perspective in competency-based assessment requires a change in assessment strategies. It also demands an emphasis on ongoing monitoring of progress made with individualized educational planning that is only possible if active learners work in collaboration with their preceptors.

Competency-based assessment engages different actors — residents, preceptors, and program administrators - each with a unique role to play, and each with a vested interest in the residency process and results. This type of assessment is not something one can "do to" residents, from teacher to learner; rather, it is a collaborative endeavour between preceptor and resident, in which the resident benefits most from the process when he or she is actively engaged.

Finally, competency-based assessment calls for different types of tools and a renewed program-wide resident assessment system. With these elements and processes in place and because of these changes in focus, strategies, and tools, competency-based assessment leads to a transformation in decisions for promotion.

All of these aspects are included in a Triple C Competency-based Curriculum, with the understanding that assessment should occur using the Evaluation Objectives ${ }^{3}$ as a tool to focus on the competencies being assessed, in a context that includes comprehensiveness, is focused on continuity of education and care, and is centred in family medicine. ${ }^{4}$

The key characteristics of competency-based assessment of learners in a Triple C curriculum are:

a. The processes and methods of assessment of residents are carefully planned and integrated into the curriculum

b. Assessment is an ongoing, formative process

c. Progress of learning is monitored

d. Summative decisions are based on demonstrations of competence

e. Educational planning, including remediation, is individualized

f. Promotion criteria are competency based 


\section{PROCESSES AND METHODS OF ASSESSMENT}

Assessment should be both embedded in the curriculum and planned based on a blue print directly related to expected program outcomes. As explained in Triple C Report - Part $1^{4}$ a competency-based curriculum starts with the end-the expected outcomes of the program-in mind. Relevant curricular content and contexts are selected to engage learners in developing these competencies. The same stated outcomes serve as the basis for ongoing assessment and for the final decision about readiness to practise independently (see Figure 2, Triple C Report - Part 1). ${ }^{4}$

Each program should plan a program-wide process for in-training assessment (ITA) that includes all essential components described in the CFPC's template for an in-training assessment process ${ }^{5}$ (see ITA Table). This process will ensure comprehensive sampling of the Evaluation Objectives ${ }^{3}$ and other observable competencies in the clinical and academic environment, within all seven CanMEDS-Family Medicine (CanMEDS-FM) Roles, ${ }^{6^{*}}$ and across the Domains of Clinical Care in residency training. ${ }^{7}$ It should ensure repeated sampling over time by multiple preceptors in many different situations, in search of consistent demonstration of competence. In this competency-based process, assessors are asked to judge the performance itself, not in comparison with other learners. In educational terms, this evaluation system will be criterion-referenced rather than norm-referenced.

To ensure continuity of education, a family physician or team should be assigned to each resident for the duration of the residency and should be responsible to review progress and provide feedback to both the resident and the program. Given that the intent is to assess competence to practise in family medicine based on assessment criteria that are relevant to this discipline, the family medicine residency program must be primarily responsible for planning and managing the assessment system.

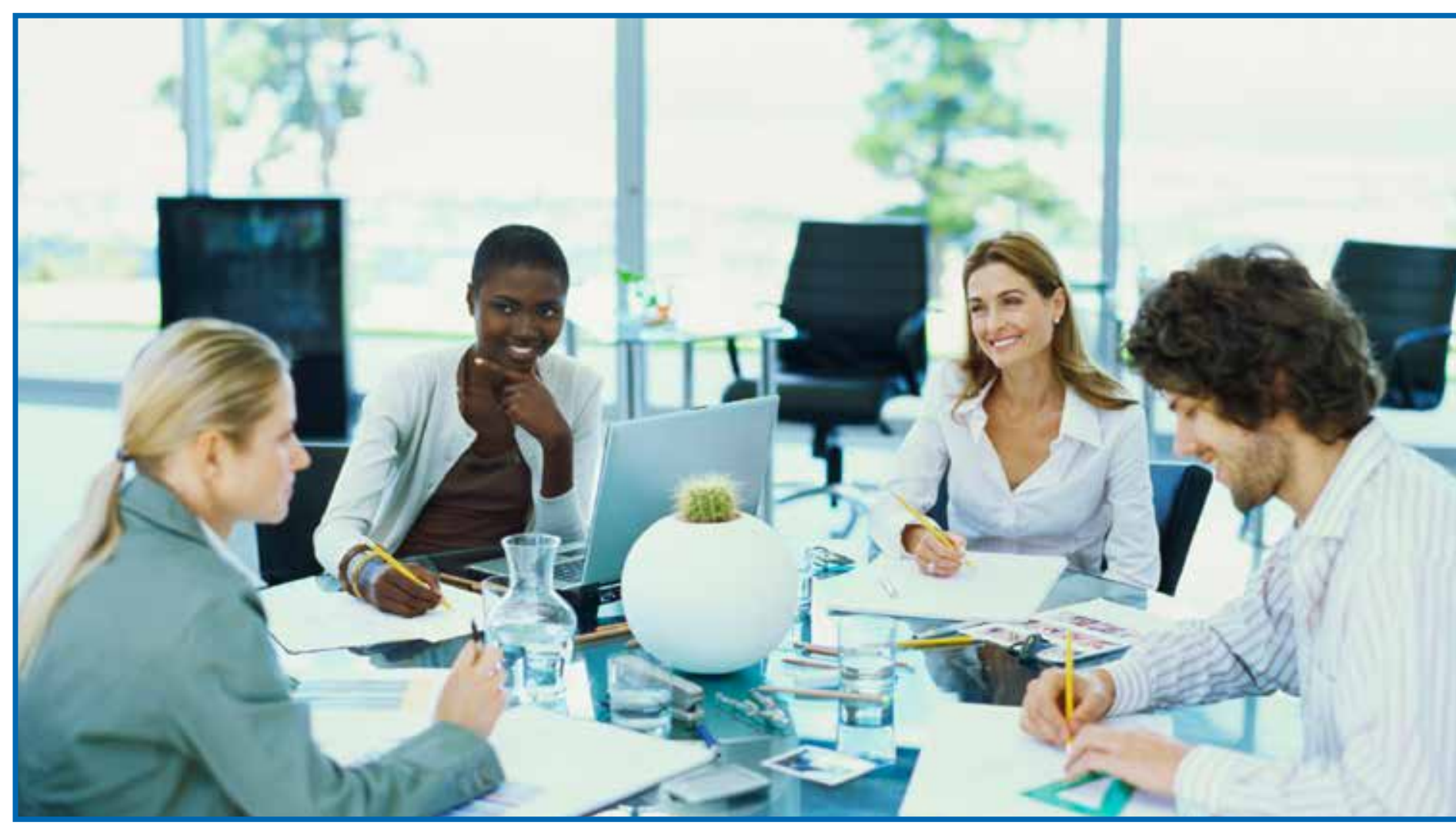

*Adapted from: Frank JR, ed. The CanMEDS 2005 physician competency framework. Better standards. Better physicians. Better care. Ottawa: The Royal College of Physicians and Surgeons of Canada; 2005. Available from: http://www.royalcollege.ca/portal/page/portal/rc/common/documents/canmeds/resources/publications/framework_full_e.pdf. Accessed 2013 Apr 15. 


\section{ASSESSMENT: AN ONGOING, FORMATIVE PROCESS}

The competency-based ITA system ${ }^{5}$ also helps with the learning process, as it provides learners with regular feedback and highlights their progress over time. The program should develop and implement strategies that will allow repeated occasions for regular feedback to learners. Preceptors should provide feedback during daily clinical and educational activities, including case discussion and direct observation of resident-patient interactions, team interactions, academic teaching, and other clinical tasks. Feedback includes reflection, positive reinforcement, and constructive coaching. Providing and seeking feedback is a shared responsibility between faculty and residents.

Preceptors are also responsible during daily clinical activities to observe residents, provide feedback, and document performance regarding specific encounters or events. Equally, the resident should seek opportunities to be observed, request feedback, and participate in documenting performance. Resident engagement is a necessary ingredient in the collaborative approach needed for a fruitful ongoing assessment process. ${ }^{8-10}$ This type of active engagement comes naturally to a number of residents, and is even more effective in a supportive environment.

Establishing a safe, supportive environment is critical. It enables residents to move away from defensive strategies during supervision, as is often the case, to a "learning stance," which involves self-exposure as the basis for useful coaching on building competencies, and is uniquely adapted to each resident's needs at a given moment. ${ }^{8-13}$ "Learner development" strategies and tools now exist that encourage an early and more widespread adoption of a learning stance among residents. . $^{8,14}, 15$

Competency-based assessment also involves day-to-day, ongoing micro-level documentation which should be completed by multiple preceptors with some input from other team members, according to the residency program's policies. The program should also provide a system to gather and organize documentation of performance into a collection of evidence. This collection will include daily field notes and other performance assessment tools. This organized documentation also serves to give the learner feedback on overall competence during periodic assessments of progress. ${ }^{5,16}$

Programs will need to work actively with both residents and preceptors to support a change in the educational culture toward constructive and collaborative supervision, and for formative feedback interactions, not only within family medicine educational experiences but in other teacher-learner interactions that occur during residency. Regular documention of performance is a necessary change from current behaviours in the educational system to successfully implement the change to competency-based assessment.

\section{MONITORING PROGRESS IN LEARNING}

The program should not only provide a framework to collect and organize documentation in either a paper or electronic portfolio, but should also implement a system to regularly monitor a resident's progress at a macro level. Each program will need to identify relevant data that should be monitored periodically to confirm the resident has acquired relevant competencies and to monitor the resident's progress. The program will select a few relevant context-specific (eg, field notes from supervision) or competency-specific (eg, 360 evaluation for Collaborator role, research project for Scholar role) data collection tools, to be housed in a portfolio.

Naccahe describes a portfolio as "a learner's organized collection of documentation and reflections, that gathers data on competencies developed by that learner over a given period of time."17 A portfolio can take many forms and can be used in several different ways, both for formative and summative 
learning and assessment. It is recognized as a useful tool in competency-based education to document the learner's achievements — what a learner actually did — for a broad range of competencies. ${ }^{17-19}$ Portfolios provide an overview of a learner's evolution over time, thus serving as an essential tool for monitoring progression in a holistic assessment approach. ${ }^{20}$ They also allow for a reflective stance. As Carraccio and Englander (2004) state, "the learner plays a pivotal role in driving the processes" of data gathering and backward reflection, and forward planning. ${ }^{18}$ Like any other assessment strategy, portfolios have their pitfalls and challenges but nevertheless remain promising for competency-based, learner-centred education. ${ }^{19}$

There are three key components to ensure effective use of a portfolio:

- Clear goals for building the program's portfolio

- Training for users (residents, preceptors, and faculty advisors) in how to use the portfolio

- Dedicated time for periodic meetings between the resident and faculty advisor to review the portfolio's content

The program should determine both the persons responsible for and the frequency of periodic progress assessments. The program and individual faculty assigned to this task engage learners actively in data gathering, guided self-assessment, and developing their learning plans. The periodic encounters between a resident and his or her faculty advisor serve to review progress and update learning plans. Residents and faculty advisors should also generate periodic progress reports which should be sent to clinical preceptors and appropriate program administrators. The program should provide faculty (and residents) with tools to assist in judging a resident's progress.

One strategy for assisting preceptors in judging a resident's progress is to create a list of observable milestones or benchmarks of competency. This list of competencies provides objective, descriptive information on usual expectations for progress at significant stages of training and in various practice domains or settings. The milestones should be constructed based on the essential skills being monitored in the resident's competency development. Benchmarks are based on preceptors' experience with usual progress, and consensus on expectations at key moments in residency (eg, upon entry, first six or 12 months, and end of residency). The use of benchmarks is under discussion and development in Canada. For the time being, programs rely most heavily on clinical teachers' past experience to determine expectations for progress at various stages of training.

Another possible strategy to help preceptors assess a resident's progress is to define a list of entrustable professional activities (EPAs) for family medicine in Canada, or "sentinel habits" (common skills and habits that make a good physician). ${ }^{21,22}$ EPAs were first developed in the Netherlands and refer to "those professional activities that constitute the mass of critical elements that operationally define a profession. They should only be entrusted upon a competent enough professional." 22,23 EPAs integrate a series of observable competencies within both domains of care and professional roles, and centre on meaningful clinical tasks. EPAs serve as a link between the formal curriculum and real-world practice. ${ }^{24}$ Pilot projects on the international stage show that EPAs help residents and preceptors assess performance, serve well to follow residents' progress, are useful for communicating this progress to colleagues, and could contribute to overall promotion decisions. ${ }^{23}$ 
It is imperative that caution be taken to avoid over-reliance on these assessment tools; adding yet another series of checklists of behaviours, activities, or topics runs the risk of becoming focused on one area. The aim is to ensure assessment of the whole individual and his or her progress toward overall competence. An over-reliance on such tools could also ignore the preceptor's subjective sense of the resident's overall competence. It is also important to note that incorporating other aspects of resident performance that have been correlated with a preceptor's judgment might also be helpful in assessing readiness for independence in residents. ${ }^{25}$

\section{SUMMATIVE DECISIONS BASED ON DEMONSTRATIONS OF COMPETENCE}

A summative evaluation plan that uses relevant tools ensures assessment of all key competencies. In a competency-based assessment system, end-of-rotation global evaluation is just one such tool. The program should also put into place a system to interpret progress reports and make periodic summative decisions, including decisions around changing a learning plan for a resident in difficulty, remediation, and dismissal. This responsibility should not be delegated to an individual but should rest with a committee or group, and usually lies with an evaluation or promotion committee.

\section{INDIVIDUALIZED EDUCATIONAL PLANNING AND REMEDIATION}

The primary objective of monitoring progress in a competency-based assessment system is to ensure learners' constant, efficient progress until they are ready for independent practice. This is achieved through timely, relevant macro-level feedback and individualized educational planning. For most residents, individualized educational planning will mean micro adjustments within the teaching and learning resources available in the program. Each preceptor-resident dyad identifies the unique competencies for focus in the ensuing months. Whereas one resident's learning plan might add more shifts in the emergency room, another might need to find more time for personal study. One preceptor might suggest more direct observation sessions to work on doctor-patient communication skills, while another might suggest adjusting clinical activities to ensure more opportunities to practise well-baby care.

The first principle behind this individualization is the recognition that learners each have their own pace, style, strengths, limitations, and unique needs. Hence, the residency program should move away from the traditional time-based, one-size-fits-all "tea-steeping" approach. ${ }^{26}$ The second principle is the recognition that each clinical setting has certain limitations in terms of opportunities. For example, one family medicine practice might focus on perinatal care and care of young children, while another might focus on chronic disease management among an older population. One teaching site might possess strong resources in evidence-based medicine, where another might present more occasions for community advocacy work for residents. Despite these differences, all programs need to ensure residents gain the required essential skills and other elements of the Evaluation Objectives, and demonstrate competence in all CanMEDS-FM Roles and across all Domains of Clinical Care.

Daily feedback and documentation of performance followed by periodic progress review provide the raw material needed to rapidly identify residents "in difficulty." A resident is considered in difficulty if he or she struggles to demonstrate a number of competencies or has a slower pace of progress than is usually observed. This is most often a manifestation of insufficient development in one or more of the essential skill dimensions (eg, professionalism). It is the program's responsibility to have identified processes in place for early identification of residents in difficulty. Once a resident in difficulty is identified, there is a shared responsibility between the resident, the primary preceptors, the faculty 
advisor, and the program to act rapidly to better define the difficulties, develop an appropriate individualized educational plan, and periodically assess the success of this plan. Programs should ensure they have appropriate resources so that remediation planning is regularly available and is tailored to the problem. These strategies are expected to maximize training efficiency by tailoring them to the specific needs of the resident and directing the training at the resident's level of competency achievement.

Experience has shown that only a limited number of residents have problems that are difficult to resolve, requiring a period of remediation in their learning process. Residency programs should have the resources to provide an extended training period for these residents, within reason.

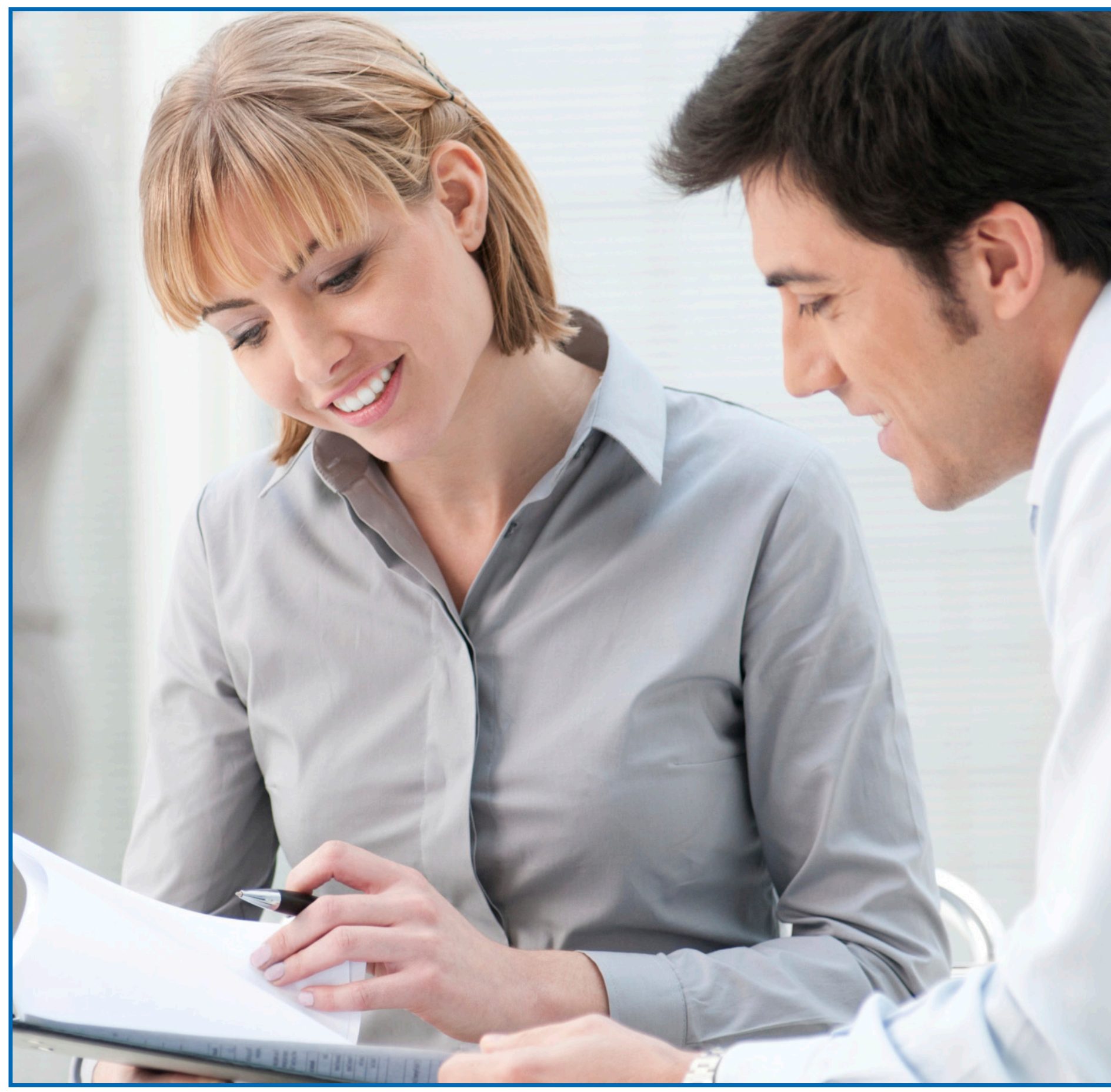




\section{COMPETENCY-BASED PROMOTION CRITERIA}

In a coherent Triple $\mathrm{C}$ curriculum, decisions for promotion are based on the demonstration of competence gathered through a competency-based assessment system. Promotion criteria should be explicitly stated and consistent with program outcomes. The family medicine residency program must be ultimately responsible for promotion decisions from one level of residency to another, and for program completion.

It is expected that changes to assessment systems leading to the collection of more robust data on resident performance on acquisition of the essential skills required for competence will position residency programs to be better able to address the following questions for promotion decisions in a Triple C competency-based system:

-What will be considered sufficient demonstration of competence?

-What will be considered sufficient progress?

- What difficulties in progress would lead to a program's decision to provide a resident with an intensive individualized education plan? When should an official remediation policy be applied?

- What persistent difficulties in progress or lack of specific competencies would lead to a decision for dismissal?

- Could the sole demonstration of a series of competencies suffice for graduation, or should some timeline requirements be maintained, either for feasibility or to foster the development of professional identity?

It is suggested that both time and demonstrated competence should be considered for promotion decisions. ${ }^{26,27}$ Because of feasibility issues, programs will organize "a curriculum that incorporates time-based rotations or learning experiences and that also offers flexibility (...), creating a hybrid model. ${ }^{1,10,11}$ This model views time as a "resource to be used to the advantage of the trainee," as discussed in "Length of Training in the Core Family Medicine Residency. ${ }^{128}$

\section{CONCLUSION}

Competency-based assessment of learners, though definitely an international trend, is still a work in progress in terms of developing practical tools, strategies, and processes. Over the last five to 10 years, we have moved in this area from pioneer experimentation to a more robust body of scholarly work based on sound educational theory and experiential knowledge. The Working Group on Certification Process has clearly defined the process of competency-based assessment for family medicine residency programs, which has led to extensive experimentation in different programs in Canada. ${ }^{5}$ With a wealth of theoretical and practical knowledge available on portfolios, some residency programs are working on how to organize and use portfolios in the Triple $\mathrm{C}$ curriculum and assessment system. In terms of benchmarks and EPAs, the international and local educational communities seem to be at the pilot project stage. However, ongoing projects within family medicine residency programs should soon bring additional knowledge and practical resources.

The implementation of a Triple $\mathrm{C}$ curriculum involves moving to a competency-based system for assessing learners, using coherent assessment strategies. This change requires a significant paradigm shift in terms of day-to-day assessment practices and preceptor-resident interactions; different types of assessment tools and processes than those used in the traditional system; and new program-wide approaches to monitoring progress, individualized educational planning, and promotion decisions. Educational continuity in the preceptor-resident interactions and between resident and faculty 
advisor are necessary for any of these actions to be meaningful and effective. Faculty will need strong guidance and support from their programs, including various forms of faculty development, in order to embrace these practices and refine their abilities in competency-based assessment.

Departments of family medicine will require significant educational and administrative resources over the next few years to accomplish this transformation. Nevertheless, there have already been significant developments in assessment within family medicine education in Canada, suggesting that the departments are taking on the challenge with enthusiasm and an innovative spirit. ${ }^{29}$ 


\section{References}

1. Oandasan I, Wong E, Saucier D, Donoff M, Iglar K, Schipper S. Triple C: linking curriculum and assessment. Can Fam Physician 2012;58:1165-1167. Available from: www.cfp.ca/ content/58/10/1165.full.pdf+html. Accessed 2013 Apr 18.

2. Saucier D, Schipper S, Oandasan I, Donoff M, Iglar K, Wong E. Key concepts and definitions of competency-based education [PowerPoint presentation]. Mississauga ON: College of Family Physicians of Canada; 2011. Available from: www.cfpc.ca/TripleCToolkit/. Accessed 2013 Jun 19.

3. College of Family Physicians of Canada, Working Group on Certification Process. Defining Competence for the Purposes of Certification by the College of Family Physicians of Canada: The Evaluation Objectives in Family Medicine. Mississauga, ON: College of Family Physicians of Canada; 2010. Available from: www.cfpc.ca/uploadedFiles/Education/Definition\%20 of $\% 20$ Competence $\% 20$ Complete $\% 20$ Document $\% 20$ with $\% 20$ skills $\% 20$ and $\% 20$ phases $\% 20$ Jan\%202011.pdf. Accessed 2013 Apr 18.

4. Tannenbaum D, Kerr J, Konkin J, Organek A, Parsons E, Saucier D, et al. Triple C CompetencyBased Curriculum. Report of the Working Group on Postgraduate Curriculum Review - Part 1. Mississauga, ON: College of Family Physicians of Canada; 2011. Available from: www.cfpc. ca/uploadedFiles/Education/_PDFs/WGCR_TripleC_Report_English_Final_18Mar11.pdf. Accessed 2013 Apr 18.

5. College of Family Physicians of Canada, Working Group on Certification Process. Template for In-training Assessment Process. Triple C Toolkit. www.cfpc.ca/TripleCToolkit/. Published June 2012. Accessed 2013 Jun 19.

6. College of Family Physicians of Canada, Working Group on Curriculum Review. CanMEDSFamily Medicine: A Framework of Competencies in Family Medicine. Mississauga, ON: College of Family Physicians of Canada; October 2009. Available from: www.cfpc.ca/ uploadedFiles/Education/CanMeds\%20FM\%20Eng.pdf. Accessed 2013 Apr 19.

7. Tannenbaum D, Kerr J, Konkin J, Organek A, Parsons E, Saucier D, et al. The Scope of Training for Family Medicine Residency: Report of the Working Group on Postgraduate Curriculum Review. Mississauga, ON: College of Family Physicians of Canada; 2011. Available from: www.cfpc.ca/uploadedFiles/Education/_PDFs/8\%20The\%20Scope\%20of\%20Training\%20 for\%20Family\%20Medicine\%20Residency_Domains\%20of\%20Clinical\%20Care\%20 and\%20Evolving\%20Professional\%20Competencies.pdf. Accessed 2013 Apr 19.

8. Giroux M, Girard G. Favoriser la position d'apprentissage grâce à l'interaction superviseursupervisé. [Fostering a learning stance through supervisor-trainee interaction.] Pédagogie Médicale 2009;10(3):193-210. French.

9. Hoff TJ, Pohl H, Bartfield J. Creating a learning environment to produce competent residents: the roles of culture and context. Acad Med 2004;79:532-540.

10. Saucier D, Paré L, Côté L, Baillargeon L. How core competencies are taught during clinical supervision: participatory action research in family medicine. Med Educ 2012;46:1194-1205.

11. Stalmeijer RE, Dolmans DH, Wolfhagen IH, Muijtjens AM, Scherpbier AJ. The development of an instrument for evaluating clinical teachers: involving stakeholders to determine content validity. Med Teach 2008;30:e272-e277. http://informahealthcare.com/doi/ abs/10.1080/01421590802258904. Accessed 2013 Apr 19. 
12. Teunissen PW, Stapel DA, Van Der Vleuten C, Scherpbier A, Boor K, Scheele F. Who wants feedback? An investigation of the variables influencing residents' feedback-seeking behavior in relation to night shifts. Acad Med 2009;84:910-917.

13. Sommers PS, Muller JH, Saba GW, Draisin JA, Shore WB. Reflections-on-action: medical students' accounts of their implicit beliefs and strategies in the context of one-to-one clinical teaching. Acad Med 1994;69(Suppl 10):S84-S86.

14. Wolpaw T, Papp KK, Bordage G. Using SNAPPS to facilitate the expression of clinical reasoning and uncertainties: a randomized comparison group trial. Acad Med $2009 ; 84: 517-524$.

15. Wolpaw TM, Wolpaw DR, Papp K. SNAPPS: A learner-centered model for outpatient education. Acad Med 2003;78:893-898.

16. Crichton T, Allen T, Bethune C, Brailovsky C, Donoff M, Laughlin T, et al. Triple C Competency-based curriculum: a competency-based approach to in-training assessment [PowerPoint presentation]. Mississauga, ON: College of Family Physicians of Canada; 2011. Available from: www.cfpc.ca/TripleCToolkit/. Accessed 2013 Jun 19.

17. Naccache N, Samson L, Jouquan J. Le portfolio en éducation des sciences de la santé: un outil d'apprentissage, de développement professionnel et d'évaluation. Pédagogie médicale 2006;7:110-127.

18. Carraccio C, Englander R. Evaluating competence using a portfolio: a literature review and web-based application to the ACGME competencies. Teach Learn Med 2004;16:381-387.

19. Van Tartwijk J, Driessen EW. Portfolios for assessment and learning: AMEE Guide no. 45. Med Teach 2009;31:790-801. Available from: http://dx.doi.org/10.1080/01421590903139201. Accessed 2013 Apr 19.

20. Snadden D. Portfolios - attempting to measure the unmeasurable? Med Educ 1999;33:478-479.

21. Ross S, Poth CN, Donoff M, Humphries P, Steiner I, Schipper S, et al. Competency-based achievement system: using formative feedback to teach and assess family medicine residents' skills. Can Fam Physician 2011;57:e323-e330.

22. ten Cate O, Scheele F. Competency-based postgraduate training: can we bridge the gap between theory and clinical practice? Acad Med 2007;82:542-547.

23. ten Cate O, Carraccio C, Englander R, Jones MD, Scheele F. Symposium: Developing Entrustable Professional Activities (EPAs) in the Procedural and Non-Procedural Specialties: Reflections and Insights. AMEE 2012 Symposia; August 27, 2012, Lyon France.

24. ten Cate O, Snell L, Carraccio C. Medical competence: the interplay between individual ability and the health care environment. Med Teach 2010;32:669-675.

25. Sterkenbug A, Barach P, Kalkman C, Gielen M, tenCate O. When do supervising physicians decide to entrust residents with unsupervised tasks? Acad Med 2010;85:1408-1417.

26. Hodges BD. The tea-steeping or i-Doc model for medical education? Acad Med 2010;85(9 Suppl):S34-S44. 
27. Royal College of Physicians and Surgeons of Canada. Competency-based Medical Education: A White Paper Prepared for the Royal College of Physicians and Surgeons of Canada, Future of Medical Education. Ottawa, ON; Royal College of Physicians and Surgeons of Canada; 2011. Available from: http://www.royalcollege.ca/portal/page/portal/rc/common/documents/ educational_initiatives/cbme.pdf. Accessed 2012 Jan 20.

28. Tannenbaum D, Kerr J, Konkin J, Organek A, Parsons E, Saucier D, et al. Length of Training in the Core Family Medicine Residency: Report of the Working Group on Postgraduate Curriculum Review. Mississauga, ON: College of Family Physicians of Canada; 2012. Available from: www.cfpc.ca/uploadedFiles/Resources/Resource_Items/Triple_C/Triple\%20 C\%20Length\%20of\%20Training.pdf. Accessed 2013 Apr 19.

29. Shaw L, Walsh A, Oandasan I, Kerr J, Konkin J, Organek A, et al. Resource implications for departments of family medicine: a discussion paper. In: Oandasan I, Saucier D, eds. Triple C Competency-based Curriculum Report - Part 2: Advancing Implementation. Mississauga, ON: College of Family Physicians of Canada; 2013. Available from: www.cfpc.ca/uploadedFiles/ Education/_PDFs/TripleC_Report_pt2.pdf. Accessed 2013 Jul 29. 


\title{
Template for In-training Asessment Process
}

\author{
Authors \\ Working Group on Certification Process
}




\section{FAMILY MEDICINE CURRICULUM: TEMPLATE FOR IN-TRAINING ASSESSMENT PROCESS}

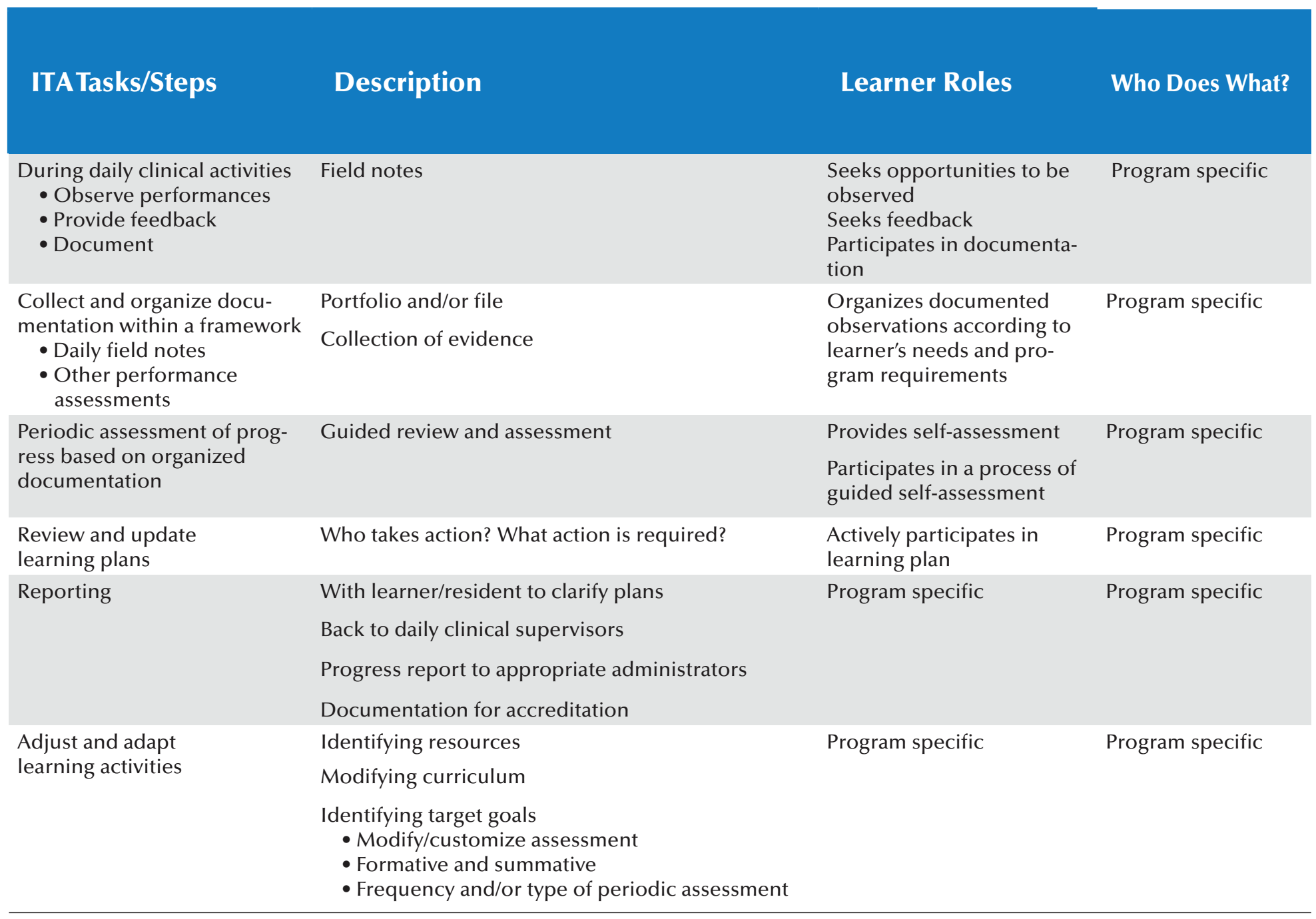

Suggested Citation:

College of Family Physicians of Canada, Working Group on Certification Process. Template for Intraining Assessment Process. Triple C Toolkit. www.cfpc.ca/TripleCToolkit/. Published June 2012. Accessed 2013 Jun 19. 


\title{
Triple C: Linking Curriculum and Assessment
}

\author{
Authors \\ Ivy Oandasan, Eric Wong, Danielle Saucier, Michel Donoff, \\ Karl Iglar, Shirley Schipper
}




\section{Triple C: linking curriculum and assessment}

Ivy Oandasan MD MHSc CCFP FCFP Eric Wong MD MCISc(FM) CCFP Danielle Saucier MD CCFP FCFP Michel Donoff MD CCFP FCFP Karl Iglar MD CCFP Shirley Schipper MD CCFP

 his article is part of a series describing the key elements of the Triple C Competency-based Curriculum. ${ }^{1-6}$ It highlights how different frameworks introduced by the College of Family Physicians of Canada (CFPC) can be used to design and implement residency programs, and teach and assess family medicine residents. The overarching viewpoint from which to understand these frameworks and their contributions lies in the goal of residency training: to develop professional competence to the level of a physician ready to begin practice in the specialty of family medicine The vision of our College is to produce family physicians who are confident and competent to practise comprehensive and continuing care anywhere in Canada. Residency programs must therefore provide residents with relevant learning experiences to gain competence in these areas.

To understand Triple C's role in residency education it is helpful to articulate its 2 distinct intents: 1) to be a curriculum that clearly identifies expected outcomes and 2) to provide a process that ensures learners are assessed for competence. Both curriculum design and assessment processes are interdependent features of a Triple C Competency-based Curriculum. The critical components that link curriculum and assessment within Triple $\mathrm{C}$ are the relevant learning experiences within which learners acquire competencies and are assessed for competence.

\section{Frameworks guiding}

\section{curriculum and assessment}

To understand the notion of competence, we must recognize that competence 1) is defined according to a specific time in the learning continuum (eg, end of residency), 2) reflects required abilities for practice in particular settings and contexts (eg, for office-based practice or for specific health care populations), and 3) is multidimensional and dynamic. ${ }^{7}$ In order to create a competency-based curriculum for residents it is necessary to consider these elements.

Three frameworks have been endorsed by the CFPC to help curriculum planners design curricula and assess learners, all of which align with Triple $\mathrm{C}$ and assess learners within a competency-based approach:

- the CanMEDS-Family Medicine (CanMEDS-FM) roles;

- the domains of clinical care ; and

- the evaluation objectives. ${ }^{10}$
Each of these frameworks provides a different lens to help program directors design their family medicine residency curricula. They also help residents and their clinical preceptors evaluate whether relevant clinical experiences are being provided. For preceptors, the frameworks help assess progressive achievement of competence by residents. For residents, the frameworks help envision what needs to be learned and help keep track of what is being learned. Each framework helps define how the family medicine curriculum must be designed, what experiences need to be provided, and what abilities need to be assessed.

\section{Design, provide, assess}

Residency programs need to design curricula that will enable learners to develop the desired competencies required of family physicians to be ready to begin practice independently. They need to ensure that their clinical sites and preceptors provide relevant learning experiences within contexts that are family medicine centred. The CanMEDS-FM roles and the domains of clinical care frameworks offer useful tools for programs to design and provide relevant learning experiences for residents, ensuring exposure to the breadth of the discipline of family medicine. Over time, the preceptor, who understands the specific competencies required of a family medicine resident, can attest to the resident's competency acquisition. Preceptors can confidently assess resident competence in family medicine, using the evaluation objectives framework as a tool. Used interdependently, the 3 CFPC frameworks all contribute to a Triple $\mathrm{C}$ curriculum.

\section{Relevant learning experiences:} critical pieces of the puzzle

Figure $1^{11}$ provides a pictorial representation of how residents are engaged in relevant learning experiences related to the 3 CFPC frameworks. Program directors want to ensure that residents have been exposed to learning experiences that reflect the breadth of family medicine and the CanMEDS-FM roles. Where learners are not getting adequate exposure, other types of learning through simulation, seminars, or online learning might need to be used. Those who

La traduction en français de cet article se trouve à www.cfp.ca dans la table des matières du numéro d'octobre 2012 à la page e608. 
Triple C I Triple C: linking curriculum and assessment

are assessing residents will observe them within relevant family medicine learning experiences in order to make a judgment about competency acquisition. The tracking of these relevant learning experiences according to the domains of clinical care and the CanMEDS-FM roles enables residents and preceptors to be active partners in ensuring that these competencies are met. Figure $2^{11}$ provides an example of how these frameworks interact with one another. In this case, a resident seeing a pregnant adolescent immigrant in the family medicine clinic is exposed to multiple CanMEDS-FM roles across different domains of clinical care, and can demonstrate areas of competence as described in the evaluation objectives. The 3 CFPC frameworks all inform the types of relevant learn ing experiences required. The provision of relevant family medicine learning experiences becomes fundamental for a successful Triple C Competency-based Curriculum.

\section{Conclusion}

The overall responsibilities of a residency program are to design and provide a family medicine curriculum that ensures the provision of relevant learning experiences that reflect the breadth of family medicine. Through these learning experiences, residents are able to be assessed for competence. The frameworks (CanMEDS-FM, domains of clinical care, and evaluation objectives) provide 3 necessary perspectives that are useful in the implementation of a competency-based curriculum. The provision of relevant learning experiences within Triple $C$ is fundamental for learners to

FM-family medicine.
Figure 1. Curriculum and assessment frameworks

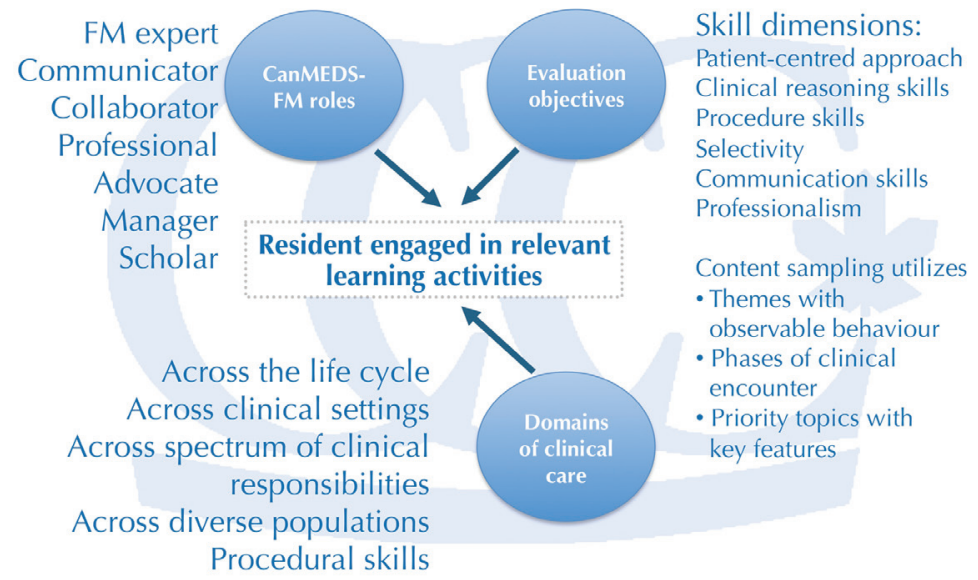

FM-family medicine.

Figure 2. An example of the frameworks in action

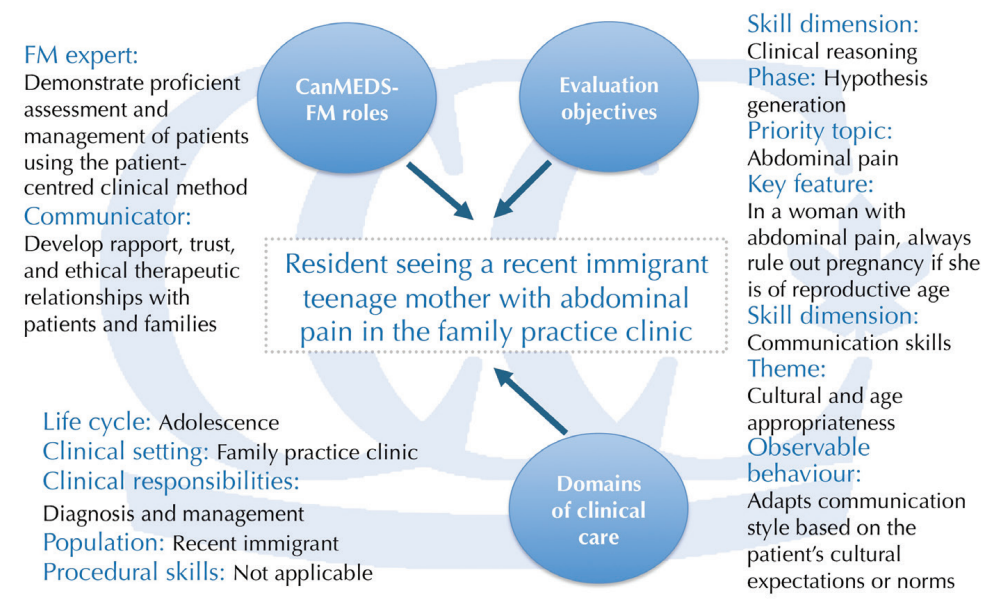

Adapted from the Alignment Sub-committee of the Triple C Competency-based Curriculum Task Force.t"

achieve competencies and to demonstrate their overall competence-that they are ready to begin practice in the specialty of family medicine.

Dr Oandasan is Associate Director, Academic Family Medicine for the College of Family Physicians of Canada in Mississauga, Ont, and is Associate Professor in the Department of Family and Community Medicine at the University of Toronto in Ontario. Dr Wong is Assistant Professor and Postgraduate Director in the Department of Family Medicine of the Schulich School of Medicine \& 
Triple C: linking curriculum and assessment | Triple C

Dentistry at the University of Western Ontario in London, Ont. Dr Saucier is Professor in the Department of Family Medicine and Emergency Medicine at Laval University in Quebec and is a staff physician at Unité de médecine familiale Laval. Dr Donoff is Professor and Associate Chair in the Department of Family Medicine at the University of Alberta in Edmonton and Centre Director for the Royal Alexandra Family Medicine Centre. Dr Iglar is a staff physician at St Michael's Hospital in Toronto and is Director of Postgraduate Education and Associate Professor in the Department of Family and Community Medicine at the University of Toronto. Dr Schipper is Assistant Professor and Residency Program Director in the Department of Family Medicine at the University of Alberta. Drs Oandasan, Wong, Saucier, Donoff, Iglar, and Schipper are Alberta. Drs Oandasan, Wong, Saucier, Donoff, Iglar, and Schipper are
members of the Alignment Sub-committee of the Triple C Competency-based Curriculum Task Force.

\section{Competing interests}

None declared

\section{References}

1. Oandasan I; Working Group on Postgraduate Curriculum Review. Advancing Canada's family medicine curriculum: Triple C. Can Fam Physician 2011;57:739-40 (Eng), e237-8 (Fr).

2. Kerr J, Walsh AE, Konkin J, Tannenbaum D, Organek A, Parsons E, et al. Renewing postgraduate family medicine education: the rationale for Triple $\mathrm{C}$. Can Fam Physician 2011;57:963-4 (Eng), e311-2 (Fr)

3. Kerr J, Walsh AE, Konkin J, Tannenbaum D, Organek A, Parsons E, et al. Continuity: middle $C$ - a very good place to start. Can Fam Physician 2011;57:1353-6 (Eng), e457-9 (Fr).

4. Walsh AE, Konkin J, Tannenbaum D, Kerr J, Organek AJ, Parsons E, et al. Comprehensive care and education. Can Fam Physician 2011;57:1475-6 (Eng), e491-3 (Fr).
5. Shaw E, Walsh AE, Saucier D, Tannenbaum D, Kerr J, Parsons E, et al. The last C: centred in family medicine. Can Fam Physician 2012;58:346-8 (Eng), e179-81 (Fr)

6. Saucier D, Shaw E, Kerr J, Konkin, J, Oandasan I, Organek AJ, et al. Competency-based curriculum for family medicine. Can Fam Physician 2012;58:707-8 (Eng), e359-61 (Fr)

7. Frank JR, Snell L, ten Cate O, Holmboe ES, Carraccio C, Swing SR, et al, Competency based medical education: theory to practice. Med Teacher 2010;32(8):638-45.

8. Organek A; on behalf of the Working Group on Postgraduate Curriculum Review. CanMEDS-Family Medicine: a competency framework for family medicine and education in Canada [PowerPoint]. Mississauga, ON: College of Family Physicians of Canada; 2012. Available from: www.cfpc.ca/ TripleCToolkit. Accessed 2012 Aug 14

9. Tannenbaum D; on behalf of the Working Group on Postgraduate Curriculum Review. The scope of training for family medicine residency: domains of clinical care and evolving professional competencies [PowerPoint]. Mississauga, ON: College of Family Physicians of Canada; 2012. Available from: www.cfpc.ca/ TripleCToolkit. Accessed 2012 Aug 14

10. Crichton T, Allen T, Bethune C, Brilovsky C, Donoff M, Laughlin T, et al. Evaluation objectives in family medicine: defining competence for the purposes of Certification [PowerPoint]. Mississauga, ON: College of Family Physicians of Canada; 2012. Available from: www.cfpc.ca/TripleCToolkit. Accessed 2012 Aug 14 .

11. Alignment Sub-committee of the Triple C Competency-based Curriculum Task Force. Linking curriculum and assessment in a competency-based residency training program [PowerPoint]. Mississauga, ON: College of Family Physicians of Canada; 2012. Available from: www.cfpc.ca/TripleCToolkit. Accessed 2012 Aug 15. 
Competency-based assessment has become a focus for residency programs during the implementation of the Triple C Competency-based Curriculum (Triple C). The Evaluation Objectives framework is recognized for its foundational importance in the assessment of competence. The paper within this section entitled "The Evaluation Objectives: Relationship With the Other Triple C Frameworks" explores the inter-relationships among the frameworks that have been introduced in Triple C: the CanMEDS-Family Medicine (CanMEDS-FM) Roles, used in designing curriculum; the Domains of Clinical Care for residency training in family medicine, indicates to educators the relevant learning experiences they should provide to residents; and the Evaluation Objectives, which are used to assess family medicine residents for readiness to begin independent practice. The relationship between these frameworks is progressively better articulated. Questions have emerged about the capability of the Evaluation Objectives to assess the CanMEDS-FM Roles and the family medicine residents' abilities to practise family medicine across the Domains of Clinical Care.

The final discussion paper in this section is a previously published article by Michel Donoff (2009), describing the importance of field notes as part of competency-based assessment. This article was reprinted here to bring together key reference materials that can be accessible in one place as the academic community advances Triple $\mathrm{C}$ competency-based assessment processes. Along with these papers, PowerPoint presentations on competency-based assessment, copies of the ITA table, examples of field notes, and tips on how to write good field notes can be found on the Triple C Toolkit website. All of these resources have been made available to offer some guidance for family medicine educators during the transition to Triple C. 



\title{
The Evaluation Objectives: Relationship With the Other Triple C Frameworks
}

\section{Authors}

\author{
Tim Allen, Tom Crichton, Cheri Bethune, Carlos Brailovsky, \\ Michel Donoff, Kathrine Lawrence, Tom Laughlin, Stephen Wetmore
}

Suggested Citation:

Allen R, Crichton T, Bethune C, Brailovsky, C, Donoff M, Lawrence K, et al. The Evaluation Objectives: relationship with the other Triple C frameworks. In: Oandasan I, Saucier D, eds. Triple C Competencybased Curriculum Report - Part 2: Advancing Implementation. Mississauga, ON: College of Family Physicians of Canada; 2013. Available from: www.cfpc.ca/uploadedFiles/Education/_PDFs/TripleC_ Report_pt2.pdf. Accessed 2013 Jul 29. 
On its journey toward a competency-based curriculum, the College of Family Physicians of Canada (CFPC) developed four main resources describing competence in family medicine: The Four Principles of Family Medicine, ${ }^{1}$ CanMEDS-Family Medicine (CanMEDS-FM) Roles, ${ }^{2 *}$ the domains of clinical care for residency training ("Domains of Clinical Care"), ${ }^{3}$ and the evaluation objectives for the purpose of Certification in family medicine ("Evaluation Objectives"). ${ }^{4}$ Some confusion has been reported on how to use these different components when designing educational programs or experiences. In general, these resources are complementary; considered together, they provide a more rich description of competence in family medicine than any single component. However, each resource is most useful for specific purposes.

The CFPC, through the Triple C Competency Based Curriculum Task Force (Triple C Task Force), has opted to use CanMEDS-FM and the Domains of Clinical Care for residency training as frameworks to guide curriculum development. The Four Principles of Family Medicine are retained as the overarching description of the principles for practice by family physicians, as defined by the CFPC. The CanMEDSFM Roles provide further direction and inspiration for ongoing professional development and lifelong learning after Certification. This discussion paper presents and justifies the primary role that is proposed for the Evaluation Objectives.

In accordance with the decision made by the CFPC Board of Examiners, the Evaluation Objectives are to be used as the framework to assess learners, both during training and for the CFPC Certification Examinations, to determine competence to begin independent family practice. The Evaluation Objectives provide the structure and components for the assessment data that is to be collected, compiled, and used for both formative and summative purposes in residency training. Included within the Evaluation Objectives are the six essential skills, phases of the clinical encounter, priority topics, procedures and themes, and key features and observable behaviours. ${ }^{4}$

Although assessment data can also be compiled and organized in additional ways, the Working Group on the Certification Process (WGCP) recommends that any other frameworks be applied only secondarily. It is important that these secondary resources neither reduce the quality and quantity of the assessment data, nor interfere with its usefulness, especially for formative feedback, as many other frameworks tend to do.

This paper will provide some additional analyses to demonstrate that assessment based on the Evaluation Objectives will confidently assess all of the roles of frameworks such as CanMEDS-FM and the Four Principles of Family Medicine, and will assess competencies across the Domains of Clinical Care. There might be a few specific content gaps, but the true underlying competencies will have been assessed, and the competent trainee, at the end of residency, will actively abstract and extend his or her competence to new areas as soon as the need is identified while in practice.

\section{Justification for using the Evaluation Objectives as the basis for the assessment of clinical competence in family medicine}

The six essential skill dimensions of the Evaluation Objectives have been consistently promoted as the best basic structure for the assessment of competence in family medicine for the purposes of Certification. These essential skills underlie the competent performance of all the roles in any framework. As such, they are framework independent and can be used to populate all the current common competency role frameworks (Four Principles, CanMEDS-FM, Accreditation Council for Graduate Medical Education [ACGME], etc.). The advantage of the Evaluation Objectives model is that it is user

*Adapted from Frank JR, ed. The CanMEDS 2005 Physician Competency Framework. Better standards. Better physicians. Better care. Ottawa: The Royal College of Physicians and Surgeons of Canada; 2005. Available from: http://www.royalcollege.ca/portal/page/portal/rc/common/documents/canmeds/resources/publications/framework_full_e.pdf. Accessed 2013 Apr 15. 
friendly and quite compatible with meaningful assessment of competence in practice. The model is case or task based, which makes it especially useable in the workplace. Designing assessment around other competency frameworks loses this ease of use and application to day-to-day tasks.

There has been a growing consensus in the literature that the definition of competence can be inspired by the competency frameworks, but that the assessment of that competence should be designed quite differently. An extract of a discussion paper prepared by Watling, sent by personal communication to T. Allen in November 2010, summarizes the situation in an eloquent fashion:

Our work on residents' perceptions of the CanMEDS roles as reflected in the in-training assessment process showed that learners perceived the CanMEDS roles as independent and mutually exclusive entities rather than as integrated components of competent practice. This perception led to concerns about their opportunity to demonstrate competence within each of the individual roles and about the ability of supervisors to fairly and accurately assess each of the roles, thus undermining the credibility of the assessment process. The structure of the standard [In-training evaluation rating (ITER)]form itself promotes this perception of the roles as individual, non-overlapping items, further straining the credibility of the process. In any process of performance assessment, perceptions of credibility are paramount; without credibility, a process is unlikely to influence learning, even if its message is accurate.

A number of other authors have sounded a similar alarm that the design of assessment strategies based around competency frameworks risks missing that which we are truly aiming to assess: the ability of learners to competently undertake their professional work. ITERs fail to capture the integrated and overlapping nature of the CanMEDS roles, and instead represent them as separate entities, implying that each role can and should be performed and assessed independently.

This sentiment is reinforced by ten Cate (2006) when he said of the CanMEDS roles: "Clearly, these roles are so intertwined that assessing each of them separately would make little sense." In fact, we have been attempting to do exactly that. Indeed, our assessment strategy may be driving learners to value "performing the roles" over performing competent clinical work that seamlessly and dynamically integrates the roles as appropriate to the situation.

Clearly, competency frameworks such as CanMEDS have stimulated essential reflection about the qualities of physicians that are meaningful. The application of such frameworks to the process of clinical assessment of learners is not straightforward. CanMEDS gives language to assessors and legitimizes constructive critique of resident performance based on elements of performance outside mere medical knowledge, and in these ways the process of assessment is strengthened. We must ensure, however, that the use of CanMEDS as a basis for assessment does not artificially reduce the complexity of the professional work of the physician to individual pieces whose sum does not reflect competent clinical performance.

[In-training assessments are important] as a way to reflect "the integration of the various roles as required for the effective and safe performance of professional work. The tools we use should support the message that assessment is ultimately interested in the holistic view of performance, rather than in an artificial deconstruction of that performance. Without a clear sense of this integrated whole as the real object of our assessment, the in-training assessment process will fail to gain credibility among either 
learners or assessors. In-training assessment should therefore be based around real clinical work that reflects the important professional activities of the specialty. Different activities draw variously on the different CanMEDS roles, but within any specialty the full range of these roles will be reflected in the scope of professional work done by its practitioners. The challenge is to enable assessment to be guided by CanMEDS but not constrained by it. Grounding assessment in real clinical work can help to maintain this precarious balance.

Table 1 offers readings recommended by Watling to further investigate the disconnect between the design of assessment strategies based on competency frameworks and what is being assessed.

\section{Table 1. Suggested reading on challenges for competency-based framework assessments}

ten Cate O. Trust, competence, and the supervisor's role in postgraduate training. BMJ 2006;333: 748-751.

Huddle TS, Heudebert GR. Taking apart the art: the risk of anatomizing clinical competence. Acad Med 2007; 82:536-541.

Whitcomb ME. Redirecting the assessment of clinical competence. Acad Med 2007;82:527-528. ten Cate O, Scheele F. Competency-based postgraduate training: can we bridge the gap between theory and clinical practice? Acad Med 2007;82:542-547.

Watling CJ, Kenyon CF, Zibrowski EM, Schulz V, Goldszmidt MA, Singh I, et al. Rules of engagement: residents' perceptions of the in-training evaluation process. Acad Med 2008;83(10 Suppl): S97-S100.

Zibrowski EM, Singh SI, Goldszmidt MA, Watling CJ, Kenyon CF, Schulz V, et al. The sum of the parts detracts from the intended whole: competencies and in-training assessments. Med Educ 2009;43:741-748.

Ginsburg S, Mcllroy J, Oulanova O, Eva K, Regehr G. Toward authentic clinical evaluation: pitfalls in the pursuit of competency. Acad Med 2010;85:780-786.

Watling CJ, Lingard L. Toward meaningful evaluation of medical trainees: the influence of participants' perceptions of the process. Adv Health Sci Educ Theory Pract 2012;17:183-194.

Watling CJ, Kenyon CF, Schulz V, Goldszmidt MA, Zibrowski E, Lingard L. An exploration of faculty perspectives on the in-training evaluation of residents. Acad Med 2010;85:1157-1162. 
The Evaluation Objectives, as currently structured, address most of the concerns raised in Watling's quotation and will lead to better assessments of competence in the workplace or in-training situations. Their form and their terminology are familiar to both preceptors and trainees, so they do not present a barrier to the modification that is most critical to improving in-training assessment (ITA): the gathering and documentation of case-specific comments and feedback from the preceptors to the residents during daily clinical work. This preceptor-resident clinical interaction is the essential "instrument" for improved ITA. Only this information can permit us to truly assess competence in the spirit of the generic definition that is most commonly used today, as described by Epstein and Hundert ${ }^{5}$ :

... the habitual and judicious use of communication, knowledge, technical skills, clinical reasoning, emotions, values, and reflection in daily practice for the benefit of the individual and community being served.

\section{SUMMARY}

The Evaluation Objectives are operational-they describe competency in situation-specific or problem-specific terms and are directly accessible and used by preceptors and learners.

The Evaluation Objectives lead directly to the elements of competence as described by Epstein and Hundert. ${ }^{5}$ Whatever other frameworks are used, it has been our observation in family medicine that when you get down to defining a competency at an operational level, you end up with the six essential skills: patient-centred approach, communication, clinical reasoning, selectivity, professionalism, and procedure skills. ${ }^{4}$ These are the building blocks of competence in family medicine-the skills that underlie all the roles and principles.

The greatest value of the other competency frameworks is that they offer a different approach to the domain of competence in family medicine-such that they could fill any significant gaps that arise from the Evaluation Objectives framework.

Although the Evaluation Objectives are independent, they can be readily linked to the other curriculum and accreditation frameworks for reporting purposes. However, it is important that they keep their current structure for the purposes of planning and conducting effective and efficient assessment.

\section{CONNECTING THE FOUR PRINCIPLES OF FAMILY MEDICINE AND CanMEDS-FM ROLES WITH THE EVALUATION OBJECTIVES}

While linking the Evaluation Objectives with other competency frameworks would help fill any gaps within the Evaluation Objectives themselves, we also need to determine whether assessment that is structured around and based mainly on the Evaluation Objectives would neglect to assess any of the roles or competencies outlined in the other frameworks. Four separate exercises, conducted as part of the work of the WGCP from 2007 to 2012 have shown that an integrated assessment based on clinical tasks, as described by the Evaluation Objectives, will, indeed, assess all the roles and generic competencies of the Four Principles, CanMEDS, CanMEDS-FM, and the Domains of Clinical Care. It is likely that any generic framework used to describe the competent physician would find the assessment based on the Evaluation Objectives more than sufficient to populate its categories.

In 2008, the WGCP conducted an internal exercise that linked the Four Principles of Family Medicine and the seven CanMEDS roles as published by the Royal College of Physicians and Surgeons of 
Canada (RCPSC) ${ }^{6}$ to the following:

1. Key features of the 20 topics most often cited as priority

2. Observable behaviours for three of the essential skills (professionalism, communication skills, patient-centered approach)

3. General key features for a fourth essential skill: procedure skills

Each of the three items identified were coded to the most appropriate principle and CanMEDS role in a method similar to the coding exercise for key features for each priority topic. ${ }^{7}$ As can be seen in Table 2, the Evaluation Objectives, derived from our practice-based physician-patient-problem model, lead to assessment of all the principles and all the roles, in proportions that are not surprising. An evaluation based on an adequate sample of these Evaluation Objectives over the six skill dimensions would necessarily assess the principles and the roles. Approximately one third of the key features and observable behaviours linked to a single role, or to a single principle of family medicine. The other two thirds linked to two roles, or to two principles; some would have also coded to additional roles or principles had more choices been permitted.

\section{Table 2. Linking Evaluation Objectives with CanMEDS Roles and the Four Principles}

- To the key features (KFs) of the top 20 priority topics

- To all the observable behaviours (OBs)

- To the general KFs for procedure skills

There were a total of $443 \mathrm{KFs}$ and OBs to link. A maximum of two links per KF or OB were permitted.

\section{Linking to the Four Principles of Family Medicine}

Skilled physician

Community based

Resource to a defined population

Doctor-patient relationship is central

\section{Links}

329

135

97

148

709

\section{Linking to the seven CanMEDS Roles}

Medical Expert

Communicator

Collaborator

Manager

Health Advocate

Scholar

Professional

\begin{tabular}{r|r} 
& 192 \\
& 190 \\
& 111 \\
& 27 \\
& 47 \\
Total & 26 \\
Average number of links per element (KF or OB) & 180 \\
\hline
\end{tabular}


A second internal exercise conducted in 2010 was slightly different but came to a similar conclusion and added some new information. By this time, the CanMEDS-FM Roles had been introduced by the CFPC. ${ }^{2}$ Two main observations led to this exercise:

1. The observable behaviours and key features that are primarily identified with one of four of the essential skills of the Evaluation Objectives (professionalism, communication skills, the patient-centred approach, or procedure skills) could also assess other essential skill dimensions.

2. The roles of CanMEDS-FM are slightly modified with respect to the RCPSC's CanMEDS framework used in the first exercise. Therefore, it was appropriate to verify that the previously documented relationships to CanMEDS were maintained with use of the CanMEDS-FM Roles.

The exercise consisted, therefore, of linking the observable behaviours and key features for procedure skills to the other skill dimensions and to the CanMEDS-FM Roles. The key features from the priority topics were not coded in this exercise.

In Table 3, we see once again that the observable behaviours, key features, and procedure skills of the Evaluation Objectives reflect widely over the CanMEDS-FM Roles, and particularly on the nonmedical expert roles. We also see for the first time that about two thirds of these elements link to a second essential skill, which is exactly the situation previously found with the priority topic key features. These assess, on an average, about 1.7 essential skills per key feature. We can see that using a clinical task or case-based approach to assessment, which is also based on key features, leads to a rich and multidimensional reflection on competence.

\section{Table 3. Linking essential skill dimensions to the CanMEDS-FM Roles}

Linking observable behaviours (OBs) and key featuers (KFs) of patient-centred approach, professionalism, communication skills, and procedure skills to:

- The other essential skill dimensions

- The seven CanMEDS-FM Roles

There were a total of $282 \mathrm{OBs}$ and KFs to link, with a maximum of two links permitted during the exercise.

Links to other essential skills (besides the primary skill)

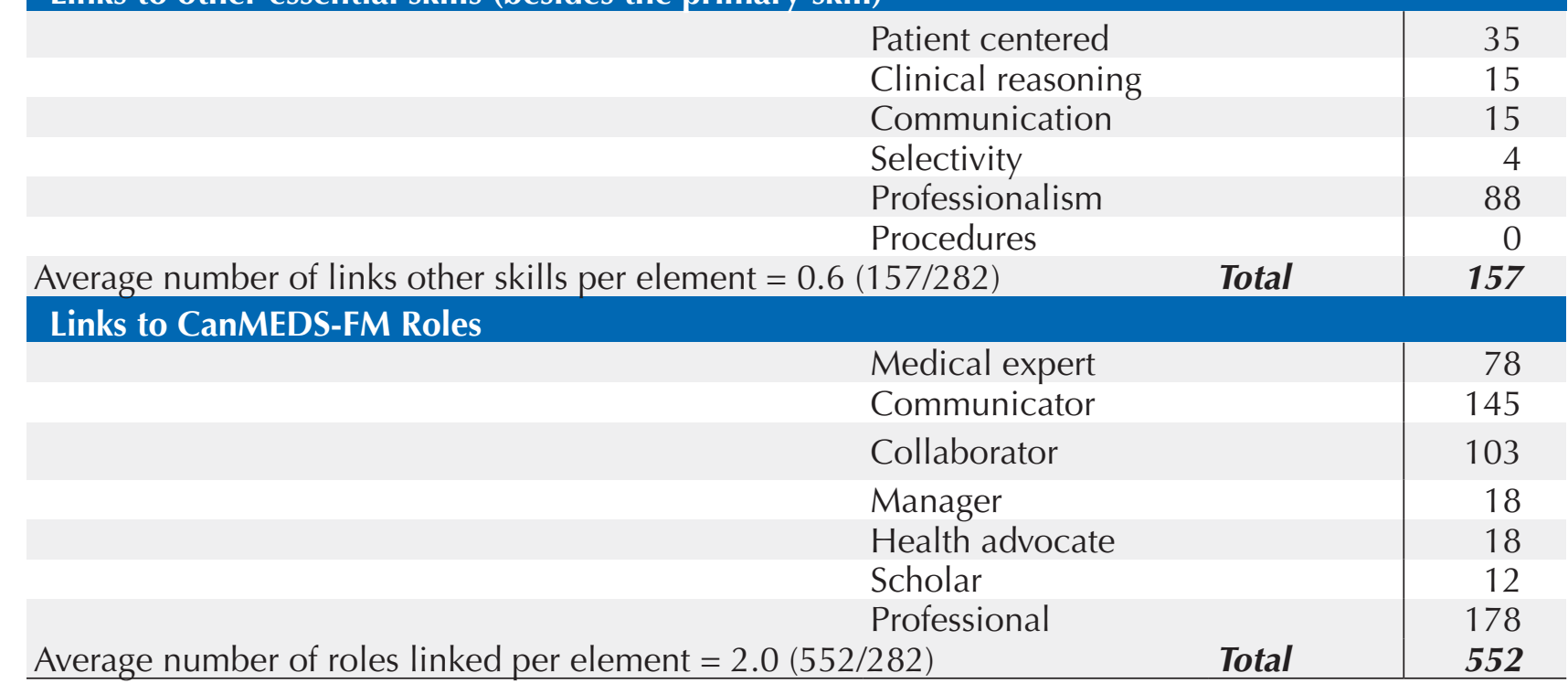


The third illustration of how the Evaluation Objectives lead to a comprehensive assessment of competence in the family physician comes from looking at the recommended assessment of procedure skills. ${ }^{8}$ Traditionally, competence in procedure skills is concentrated mostly on the procedure itself. The Evaluation Objectives recommend an assessment in this dimension based primarily on the general key features of procedure skills, and only secondarily on the procedure itself. Both are necessary, but the first is more determinant of overall competence than the second. This is analogous to the relationship between the six essential skill dimensions and the priority topics with their key features; the latter serve mainly as a substrate to demonstrate the first, not the other way round.

The exercise consisted of coding, or linking, each of the ten general key features of procedure skills to three frameworks: the essential skills (the five essential skills other than procedure skills), the Four Principles of Family Medicine, and the CanMEDS-FM Roles. A maximum of two links per key feature was permitted in each framework for this exercise, completed internally by the WGCP.

Table 4 shows that the key feature case-based approach leads to assessment in much more than simple procedure skills themselves: all six of the essential skill dimensions may be assessed, and five of the RCPSC CanMEDS roles-including the Professional, Communicator, and Collaborator roles-can be assessed through the Evaluation Objectives. This can be done in the context of learners engaged in clinical tasks during regular, supervised clinical work, and appears to be natural and pertinent rather than forced. This exercise shows that assessment of procedure skills based on the Evaluation Objectives will lead to an assessment of competence that meets the expectations of CanMEDS-FM and the Four Principles of Family Medicine.

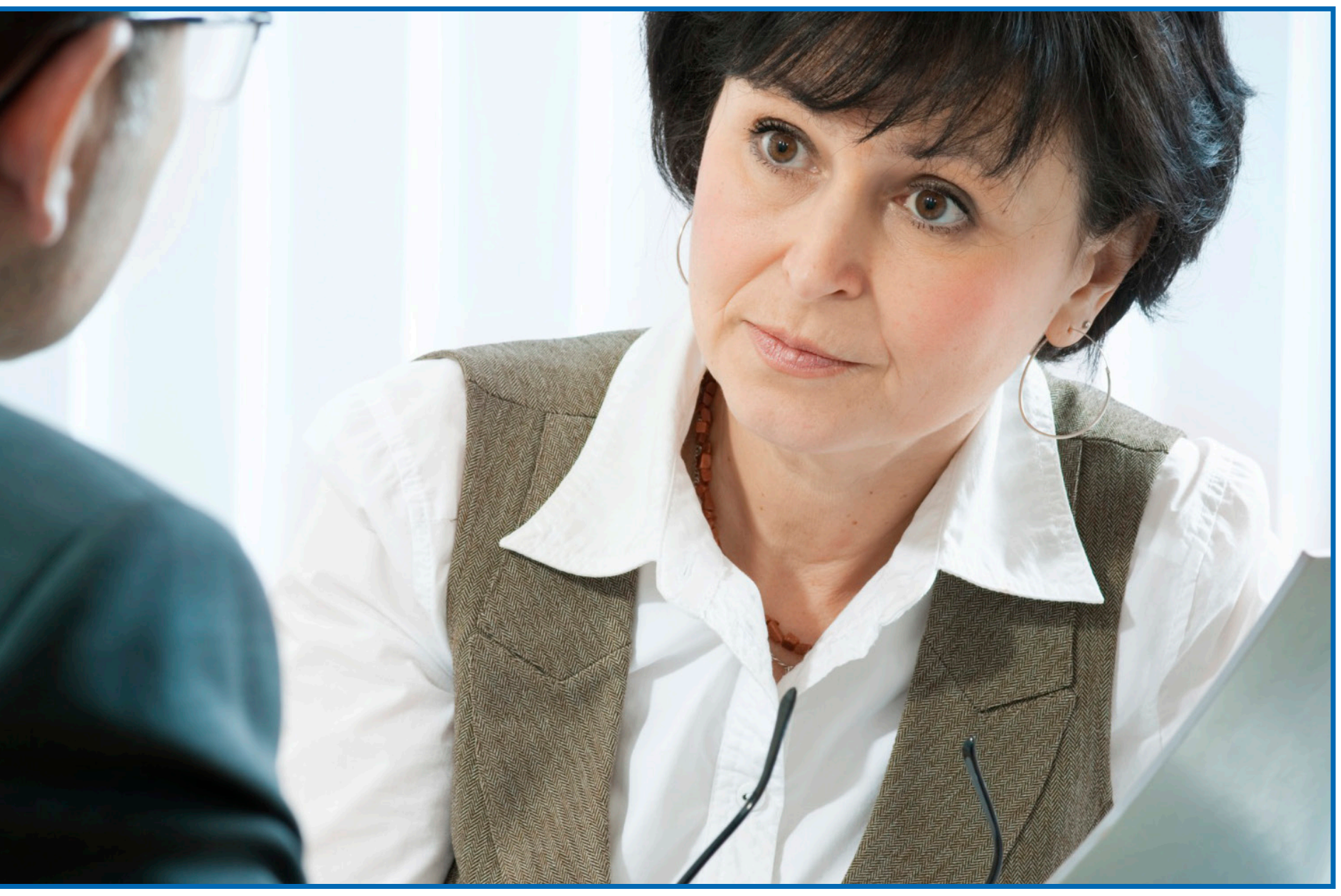


Table 4. Linking the general key features of procedure skills in family medicine

$\begin{array}{ccc}\text { Key Feature } & \begin{array}{c}\text { Essential Skill } \\ \text { Dimension }\end{array} & \begin{array}{c}\text { Four } \\ \text { Principles }\end{array} \\ \text { CanMEDS Role }\end{array}$

1. To decide whether or not you are going to do a procedure, consider the following:

a) The indications and contraindications to the procedure

b) Your own skills and readiness to do the procedure, (eg, your level of fatigue and any personal distracters)

c) The context of the procedure, including the patient involved, the complexity of the task, the time needed, the need for assistance, and location

\begin{tabular}{|c|c|c|}
\hline Clinical reasoning & $\begin{array}{l}\text { Skilled } \\
\text { clinician }\end{array}$ & Medical expert \\
\hline $\begin{array}{l}\text { Clinical reasoning } \\
\text { Professionalism }\end{array}$ & $\begin{array}{l}\text { Skilled } \\
\text { clinician }\end{array}$ & $\begin{array}{l}\text { Medical expert } \\
\text { Professional } \\
\text { Manager }\end{array}$ \\
\hline $\begin{array}{l}\text { Clinical reasoning } \\
\text { Selectivity }\end{array}$ & $\begin{array}{l}\text { Skilled } \\
\text { clinician }\end{array}$ & Medical expert \\
\hline
\end{tabular}

2. Before deciding to go ahead with the procedure:

a) Discuss the procedure with the patient, including a description of the procedure and possible outcomes, both positive and negative, as part of obtaining the patient's consent
b) Prepare for the procedure by ensuring appropriate equipment is ready

Communication

skills

Skilled

clinician

Medical expert

Clinical reasoning

Professionalism

Clinical reasoning

Skilled

clinician

c) Mentally rehearse the following:

- The anatomic landmarks necessary for procedure performance

Clinical reasoning

Skilled

clinician
Medical expert

Communicator

Medical expert

- The technical steps necessary in sequential fashion, including any preliminary examination

- The potential complications and their management

3. During performance of the procedure:

a) Keep the patient informed to reduce anxiety

b) Ensure patient comfort and safety at all times

Patient-centred approach

Patient-centred approach

Clinical reasoning

Professionalism expected, re-evaluate the situation, stop, and seek assistance as required

5. Develop a plan with your patient for aftercare and follow-up after completion of a procedure
Patient-centred approach
Doctor-patient Medical expert relationship

Communicator

Doctor-patient Medical expert relationship

Professional

Medical expert

Skilled

clinician

Collaborator

Professional

Doctor-patient Medical expert relationship
Professional

Manager 
In the fourth exercise (2012) we looked at the relationships and connections between the Evaluation Objectives and the Domains of Clinical Care.

The Domains of Clinical Care have been developed to describe the comprehensiveness of family medicine and the settings and general content to which learners are to be exposed during their learning experiences, so they will be most helpful in curriculum development. ${ }^{3}$ The Domains of Clinical Care have been organized using a framework that describes care provided across the life cycle, within different clinical settings, along a spectrum of clinical responsibilities, for defined populations, and according to specific procedural skills. The current Domains of Clinical Care are shown in Box 1.

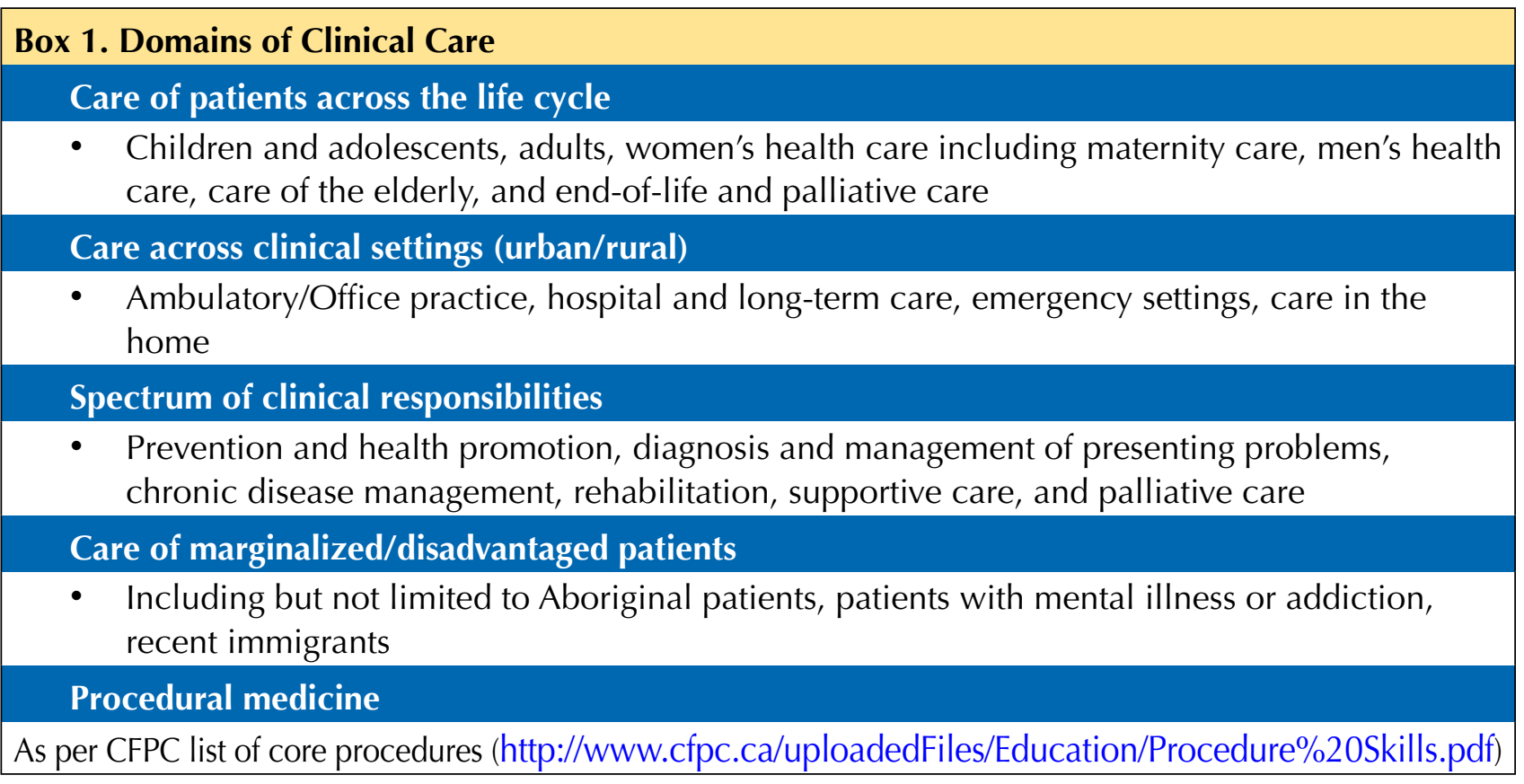

How should the Evaluation Objectives be linked, both individually and collectively, to the Domains of Clinical Care? Although it is important to be able to see and use the connections between the Evaluation Objectives and relevant learning activities, there are several reasons for not labeling or categorizing the individual Evaluation Objectives according to the specific Domains of Clinical Care:

1. Any unit or context that provides integrated health care could provide the opportunity to learn and assess almost any specific competency or Evaluation Objective. As we move to a competency-based model for assessment and curriculum, it is also important to liberate as much as possible the desired competency outcomes from any one specific educational time or place. For example, a one-month cardiology rotation might not be the best place to learn many things that relate to cardiology competencies for family medicine residents.

2. The Domains of Clinical Care are not, and were not intended to be, mutually exclusive. Similarly, most of the desired competencies can be learned or demonstrated in various ways in many of the Domains of Clinical Care. Specific labeling would promote an overly reductionist approach to educational planning, and limit the flexibility that is a hallmark of good competency-based education. 
3. The major determinants of competence (the essential skills) are, to a large degree, generalizable and transferable from one domain to another. This is not to say that they are completely content- or context-independent, nor that some contexts are not more likely than others to lead to the achievement of competence. However, these "better" contexts can be clearly identified from the Evaluation Objectives themselves. Introducing other levels of categorization would present some danger to the progress made toward defining competence in family medicine as an integral whole. The Evaluation Objectives themselves provide a pragmatic and holistic definition for the assessment of competence of a family physician in dealing with problems and situations that have been identified as priority for the comprehensive practice of family medicine. Competence in family medicine is not defined as a collection of a series of competencies in other specialties. The Domains of Clinical Care must not simply become a replacement for the traditional specialty-, discipline-, or systembased approach to curriculum planning and assessment.

Will assessment based on the Evaluation Objectives ensure the sufficient assessment of competence across all the clinical domains? To answer this question we must review the Evaluation Objectives to see which might apply in one or more of the various clinical domains. Each Evaluation Objective is coded already according to all elements that describe the specific competence in operational terms: the topic, the key feature, the essential skills, and the phase of the clinical encounter. Further detail on the key feature is provided in the explanation of each. A searchable database version of the Evaluation Objectives, ${ }^{9}$ developed by the WGCP, was created to assist with coding the Evaluation Objectives to the Domains of Clinical Care. This database permits searches by topic, essential skill, phase of the clinical encounter, keyword, or various combinations of these. It generates outputs of the key features that fit the search criteria. It will also generate one or more key feature-specific field note that can be filled in with respect to specific cases. The database does have limitations - it does not yet permit searching by observable behaviours or by procedures key feature, and the current search capacity is limited to one keyword at a time, which will be modified in a later version.

The initial results of a review of the Evaluation Objectives by Domains of Clinical Care are found in Table 5. For each domain, the Evaluation Objectives were searched by appropriate codes or keywords in order to identify the number of key features that might assess competence in the clinical domain. The results are approximate and suggestive; further and more detailed individual inspection might reveal that a key feature is not particularly pertinent for the domain in question and there could be some overlap in the criteria. Results fall into three categories:

1. Ample explicit examples for the assessment of competence in three of the five domains:

- Care of patients across the life cycle

- Spectrum of clinical responsibilities

- Procedural medicine

Appendix 1 shows a detailed search output for care of the elderly as an example of how the Evaluation Objectives could be used to guide the choice of learning activities to achieve competencies in a subsection of a domain.

2. Likely provides opportunity to assess a fourth domain-care of marginalized/ disadvantaged populations - but all the subsections are not equally coded to be retrievable at this time. 
Further clarification of the competencies desired in this domain is necessary.

3. Not coded to identify the fifth domain-care across clinical settings—-so searches are relatively ineffective. However, there is no reason to expect that the Evaluation Objectives do not cover these areas very well, given the nature of their genesis. In these cases, the domains are much less determinant of the competencies to be assessed than are the specific problems to be dealt with themselves. This exemplifies the problems with traditional time- and placebased curricula, as opposed to competency-based curricula.

Further clarification of any settings-specific competencies in this domain will be necessary before reviewing the Evaluation Objectives again. 


\section{Table 5. Frequencies of Evaluation Objectives associated with the different Domains of Clinical Care}

\section{Clinical Domain}

Keyword and Code Searches: Number of Competencies (Key Features)

Care of patients across the life cycle

- Children and adolescents

- Adults

- Women's health care including maternity care

- Men's health care

- Care of the elderly

- End-of-life and palliative care

\section{Care across clinical settings (urban/rural)}

- Ambulatory/Office practice

- Hospital and long-term care

- Emergency settings

- Care in the home

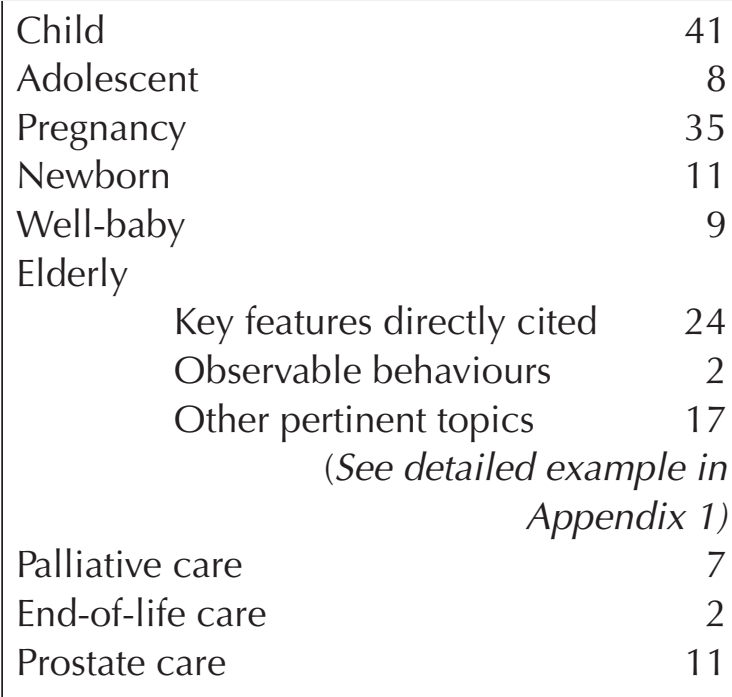

Office 4 Hospital 7

Home 5

Long term 4

Competency was not described in terms of location of care, so keyword search is not directly effective here. Specific rural competencies remain to be identified Acute 38

Emergency 7

Urgent

Selectivity

(64 hypothesis phase, 65 diagnosis, 69 treatment)

Many pertinent topics Many topics are described in searchable terms. Indirectly, can infer that the Evaluation Objectives cover emergency care through these items 


\section{Spectrum of clinical responsibilities}

- Prevention and health promotion

- Diagnosis and management of presenting problems

Acute

Chronic 58

Diagnosis $\quad 799$

- Chronic disease management

- Rehabilitation

Management (treatment)

336

- Supportive care, palliative care

\section{Care of marginalized/disadvantaged patients}

Including but not limited to:

- Aboriginal patients

- Patients with mental illness or addiction

- Recent immigrants

\section{Procedural medicine}

- As per CFPC list of core procedures: prevention)

Prevention (periodic, screening,

Palliative

End-of-life

Pain

Chronic

Topics (total)

Key features (total)

99

Each key feature may be coded to more than one skill and more than one phase

Substance abuse

Immigrants

Many mental health topics and key features

Depression

$\mathrm{Eg}$,

Behavioural

11

Schizophrenia

6

Anxiety

8

Crisis

7

Dementia

Personality disorder

There are no satisfactory keywords to identify some the pertinent competencies for one subsection in this domain; requires further definition

before reviewing

Core procedure list 65

General KF's of procedure skills

\section{8}




\section{SUMMARY}

The following take-home messages act as a summary of linking other frameworks to the Evaluation Objectives:

1. The Evaluation Objectives are case based, situation based, or problem based, and are easy to apply in the clinical setting.

2. Most Evaluation Objectives assess more than one essential skill, more than one phase of the clinical encounter. Most Evaluation Objectives also assess more than one CanMEDS-FM Role, and more than one Domain of Clinical Care.

3. The Evaluation Objectives, as a whole, assess all the CanMEDS-FM Roles and all the Domains of Clinical Care.

4. Assessment based on the Evaluation Objectives leads to a rich, multidimensional, and holistic assessment of competence of the comprehensive family physician.

\section{CONCLUSION}

Assessment based on the Evaluation Objectives will give a comprehensive reflection on competence in the CanMEDS-FM Roles and on the Four Principles of Family Medicine. It will also assess across the family medicine Domains of Clinical Care.

The structure and organization of the Evaluation Objectives favour spontaneous use in the clinical workplace environment and a meaningful and rigorous assessment of the elements of competence. Their use will promote the gathering of numerous valid observations from several observers on multiple occasions and in multiple situations, thus providing the key ingredients for successful assessment. This, in turn, is one of the major keys to successful learner-centred training and to successful certification decisions.

While Evaluation Objectives may be linked to other frameworks used in family medicine, the WGCP believes the Evaluation Objectives should not be classified or divided according to the CanMEDS-FM Roles or to the Domains of Clinical Care. The frameworks are all related but remain independent frameworks.

The Evaluation Objectives can be used to help choose or plan learning activities, and they are effective as the prime means for the determination of the achievement of competence to start the independent practice of comprehensive family medicine. 


\section{References}

1. College of Family Physicians of Canada. Four principles of family medicine. College of Family Physicians of Canada. 2006. www.cfpc.ca/Principles/. Accessed 2013 Apr 3.

2. College of Family Physicians of Canada, Working Group on Curriculum Review. CanMEDSFamily Medicine: A Framework of Competencies in Family Medicine. Mississauga, ON: College of Family Physicians of Canada; October 2009. Available from: www.cfpc.ca/ uploadedFiles/Education/CanMeds\%20FM\%20Eng.pdf. Accessed 2013 Apr 3.

3. Tannenbaum D, Kerr J, Konkin J, Organek A, Parsons E, Saucier D, et al. The Scope of Training for Family Medicine Residency: Report of the Working Group on Postgraduate Curriculum Review. Mississauga, ON: College of Family Physicians of Canada; 2011. Available from: www.cfpc.ca/uploadedFiles/Education/_PDFs/8\%20The\%20Scope\%20of\%20Training\%20 for $\% 20$ Family\%20Medicine $\% 20$ Residency_Domains $\% 20$ of $\% 20$ Clinical\%20Care $\% 20$ and\%20Evolving\%20Professional\%20Competencies.pdf. Accessed 2013 Apr 4.

4. College of Family Physicians of Canada, Working Group on Certification Process. Defining Competence for the Purposes of Certification by the College of Family Physicians of Canada: The Evaluation Objectives in Family Medicine. Mississauga, ON: College of Family Physicians of Canada; 2010. Available from: www.cfpc.ca/uploadedFiles/Education/Definition\%20 of\%20Competence $\% 20$ Complete $\% 20$ Document $\% 20$ with $\% 20$ skills $\% 20$ and $\% 20$ phases $\% 20$ Jan\%202011.pdf. Accessed 2013 Apr 3.

5. Epstein RM, Hundert EM. Defining and assessing professional competence. JAMA 2002;287:226-235.

6. Frank JR, ed. The CanMEDS 2005 Physician Competency Framework. Better standards. Better physicians. Better care. Ottawa: The Royal College of Physicians and Surgeons of Canada; 2005. Available from: http://www.royalcollege.ca/portal/page/portal/rc/common/documents/ canmeds/resources/publications/framework_full_e.pdf. Accessed 2013 Apr 3.

7. Lawrence K, Allen T, Brailovsky C, Crichton T, Bethune C, Donoff M, et al. Defining competency-based evaluation objectives in family medicine: key-feature approach. Can Fam Physician 2011;57:e373-e380. Available from: www.cfp.ca/content/57/10/e373.full.pdf+html. Accessed 2013 Apr 3.

8. Wetmore S, Laughlin T, Lawrence K, Donoff M, Allen T, Brailovsky C, et al. Defining competency-based evaluation objectives in family medicine: procedure skills. Can Fam Physician 2012;58:775-780. Available from: www.cfp.ca/content/58/7/775.full.pdf. Accessed 2013 Apr 3.

9. Evaluation Objectives in Family Medicine searchable database. Mississauga, ON: College of Family Physicians of Canada; 2013 www.cfpc.ca/KeyFeatures/. Accessed 2013 Jun 19. 


\section{Appendix 1}

\section{USING THE EVALUATION OBJECTIVES FOR THE ASSESSMENT OF COMPETENCE IN CARING FOR THE ELDERLY_EXAMPLE OF A KEYWORD SEARCH}

\section{EXERCISE}

1. Do a keyword search of the Evaluation Objectives document ("elderly" in this case; manually on the pdf document, or using the searchable database version)

2. Reflect and complete your list:

a. Are there other keywords that would be appropriate to search?

b. Look through the priority topics and the observable behaviours. Select those (not already chosen) that would seem appropriate

This list describes a certain number of situations that the family physician should be competent to deal with and do well in the area of caring for the elderly. With this information you should be able to identify the particular situations and the skills, phases, and behaviours that reflect competent care in this area. Although this list might seem limited, demonstrable competence in all of these would likely be more than sufficient to infer overall competence with respect to the elderly. The addition of the skills and phases to the key features $(\mathrm{KFs})$ and observable behaviours (OBs) will be helpful (included in latest version of Evaluation Objectives). Planning learning around these priorities would not be inappropriate, and would likely be sufficient.

\section{RESULTS}

Keyword search: "Elderly" appears 26 times (other than table of contents, etc.)

- $2 \mathrm{OBs}$

- 1 complete topic (elderly), 5 KFs

- 16 other topics, $19 \mathrm{KFs}$ total

\section{Example:}

\section{Observable Behaviours}

\section{COMMUNICATION SKILLS}

Ignores the patient while exclusively engaging the caregiver, especially with children, the elderly, those with cognitive impairment (eg, no questions to the patient, patient not involved in management plan).

\section{PROFESSIONALISM}

Discloses patient information against his or her expressed wishes, especially with respect to adolescents, the elderly, and patients with different cultural issues.

\section{Priority topics where the KFs make specific mention of the elderly}

\section{ABDOMINAL PAIN}

5: In specific patient groups (eg, children, pregnant women, the elderly), include group-specific surgical causes of acute abdominal pain in the diagnosis. 


\section{ANEMIA}

5: Consider and look for anemia in appropriate patients (eg, those at risk for blood loss [those receiving anticoagulation, or elderly patients taking a nonsteroidal anti-inflammatory drugs]) or in patients with hemolysis (mechanical valves), whether they are symptomatic or not, and in those with new or worsening symptoms of angina or coronary heart failure (CHF).

\section{BEHAVIOURAL PROBLEMS}

5: In elderly patients known to have dementia, do not attribute behavioural problems to dementia without assessing for other possible factors (eg, medication side effects or interactions, treatable medical conditions such as sepsis or depression).

\section{DEHYDRATION}

2: In the dehydrated patient, assess the degree of dehydration using reliable indicators (eg, vital signs), as some patients' hydration status could be more difficult to assess (eg, elderly, very young, pregnant).

\section{DEPRESSION}

6: In a patient presenting with symptoms consistent with depression, consider and rule out serious organic pathology, using a targeted history, physical examination, and investigations (especially in elderly or difficult patients).

10: In the very young and elderly presenting with changes in behaviour, consider the diagnosis of depression (as they may not present with classic features).

\section{DIARRHEA}

5: Pursue investigation, in a timely manner, of elderly with unexplained diarrhea, as they are more likely to have pathology.

\section{DISABILITY}

2: Screen elderly patients for disability risks (eg, falls, cognitive impairment, immobilization, decreased vision) on an ongoing basis.

6: In patients at risk for disability (eg, those who do manual labour, the elderly, those with mental illness), recommend primary prevention strategies (eg, exercises, braces, counseling, work modification).

\section{ELDERLY}

1: In the elderly patient taking multiple medications, avoid polypharmacy by monitoring side effects, periodically reviewing medication (eg, is the medication still indicated, is the dosage appropriate), and monitoring for interactions.

2: In the elderly patient, actively inquire about non-prescription medication use (eg, herbal medicines, cough drops, over-thecounter drugs, vitamins).

3: In the elderly patient, screen for modifiable risk factors (eg, visual disturbance, impaired hearing) to promote safety and prolong independence.

4: In the elderly patient, assess functional status to anticipate and discuss the eventual need for changes in the living environment, ensure that social support is adequate.

5: In older patients with diseases prone to atypical presentation, do not exclude these diseases without a thorough assessment (eg, pneumonia, appendicitis, depression). 


\section{FEVER}

8: In an elderly patient, be aware that no good correlation exists between the presence or absence of fever and the presence or absence of serious pathology.

\section{FRACTURES}

4: In assessing elderly patients with an acute change in mobility (ie, those who can no longer walk) and equivocal X-ray findings (eg, no obvious fracture), investigate appropriately (eg, with bone scans, computed tomography) before excluding a fracture.

\section{GRIEF}

3: Recognize atypical grief reactions in the very young or the elderly (eg, behavioural changes).

\section{IMMUNIZATION}

3: Identify patients who will specifically benefit from immunization (eg, not just the elderly and children, but also the immunosuppressed, travelers, those with sickle cell anemia, and those at special risk for pneumonia and hepatitis A and B, and ensure it is offered.

\section{INFECTIONS}

4: Look for infection as a possible cause in a patient with an ill-defined problem (eg, confusion in the elderly, failure to thrive, unexplained pain [necrotizing fasciitis, abdominal pain in children with pneumonia]).

\section{PARKINSON'S DISEASE}

3: In an elderly patient with a deterioration in functional status, look for and recognize Parkinson's disease when it is present, as it is a potentially reversible contribution to the deterioration.

\section{PNEUMONIA}

9: Identify patients (eg, the elderly, nursing home residents, debilitated patients) who would benefit from immunization or other treatments (eg, flu vaccine, Pneumovax, ribavarine) to reduce the incidence of pneumonia.

\section{THYROID}

1: Limit testing for thyroid disease to appropriate patients, namely those with a significant pre-test probability of abnormal results, such as those with classic signs or symptoms of thyroid disease; those whose symptoms or signs are not classic, but who are at a higher risk for disease (eg, the elderly, postpartum women, those with a history of atrial fibrillation,; and those with other endocrine disorders).

\section{UTI (URINARY TRACT INFECTION)}

3: In diagnosing urinary tract infections, search for and/or recognize high-risk factors on history (eg, pregnancy; immune compromise, neonate, a young male, or an elderly male with prostatic hypertrophy).

5: Given a non-specific history (eg, abdominal pain, fever, delirium) in elderly or very young patients, suspect the diagnosis and do an appropriate work-up. 
Other priority topics that might be particularly pertinent for the elderly (but make no mention of them as distinct from other groups of patients)

- Atrial fibrillation

- Bad news

- Cancer

- Chronic disease

- Dementia

- Dizziness

- Domestic violence (sexual, physical, psychological)

- Fatigue

- Loss of consciousness

- Loss of weight

- Low-back pain

- Mental competency

- Multiple medical problems

- Osteoporosis

- Palliative care

- Prostate

- Stroke 


\title{
Field Notes:
}

Assisting Achievement and Documenting Competence

\author{
Author \\ Michel G. Donoff
}


Originally published in

Canadian Family Physician

and reprinted with permission

\section{Field notes}

\section{Assisting achievement and documenting competence}

Michel G. Donoff MD CCFP FCFP

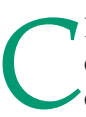

linical preceptors remain central to the enterprise of successfully educating learners in the areas of professionalism and clinical competence. The importance of a preceptor's role is further highlighted as we search for competence-based approaches to learning and assessment. Competence-based approaches must address the necessary skills and tasks specific to a discipline or specialty, ${ }^{1}$ including those that cannot be learned or assessed anywhere other than the actual environments in which they are practised. Medical education requires experiential learning ${ }^{2}$; this fact requires preceptors to role-model, guide, and assess competence. Attempts to improve clinical education are best directed toward supporting clinical teachers and learners as they work together in clinical environments. The concept of field notes was developed specifically for this purpose.

\section{Background}

Field notes are brief documents that remind both learners and preceptors that observations have been made and feedback has been provided. They are designed to be generic for convenience and versatility. Observations can range from interactions with patients, interactions with team members, discussions of clinical or professional thinking, written communication, learner presentations, and psychomotor or clinical skills. They take less than a minute to complete but serve as a marker that clinical competence has been assessed.

In the late 1980s, the Department of Family Medicine at the University of Alberta in Edmonton printed prescription-sized notepads specially formatted to encourage preceptors to briefly document observed actions or events and summarize the feedback provided. Although there have been several variations printed over the ensuing years, the basic function remains the same.

The chosen name field note is a very clear reference to the intention that these notes be used and guided by reference to qualitative methodology. Qualitative methods, specifically participatory action research methods, seem to provide a useful analogy for the processes involved when a teacher and a learner work together to build a meaningful and trustworthy understanding of the learner's developing competencies. ${ }^{3}$ Like qualitative research, clinical teaching is value-laden, promoting change through the act of inquiry, encouraging participants to mutually interpret all actions and behaviour, and generating a sense

Cet article se trouve aussi en français à la page e100. of co-ownership of the emerging new understanding. Formative assessment is done "with" the learner, rather than "to" the learner. The focus of interest changes from trying to determine a binary state, competent or not, to attempting to understand the learner's "habits of competence." In essence, we are less interested in the specific skills a learner demonstrates at a given point in time and more interested in his or her ability to demonstrate ongoing and continuous improvement through effective use of feedback and guided self-assessment.

Preceptors have indicated that they quite clearly appreciate when learners do or do not exhibit the reassuring habit of becoming competent. Preceptors reach impressions about learners not from objective measurement of knowledge or skills, but rather from repeated observation of how they address the problems and needs of patients and team members. Learners frequently demonstrate gaps in their knowledge and skills or, at times, display behaviour that suggests unhelpful attitudes. Preceptors request appropriate faculty development and useful tools and processes to address learner competency gaps. They correctly identify effective and timely feedback as essential.

Of some concern is that numerous preceptors indicate they are passing or promoting learners who do not yet demonstrate repeated, consistent, and habitual behaviour that ensures ongoing effective approaches to building clinical competence and professionalism. Often, when preceptors do not see reassuring habits of learning, they continue to give feedback on very specific and random observations, but lack an organized approach that will move feedback and discussion to the higher levels required for attaining competence.

Tools to assist preceptors and learners in addressing these higher-order levels of competence achievement are invaluable. Therefore, we will describe some tips and suggestions for using field notes in 2 phases of feedback: daily feedback with learners and documented feedback for ongoing competence review.

Field notes for day-to-day feedback

Anecdotal evidence from preceptors and advisors of residents consistently supports the idea that residents often do not recognize when they are being given oral feedback. Teachers are advised to announce that feedback is going to be given when wishing to help

La traduction en français de cet article se trouve à www.cfp.ca. 
improve attention. A written note performs that function powerfully.

Field notes should provide positive feedback-learners need positive reinforcement as well as constructive criticism-and discuss all dimensions and phases of clinical and professional competence. Feedback about clinical encounters with patients is important, but so is feedback on hypothesis generation and differential diagnosis, data interpretation, and management plans. Also, notes should discuss communication skills (written and verbal), learning approaches, management skills, and, of course, professional behaviour.

The value of a note depends less on the detail of observation and more on the detail of feedback. It is important to be very clear about suggestions for improvement and skills to reinforce. Time and effort can be saved by avoiding lengthy descriptions of the events themselves. Using a few words to stimulate memory of an event is sufficient; this works best if feedback is provided soon after the event, as it should be anyway.

Notes can defer discussion from a busy time to later that same day or within a few days. Use the simplest format for notes available-one preceptor's reminder is another preceptor's distraction. Consider letting the learner write some notes; identifying the observer and capturing the received feedback clearly distinguishes this process from logbooks.

Field notes for regular competence review Many programs want an organized and structured method for reviewing and tracking a learner's progress toward competence. The plethora of portfolio-based projects, articles, and conferences attest to the prevalent desire to address this need.

Field notes can be valuable additions or even the main contributor to competence review documents, such as intraining evaluation rating (ITER) forms. Even when we do use rating scales, as most ITER forms do, we are usually summarizing progress for formative purposes rather than for making hard-line summative decisions. The value of evaluation ratings to guide learning plans and curriculum decisions rests largely on the input of day-to-day interactions between the learner and those in his or her clinical settings. Many of the problems associated with using ITER forms stem from using them as the first and only communication on learner progress.

Learners or preceptors can "stack" field notes to focus attention on chosen competencies or issues. A stack is a group of field notes, which identify a topic, competence, or professional issue that would benefit from ongoing feedback. Stacking field notes can change feedback from random and isolated to purposeful with continuity. Users should consider when sufficient progress has been achieved for a topic or whether the topic remains a focus of active learning; such "completed" stacks can also be identified. Discussion between the

\section{TEACHING TIPS}

- Use field notes to give positive feedback as well as constructive criticism.

- Use field notes to discuss all dimensions and phases of clinical and professional competence.

- Field notes should focus on suggestions for improvement and skills to reinforce, rather than detailed observation.

- Group field notes into stacks according to topics, competencies, or professional issues that would benefit from ongoing feedback.

- Field notes can be applied to competence review documents, such as in-training evaluation rating forms.

- Use the program's learning objectives or evaluation system as a reference to focus field note stacks and direct attention for documented feedback and selfassessment.

- Use single-entry documentation and the simplest format of notes available.

- Electronic field notes and corresponding review folders are encouraged.

\section{CONSEILS AUX ENSEIGNANTS}

- Utilisez des feuilles de route pour donner de la rétroaction positive ainsi que des critiques constructives.

- Utilisez des feuilles de route pour discuter de toutes les dimensions et les étapes de la compétence clinique et professionnelle.

- Les feuilles de route devraient comporter des suggestions de points à améliorer et d'habiletés à renforcer, plutôt que des observations détaillées.

- Regroupez les feuilles de route par sujets, compétences ou questions professionnelles qui bénéficieraient d'une rétroaction continue.

- Les feuilles de route peuvent servir pour les documents d'examen de la compétence, comme les fiches d'évaluation en cours de formation.

- Utilisez les objectifs d'apprentissage ou le système d'évaluation du programme comme points de référence pour cibler les regroupements de feuilles de route et diriger l'attention dans la rétroaction documentée et l'autoévaluation.

- Utilisez la documentation à inscription simple et le format de feuilles le moins compliqué possible.

- On encourage le recours aux feuilles de route électroniques et aux dossiers d'examen correspondants.

learner and the preceptor or advisor about progress using stacked notes can be an excellent opportunity for guided self-assessment.

Learner-specific issues should be used to name stacks and solicit future feedback. Program learning or evaluation objectives as references can focus field note collections (ie, stacks) and direct attention to 


\section{Teaching Moment}

documented feedback. Single-entry documentation is valued with all types of record keeping; in competence education it is efficient to use the same documentation to record feedback and review progress.

Either paper or electronic field notes and corresponding review folders can be used. As with electronic medical records, there is an up-front development cost for providing electronic versions, but preceptors and learners are easily motivated to use electronic tools when available.

\section{Conclusion}

Field notes are generic, user-friendly documentation tools, which were initially intended to assist with day-to-day feedback. In recent years, grouping notes into stacks has promoted focused and continuous feedback. Even more recently, objectives expressed as observable attitudes and key features have further promoted an effective learning focus. Current research is investigating the collection and organization of field notes in a systematic fashion to allow timely and formative review of competency progress throughout a program. Collaborative, qualitative principles of inquiry remain central to a trustworthy competence-based approach to medical education. The outcome of these processes might be summarized as guided self-assessment.

Teaching Moment is a quarterly series in Canadian Family Physician, coordinated by the Section of Teachers of the College of Family Physicians of Canada. The focus is on practical topics for all teachers in family medicine, with an emphasis on evidence and best practice. Please send any ideas, requests, or submissions to Dr Allyn Walsh, Teaching Moment Coordinator, atwalsha@mcmcaster.ca.

Dr Donoff is a Professor in the Department of Family Medicine at the University of Alberta in Edmonton.

Competing interests

None declared

Correspondence

Dr Michel Donoff, 15160-49 Ave, Edmonton, AB T6H 5M8;

telephone 780 492-0780; fax 780 735-4978; e-mail mike.donoff@ualberta.ca

References:

1. Albanese MA, Mejicano G, Mullan P, Kokotailo P, Gruppen L. Defining characteristics of medical competencies. Med Educ 2008;42 (3):248-55

2. Maudsley G, Strivens J. Promoting professional knowledge, experiential learning and critical thinking for medical students. Med Educ 2000;34(7):535-44.

3. Donoff MG. The science of in-training evaluation. Can Fam Physician 3. Donoff MG. The
1990;36:2002-6

4. Epstein RM. Assessment in medical education. $N$ Engl J Med 2007;356(4):387-96 
The critical elements of the Triple C Competency-based Curriculum (Triple C) were defined within the Triple C Report-Part 1, and in the section "Key Elements for a Triple C Competency-based Curriculum" of the Triple C Report - Part 2. Complementary important information on assessment was provided in the preceding section of this report. The editors determined that "A Guide for Translating the Triple C Competency-based Recommendations Into a Residency Curriculum" would be a helpful resource to include here to summarize in a checklist form all of the key characteristics to consider in a Triple C curriculum. The guide should prove particularly useful during this time of innovation and implementation of Triple $\mathrm{C}$ across family medicine residency programs in Canada. The in-depth guide allows readers to reflect on what has already been successfully implemented and to determine what yet needs to be done. In this way, the guide acts as a Road Map, helping the community of family medicine educators find a way forward to identify the changes required to align their programs with Triple C. It can assist with the process of putting theory into application when constructing or reviewing residency curriculum. 



\title{
A Guide for Translating the Triple C Competency-based Recommendations Into a Residency Curriculum
}

\author{
Authors \\ Danielle Saucier, \\ on behalf of the \\ Working Group on Postgraduate Curriculum Review
}

\section{Suggested Citation:}

Saucier D. A Guide for translating the Triple C Competency-based recommendations into a residency curriculum. In: In: Oandasan I, Saucier D, eds. Triple C Competency-based Curriculum Report - Part 2: Advancing Implementation. Mississauga, ON: College of Family Physicians of Canada; 2013.Available from: www.cfpc.ca/uploadedFiles/Education/_PDFs/TripleC_Report_pt2.pdf. Accessed 2013 Jul 29. 
This Triple C Competency-based guide takes recommendations from the Triple C Competency-based Curriculum (Triple C) and translates them into a form that can be used for planning and implementing family medicine residency curricula. This guide is intended to serve as a tool for assessing an existing program, as a guide to improve specific curricular elements in a residency program, or as a blueprint for program development. These are not program accreditation criteria.

The guide is built around the basic curricular elements or building blocks described in the Triple $C$ Report - Part 1 (Section 2) ${ }^{1}$ and in the Triple C Toolkit, ${ }^{2}$ as outlined in Figure 1:

- Program outcomes

- Overall curriculum planning and design, including learning opportunities and resources, with an expansion on competency-based teaching and learning methods

- Assessment of learners

- The backward feedback loop of outcome-based program evaluation, here stated as program accountability and quality management

Figure 1. Building blocks of curriculum development

The Building Blocks

\begin{tabular}{|c|c|c|}
\hline Design & $\begin{array}{l}\text { Design and provide } \\
\text { curriculum }\end{array}$ & Assess \\
\hline $\begin{array}{l}\text { DEFINED } \\
\text { PROGRAM } \\
\text { OUTCOMES }\end{array}$ & $\begin{array}{c}\text { Triple C Competency-based } \\
\text { LEARNING OPPORTUNITIES } \\
\text { Clinical experiences } \\
\text { Academic program } \\
\text { Other activities }\end{array}$ & \multirow{3}{*}{ 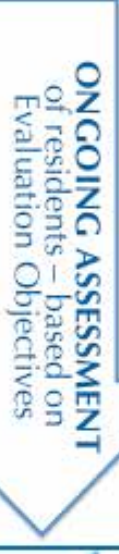 } \\
\hline & $\begin{array}{l}\text { Triple C Competency-based teaching } \\
\text { and learning STRATEGIES }\end{array}$ & \\
\hline $\begin{array}{l}\text { Competency-based } \\
\text { and guided by } \\
\text { CanMEDS-FM* }\end{array}$ & $\begin{array}{c}\text { Triple C Competency-based } \\
\text { RESOURCES } \\
\text { Clinical resources } \\
\text { Teaching materials } \\
\text { Faculty }\end{array}$ & \\
\hline
\end{tabular}

*CanMEDS-FM adapted from Frank JR, ed. The CanMEDS 2005 Physician Competency Framework. Better standards. Better physicians. Better care. Ottawa: The Royal College of Physicians and Surgeons of Canada; 2005. Available from: http://www.royalcollege.ca/portal/page/portal/rc/common/documents/canmeds/ resources/publications/framework_full_e.pdf. Accessed 2013 May 27.

Figure adapted from Saucier D, Schipper S. Triple C: Implications for family medicine residency programs [PPT]. CFPC; 2012 
The Working Group on Postgraduate Curriculum Review (WGCR) has produced this guide based on an extensive review of the literature on competency-based education in medicine. Most of these articles discussed principles and high-level implications of competency-based education, with a limited number of actual descriptions of existing competency-based programs. Most of these descriptions dealt with course development and competency-based teaching and learning strategies at the undergraduate level. A few articles addressed clinical experience, either during clerkship or at the postgraduate level, with practical details. The WGCR reviewed all of this information, but primarily explored the wealth of educational experience among several groups: its members, family medicine program directors, local site directors, undergraduate clerkship directors, faculty developers, educational leaders in various roles within programs, and residents experiencing the program. This guide is based on the WGCR's expert opinion of key observable, practical program characteristics that best translate the Triple C competency-based concepts in the day-to-day makeup of a family medicine residency program.

\section{HOW TO USE THIS GUIDE}

This guide is organized into five sections, according to the building blocks in Figure 1. A limited number of key characteristics are listed within each of these sections. Each of these key characteristics is then further explained in the "Description" column as specific, observable items. The last column highlights the aspects of Triple $C$ that are most influential on a given key characteristic: comprehensiveness, continuity, centred in family medicine, and competency based. These are all deeply interconnected, so while some items refer specifically to one or two aspects of Triple C, others refer to all aspects.

Altogether, this guide provides a portrait of the ideal family medicine residency program. But in real life, programs and local sites are continuously challenged with feasibility issues; transformation into a Triple C curriculum is definitely a long-term endeavour. The WGCR considers that programs should aim to meet all key characteristics, whereas it is probably not possible to meet all of the unique descriptors in the central column simultaneously. Some of them might, in fact, conflict. For example, continuity in patient care in one clinical setting over a long period of time is often in tension with the resident's experience in comprehensiveness of family medicine practice within the full range of the Domains of Clinical Care. ${ }^{3}$ Therefore, programs continuously have to make decisions on the best acceptable compromise at one given point in time, and in one site, with its unique resources and challenges. 


\section{GUIDE FOR A TRIPLE C COMPETENCY-BASED FAMILY MEDICINE RESIDENCY CURRICULUM}

\section{KEY}

CHARACTERISTICS

DESCRIPTION

TRIPLE C ASPECTS

\section{Program outcomes}

Defined program learning outcomes or competencies include:

- Program-level adaptation of the CanMEDS-FM competency framework of Roles

- These Roles must be demonstrated within all Domains of Clinical Care in residency training in FM
- End-of-residency expectations related to competencies are explicitly stated to both FM residents and faculty. They serve as the basis for:

o Curricular planning

o Ongoing assessment

o Program evaluation

- Program outcomes are further detailed into key milestones/competency benchmarks, which provide a transparent road map for both learners and faculty
Competency based

Comprehensive

Centred in FM

Overall curriculum planning and design

Competency-based curriculum
- The following three components of competency-based education are integrated into the curriculum:

o Defined educational outcomes

o Relevant learning opportunities and contexts

o Ongoing assessment

- Learning opportunities and contexts are congruent with stated outcomes:

o Intentionally designed to allow residents to acquire the expected competencies

o Offer sufficient opportunities for residents to acquire the expected competencies

o Provide opportunities for residents to be assessed on these competencies by appropriate teachers

- Congruence of the whole program is ideally demonstrated through curricular mapping

- Residents are actively engaged in developing and demonstrating their competencies

- The curriculum is both time and competency based, with an established time minimum and maximum for progression and some flexibility in educational planning to adapt to learners' needs 


\section{KEY}

\section{CHARACTERISTICS}

Program structure includes:

- Integrated curriculum

- Within-program, context-specific flexibility of design, based on local sites' resources

FM program planners maintain ownership over all aspects of the curriculum

The FM experience forms the central and continuous focus of residency training

\section{DESCRIPTION}

The overall program structure provides:

- Repeated occasions to practise/reinforce key competencies over the period of training

- Relevant learning experiences within the full range of Domains of Clinical Care in residency training in FM

- Opportunities to integrate focused learning experiences into the FM context

- Opportunities for progressively increased responsibility, particularly for complex, multi-problem patients or complex professional situations

- Common ground between sites based on competencies-more so than a curriculum based on identical activities/rotations

- FM program director and program committee are responsible for determining relevant content throughout learning activities/rotations

- Learning activities/rotations delegated to focusedpractice FPs or to consultant specialists are primarily designed by FM to meet specific educational outcomes

- The majority of residency training occurs within FM

- Residents experience comprehensive FM practice within the full range of Domains of Clinical Care in most of the learning activities/rotations, including a variety in several aspects:

o Patients across the life cycle and patient populations, as well as underserved populations

o FM problems: undifferentiated, complex, acute, chronic, etc.

o Practice settings: office, walk-in, emergency, in-hospital, home, chronic care, etc.

o Spectrum of clinical responsibilities: acute, chronic, preventive, and end-of-life care; collaboration and coordination of care

o Dimensions of continuity of care

o Procedural skills

- In these activities and contexts, residents have ample opportunities to do the following:

o Function in the role of an FP (experiencing generalist problem solving, selectivity and adaptation, complexity, breadth, and integration)

o Observe and interact with various FP role models
TRIPLE C ASPECTS

Competency based

Comprehensive
Centred in FM

Competency based
Centred in FM

Continuity

Comprehensive

Competency based 


\section{KEY}

\section{CHARACTERISTICS DESCRIPTION}

FM-relevant focused experiences are complementary and used only when locally relevant
- Depending on each program or site's context and resources, some FM-focused or specialized learning activities/rotations can complement the continuous focus of residency training, and should be selected based on the following:

o An FM-relevant patient population: focused primary care or broad-based secondary care

o Relevance of clinical experience toward the acquisition of specific competencies

o The teacher's characteristics: positive attitude toward the role of FPs, and intra-professional interactions between the consultant specialist and FP surrounding the care of patients

o The local resource with the broadest exposure and the most integrated approach to care in a given Domain of Clinical Care

- These experiences can be structured either longitudinally or in a block, but must be integrated back into the FM context

Continuity in patient The program ensures opportunities for residents to care experience:

- Continuity of patient and family care over time (ie, longitudinal, interpersonal, and interdisciplinary continuity), by strategies such as the following:

o Residents assume primary responsibility for an identified panel of patients over a long period of time

o A longitudinal curriculum enables residents to be available to their identified patients when they need them

- Geographic and informational continuity of care:

o Care for the same patient in different clinical settings

o Follow-up and planning of care as the patient moves from one clinical setting to another (eg, discharge planning from the hospital)
TRIPLE C ASPECTS

Centred in FM

Comprehensive

Continuity

Competency based

\section{Continuity \\ Comprehensive \\ Competency based}




\section{KEY}

\section{CHARACTERISTICS \\ DESCRIPTION}

Continuity in

education

and FM-oriented consultants* as core teachers
- Continuity of supervision is ensured by strategies such as the following:

o Ongoing interactions with designated key preceptors

o Communication of educational information both between preceptors and learning contexts

- Continuity in curriculum is ensured by strategies such as the following:

o Coherent academic programming across learning experiences and settings

o Explicit strategies to facilitate integration of one learning experience to overall competencies

- Continuity in the learning environment is ensured by strategies such as the following:

o Placements that are long enough to enable residents to develop relationships and understand context

o Some element of continuity in any new placement, either educational or clinical

o Creating a bounded, familiar educational and work environment, including not only the physical environment, but also the members of the health care team in that environment

- FPs are the core teachers in the program:

o Acting as a role model for all CanMEDS-FM Roles

o Modeling comprehensive and continuing care, individually or as a group

o Demonstrating learning processes and generalist problem solving

o Actively engaging throughout the program in daily supervision, formal teaching, and resident assessment

o Supporting the development of residents' professional identity

o Providing an introduction to the culture of family medicine

- FPs are complemented by other faculty, depending on local context (in order of preference):

o Comprehensive FP with an area of special interest/ focused practice (ie, care of elderly, palliative care, etc.)

o FP with a focused practice (eg, full-time palliative care)

o FM-oriented consultants* in broad-based secondary care (ie, internist, generalist psychiatrist)

o FM-oriented consultants in a more specialized setting (tertiary care, subspecialty

\section{TRIPLE C ASPECTS}

Continuity

Competency based
Centred in FM

Competency based

Comprehensive

Continuity

*These are consultants with an understanding of, and respect for, the role of the FP and the importance of a collaborative relationship between the consultant and the FP. 


\section{KEY}

\section{CHARACTERISTICS}

The academic teaching program is competency oriented

\section{DESCRIPTION}

The teaching program should:

- Address key competencies and be structured and comprehensive

- Be complementary to the clinical experience and autonomous learning

- Use relevant teaching and learning strategies (see next section, "Teaching and learning methods")

\section{Teaching and learning methods}

Residents are active Throughout the program, residents take on enhanced learners responsibility:

- For their learning, in a variety of ways and venues

- For demonstration of acquisition of competencies

- To actively seek out feedback (guided self-assessment)

Residents and faculty collaborate in the learning processes Teaching and learning strategies throughout the program support:

- Achievement of competencies

- Development of residents' professional identity

- Becoming a reflective practitioner
- Responsibility for learning is shared by preceptors and learners in a collaborative process

- Preceptors engage regularly in guiding, coaching, and providing feedback

Key teaching and learning strategies:

- Include learner-centredness, principles of adult learning, experiential learning, application of cognitive learning, and deliberate practice theories

- Focus on competencies rather than just knowledge:

o Residents take primary responsibility for care

o Residents practise problem solving and other skills, attitudes, etc., with more application of knowledge than solely knowledge transfer

o Strategies offer occasions to practise transfer of learning from one context to the other, and integration of various competencies into whole learning tasks

- Provide occasions for reflective practice:

o Engage residents in reflection both in action and on action

o Preceptors model a reflective stance as a tool for continuous improvement and as a basis for selfdirected learning

- Focus on the FP's perspective:

o Present the FP's perspective on the problem

o Provide occasions to learn about context, culture, and content of FM

- Use FPs as experts, alone or in collaboration with other physicians and other health professionals

\section{TRIPLE C ASPECTS}

Competency based

Comprehensive

Competency based

Competency based

Competency based

Centred in FM

Comprehensive
Centred in FM

Competency based 


\section{KEY}

\section{CHARACTERISTICS}

Competencyoriented teaching methods

Explicit use of role modeling

\section{DESCRIPTION}

- Use a combination of teaching methods and formats, as relevant to the competencies taught

- Provide occasions to practise complex skills safely (eg, simulation lab or role-play), with immediate formative feedback

- Through precepting and conducting direct observation/video review:

o Provide explicit feedback and coaching around identified competencies

o Encourage the resident's autonomy

- Program provides occasion for residents to observe FP Centred in FM role models at work, both formally and informally, and Competency based in a variety of contexts, and allows them to observe CanMEDS-FM Roles

- FP faculty often "think out loud" — they are explicit about problem solving, decision making, patientcentredness, reflective practice, professional identity, etc.

- FP faculty encourage residents to explore and develop FM competencies

Assessment of learners

Carefully planned

- Assessment should be embedded in the curriculum and integrated processes and methods of assessment of residents
TRIPLE C ASPECTS

Competency based and should:

o Be planned based on a blueprint directly related to expected program outcomes

o Include all essential components of in-training assessment, as per CFPC template

o Sample observable competencies within all seven CanMEDS-FM Roles across the Domains of Clinical Care in residency training, using the CFPC Evaluation Objectives as a tool

o Include repeated sampling over time by multiple preceptors through a variety of methods, in search of consistent demonstration of competence

o Judge the behaviour itself, not in comparison with other learners (criterion-referenced rather than norm-referenced)

- To ensure continuity of education, a family physician or team should be assigned to each resident for the duration of the residency and should be responsible to review progress and provide feedback to both the resident and the program

- The FM residency program must be primarily responsible for planning and managing the evaluation system 
Ongoing, formative process of assessment

- The program should develop and implement strategies that will provide learners with regular feedback:

o Preceptors should provide feedback during daily clinical and educational activities, including case discussion and direct observation of residentpatient interactions, team interactions, academic teaching, and other clinical tasks

o Feedback includes reflection, positive reinforcement, and constructive coaching

o A system should be in place to collect and organize documentation of performance into a collection of evidence, including daily field notes and other performance assessment tools

o Preceptors also provide feedback on a larger scale during periodic assessment of progress, based on organized documentation

o Providing and seeking feedback is a shared responsibility between faculty and residents, who must play an active role and engage in guided self-assessment

Progression of learning is monitored
- The program should put into place a system to regularly monitor a resident's progression, which:

o Provides an overall tool and framework to collect and organize documentation into a collection containing a variety of data, in either a paper or online portfolio

o Identifies relevant data that will be monitored periodically to confirm acquisition of competencies

o Selects a few relevant data collection tools, either context specific (eg, field notes from supervision), or competency specific (eg, 360 evaluation for Collaborator role, research project for Scholar role)

o Establishes a system of periodic assessment of progress based on organized documentation; these periodic encounters between a resident and his or her faculty advisor serve to review progression and review and update learning plans

o Generates a periodic progress report, which is sent to daily clinical preceptors and to appropriate program administrators

- The program should provide faculty with tools to serve as a basis for their judgment on a resident's progression:

o Provide observable milestones/benchmarks, setting the expectations at significant stages of training in various domains or settings of practice

o Ensure that expectations about balance between CanMEDS-FM Roles are specified

- The program and individual faculty advisors engage learners actively in data gathering, guided selfassessment, and developing their learning plans 


\section{KEY CHARACTERISTICS DESCRIPTION}

Competency-based

summative assessments

Individualized

educational planning,

including remediation

Competency-based promotion criteria established
- A summative evaluation plan ensures assessment of all key competencies, using relevant tools

- End-of-rotation global evaluation is just one tool among others

- A system to interpret progress reports and make summative decisions, including those around remediation and dismissal decisions, has been

- The program has identified processes for early identification of residents in difficulty

- Remediation planning is regularly offered and is tailored to problem definition

- A longer training period, within reason, is available for residents in need of remediation

- The FM residency program must be ultimately responsible for promotion decisions, both from one level of residency to another and for program completion

- Promotion criteria are explicitly stated and are coherent with program outcomes

- Decisions for promotion are based on the demonstration of competence gathered through a competency-based assessment system

\section{Program accountability and quality management}

Established measures of program quality and mechanisms for program improvement

\section{The FM program should:}

- Be able to demonstrate that most of its residents have achieved most of the expected outcomes

- Build in a quality assurance system that can identify and address/correct:

o Areas of lower performance of its residents

o Educational opportunities that do not allow for acquisition of required competencies

- Monitor its ability to meet societal needs through strategies such as tracking of graduate outcomes related to location and patterns of practice
TRIPLE C ASPECTS

Competency based

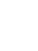

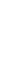

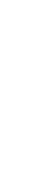

\section{Competency based}

\section{Centred in FM}

Competency based

Comprehensive

Centred in FM

\section{ACKNOWLEDGEMENT}

The members of the Working Group on Postgraduate Curriculum Review collaborated to produce this guide. They are, in alphabetical order, Jonathan Kerr, Jill Konkin, Victor Ng, Andrew Organek, Ean Parsons, Danielle Saucier (lead author), Liz Shaw, David Tannenbaum (Chair), and Allyn Walsh. 


\section{References}

1. Tannenbaum D, Kerr J, Konkin J, Organek A, Parsons E, Saucier D, et al. Triple C Competencybased Curriculum. Report of the Working Group on Postgraduate Curriculum Review Part 1. Mississauga, ON: College of Family Physicians of Canada; 2011. Available from: www.cfpc.ca/uploadedFiles/Education/_PDFs/WGCR_TripleC_Report_English_Final_18Mar11.pdf. Accessed 2013 Feb 27.

2. Saucier D, Schipper S. Triple C Competency-based Curriculum: implications for family medicine residency programs [PowerPoint Presentation]. Mississauga, ON: College of Family Physicians of Canada; 2012. Available from: http://www.cfpc.ca/TripleCToolkit/. Accessed 2013 Feb 7.

3. Tannenbaum D, Kerr J, Konkin J, Organek A, Parsons E, Saucier D, et al. The Scope of Training for Family Medicine Residency: Report of the Working Group on Postgraduate Curriculum Review. Mississauga, ON: College of Family Physicians of Canada; 2011. Available from: www.cfpc.ca/uploadedFiles/Education/_PDFs/8\%20The\%20Scope\%20of\%20Training\%20 for $\% 20$ Family\%20Medicine $\% 20$ Residency_Domains $\% 20$ of $\% 20$ Clinical\%20Care $\% 20$ and\%20Evolving\%20Professional\%20Competencies.pdf. Accessed 2013 Feb 7. 
Any change often brings with it both foreseen and unforeseen effects. For Triple C, those effects are the implications on the length of training and on enhanced skills training. Canada has the shortest family medicine residency program in the world, and with the move toward competency-based education, the notion of fixed time for learning has come into question. What impact does a Triple C competency-based approach have on decisions about how long a resident is expected to take to become a family physician? "Length of Training in the Core Family Medicine Residency" is shared to both raise and answer questions and to stimulate discussion within the academic community.

Family medicine as a discipline has always been recognized for its comprehensive and generalist approach to care. Based on population need and physician interest, many family physicians have focused their practice in specific domains within family medicine. Several residency programs have offered enhanced skills training for their residents in areas such as emergency medicine, sports medicine, and anaesthesia. "Triple C Implications for Enhanced Skills Training in Family Medicine Programs: A Discussion Paper" offers an opportunity for family medicine educators to reflect on the type of education being offered by residency programs. The goal is to enable the principles of comprehensive care, continuity of care and education, and learning centred in family medicine to be upheld in producing physicians who are ready to practise comprehensive family medicine. 
078 Triple C Report - Part 2 


\section{Length of Training in the Core Family Medicine Residency}

\section{Authors}

Members of the Working Group on Postgraduate Curriculum Review:

David Tannenbaum, Chair; Jonathan Kerr; Jill Konkin; Andrew Organek; Ean Parsons; Danielle Saucier; Liz Shaw; Allyn Walsh 
(C) 2012 The College of Family Physicians of Canada.

All rights reserved.

Suggested Citation:

Tannenbaum D, Kerr J, Konkin J, Organek A, Parsons E, Saucier D, Shaw L, Walsh A. Length of Training in the Core Family Medicine Residency: Report of the Working Group on Postgraduate Curriculum Review. Mississauga, ON: College of Family Physicians of Canada; 2012. 
Many stakeholders ask if and how the move to the Triple C Competency-based Curriculum (Triple C) will influence the length of training in the core family medicine residency. The Working Group on Postgraduate Review has made a formal recommendation in Part 1 of its report on Triple C (page 4):

"Most residents should achieve the expected learning outcomes of the core family medicine program within a 24-month time frame; however, some will require a longer training period, which should be available when needed."1

Any decisions made on a national basis regarding the duration of residency training have substantial organizational and financial implications on the administration of the postgraduate education system and the availability of new physician resources across the country. Decision-making in this area thus involves and affects major stakeholders, such as medical student and resident associations, the schools of medicine, provincial licensing authorities, and ministries of health. In this section, we discuss the educational rationale behind the recommendation above, as well as some issues to consider over the next years as further decisions are made on length of training. The basis for this discussion can be found in the Report of the Working Group on Postgraduate Curriculum Review - Part 1, March $2011 .{ }^{1}$

The present standard for length of training in family medicine in Canada is 24 months. ${ }^{2}$ This is the period of training approved by the College of Family Physicians of Canada (CFPC) that, upon successful completion of the CFPC's Certification examination, allows for Certification in Family Medicine in Canada. Current recommendations for length of training arise from historical traditions rather than objective evidence.

Although the literature shows little evidence on the optimal length of training for family medicine, the debate on the length of residency training has been going on in Canada for a long time..$^{3-9}$ Two full years of residency is currently the shortest length of training in family medicine in the Western world; program length varies from two to five years throughout the world. Discussion is leaning toward lengthening the basic program in a number of countries. ${ }^{10,11}$ Rationale for the varied length of training is based on traditions, local political factors, and variation in the health care systems of different

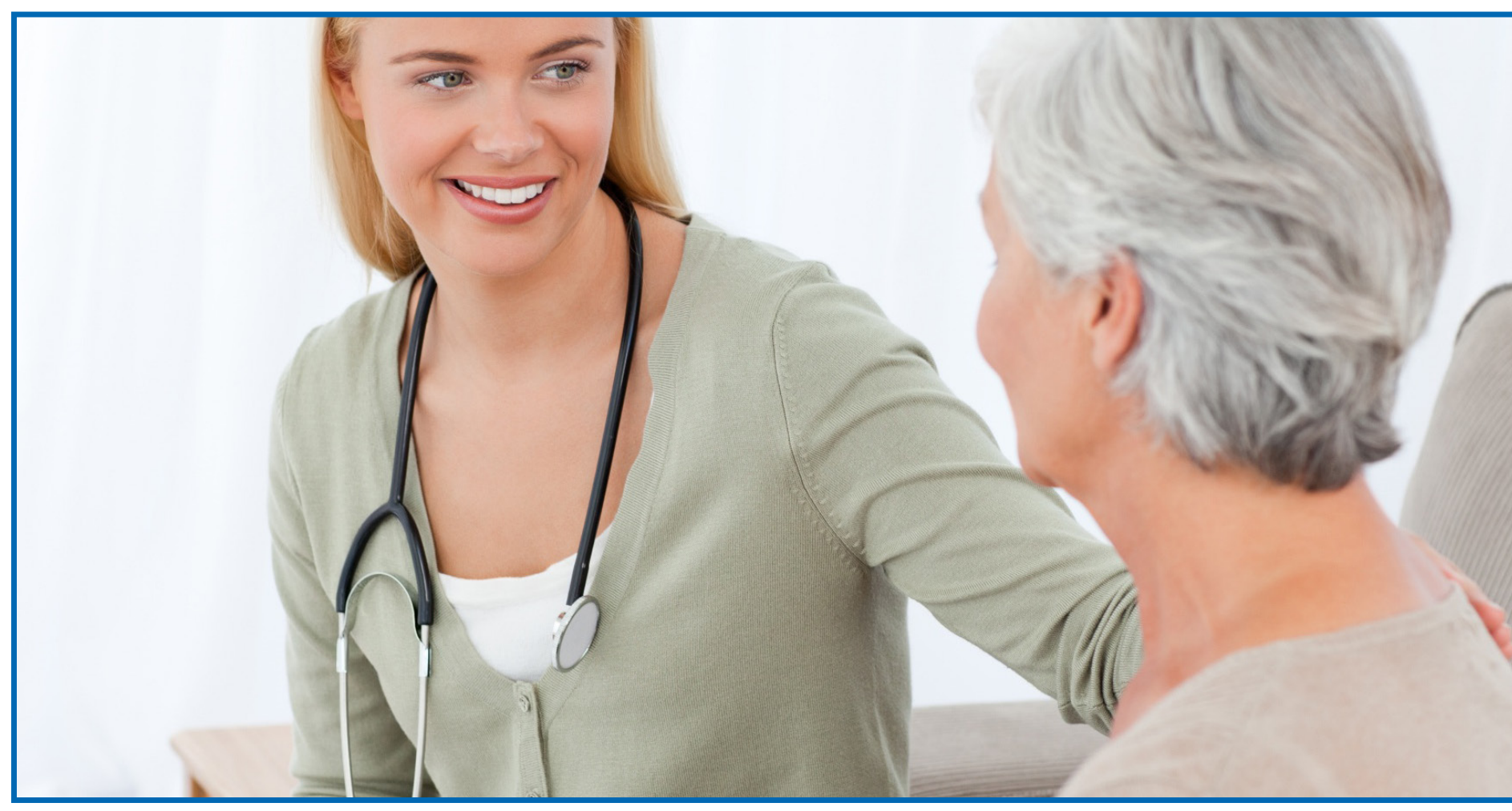


countries. Many national systems increase the total length of training to develop "enhanced skills" for practice. The move toward competency or outcome-based models brings in new arguments.

Hodges describes the traditional model of residency training as being time-based or, "... a "teasteeping" model, in which the student "steeps" in an educational program for a historically determined fixed time period to become a successful practitioner."12 By contrast, the theoretical approach to competency-based education allows each learner to evolve at his or her own pace until the learner has developed all or most of the expected competencies. This approach would be difficult to implement given the complexity of residency education systems. Alternatively, a curriculum that incorporates time-based rotations or learning experiences and that also offers flexibility can serve the purpose of competency-based education, creating a hybrid model.9,12,13 This model views time as a "resource to be used to the advantage of the trainee." ${ }^{\prime 13}$

A competency-based approach acknowledges that residents do not all learn at the same rate, and that some might need extra time (and support) to acquire the expected competencies. Thus, the standard length of training should be based on the time required for the majority of residents to achieve the expected competencies. Further, competency based education involves more than a checklist of minute competencies (a reductionist view); it emphasizes that the learning context is key for the development of professional identity and the progressive entry into the unique culture of the discipline of family medicine. This professional maturation into a confident and competent family physician definitely takes time. Completion of a competency-based residency training program is only part of the competency trajectory for a family physician, which also includes early practice mentoring and continuing professional development. ${ }^{1}$

Based on our review of the elements of the educational process and our ample experience with the rate of residents' progression, we conclude that two years is the minimum time required to develop professional identity. ${ }^{1,10}$ We also hypothesize that the majority of residents will be able to acquire and demonstrate the expected outcomes of the core program in a period of 24 months. However, undoubtedly, some residents will need additional time in order to meet the required competencies; hence extensions to the usual training period must be made available when needed. There will be circumstances where programs determine that the overall rate of progression for a given resident is insufficient and that a formal remediation strategy according to university standards be implemented. Dismissal from residency training remains a possibility in a competency-based training program.

Against the background of a standard training program, we recommend that increased flexibility in both program design and length be introduced in each family medicine residency program, based on attainment of competencies. This is necessary to allow for individualized learning plans for residents who are lagging behind in some areas and for the few learners who require a structured remediation plan. These changes have implications for the processes and rules for successful completion of learning experiences and for promotion through the residency training years; they can only occur with changes in policies and rules in the present postgraduate residency system within each medical school, and with support from each provincial licensing authority. There are also financial implications related to this issue.*

We consider that multiple forces will be in play over the next few years in determining the length of time to achieve the required competencies. Certain factors favour lengthening the basic training period. The first is the societal expectation for programs to ensure that all ${ }^{1}$ core competencies for comprehensive care are acquired, including the growing demands around the "evolving professional

*Quebec provides an example of how flexibility of this sort may be implemented. A carte de stage follows each resident, and provincially-determined guidelines offer program directors and postgraduate deans some leeway to organize individualized learning plans 
competencies" (outlined in Scope of Training for Family Medicine Residency). ${ }^{14}$ Once each program has put in place a competency-based in-training assessment system, we will be in a position to determine the median time required for residents to attain these outcomes as well as the degree of variations on this time. Ongoing discussion will be required to consider the maximum duration of residency. Reexamination of this issue will need to occur at a national level once the data is available.

A second factor might point toward lengthening the training program: the reductions in resident training hours that are being mandated for reasons of patient safety and residents'well-being. ${ }^{1}$ This major change in the system will lead to reduced clinical exposure that may well affect the acquisition of competencies that require repeated practice and feedback. However, the impact of this issue on the quantity and quality of educational experiences is unknown; an assessment will need to occur at a national level once training hours are reorganized.

To counterbalance these considerations, there are a number of factors that may lead to gains in efficiency and reduced time requirements. Triple $\mathrm{C}$ calls for efficiencies in training programs, primarily through the removal or significant modification of rotations that do not specifically support the acquisition of desired family medicine competencies. ${ }^{1}$ The emphasis on improved systems of feedback and evaluation, active learner involvement in the acquisition of competencies, and competencyoriented academic programming and supervision strategies also have the potential for more effective acquisition of competencies.

Gains in efficiency can also be made during undergraduate medical training as schools of medicine throughout Canada endorse the Future of Medical Education in Canada report and move toward competency-based, more relevant medical education. ${ }^{15}$ Undergraduate medical programs that promote a generalist competency base could lead to learners entering residency better prepared and with many fundamental competencies already acquired.

\section{CONCLUSION}

As family medicine programs across the country adopt a competency-based approach to education, the interplay between factors that could increase training time and those that could increase efficiency will inform the unanswered questions around length of training.

Still, there remains a minimum required period of 24 months for the development of the residents' professional identity as a family physician. Rigorous evaluation of the impact of competency-based systems in family medicine residency programs will be essential. 


\section{References}

1. Tannenbaum D, Kerr J, Konkin J, Organek A, Parsons E, Saucier D, Shaw L, Walsh A. Triple Ccompetency-based Curriculum. Report of the Working Group on Postgraduate Curriculum Review - Part 1. Mississauga,ON: College of Family Physicians of Canada; 2011. Available from: www.cfpc.ca/uploadedFiles/Education/_PDFs/WGCR_TripleC_Report_English_Final_1 8Mar11.pdf. Accessed 2011 Jul 22.

2. College of Family Physicians of Canada. Standards for Accreditation for Residency Training Programs. Mississauga, ON: College of Family Physicians of Canada; 2006. Available from: www.cfpc.ca/uploadedFiles/Education/Red\%20Book\%20Sept.\%202006\%20English.pdf. Accessed 2012 Jan 20.

3. Vinger I. Graduate training in family medicine: two years or three? Can Fam Physician 1979;25:1107-8.

4. Lehmann F. Should family medicine residency be 3 years? YES. Can Fam Physician 2009;55:342, 344, 346.

5. Raiche, P. Should family medicine residency be 3 years? NO. Can Fam Physician 2009;55:343-4, 347-8.

6. Noel K. Two years is not enough: learning from the past, looking to the future. Can Fam Physician; 2010;56:410-11, e167-8.

7. Wilson JG. Two years could be enough. Can Fam Physician 2010;56:633.

8. Saucier D. Second thoughts on third-year training [Editorial]. Can Fam Physician 2004;50:687-9 (Eng), 693-5 (Fr).

9. Saucier D, Blais J. «Enfin une résidence de quatre ans en médecine familiale» (Le journal du futur, 1er mais 2010). L'Actualité médicale 1998;June:21.

10. Emery JD, Skinner LP, Morgan S, Guest BJ, Vickery AW. Future models of general practice training in Australia. Med J Aust 2011;194(11):S97-100.

11. Carney PA, Green LA. An emerging epidemic of innovation in family medicine residencies. Fam Med 2011;43:461-3.

12. Hodges BD. The tea-steeping or i-Doc model for medical education? Acad Med 2010;85(9 Suppl):S34-4.

13. Royal College of Physicians and Surgeons of Canada. Competency Based Medical Education: White Paper Prepared for the Royal College of Physicians and Surgeons of Canada. Ottawa, ON; Royal College of Physicians and Surgeons of Canada; 2011. Available from: http://rcpsc. medical.org/residency/fmec/CBME.pdf. Accessed 2012 Jan 20.

14. Tannenbaum D, Kerr J, Konkin J, Organek A, Parsons E, Saucier D, Shaw L, Walsh A. The Scope of Training for Family Medicine Residency: Report of the Working Group on Postgraduate Curriculum Review. Mississauga, ON: College of Family Physicians of Canada 2011. Available from: www.cfpc.ca/uploadedFiles/Education/_PDFs/8\%20The\%20Scope\%20of\%20 Training\%20for\%20Family\%20Medicine\%20Residency_Domains\%20of\%20Clinical\%20 Care\%20and\%20Evolving\%20Professional\%20Competencies.pdf. Accessed 2013 Feb 7.

15. Association of Faculties of Medicine of Canada. Future of Medical Education in Canada website. 2010. www.afmc.ca/fmec. Accessed Dec. 6, 2011. 


\section{Triple C Implications for Enhanced Skills Training in Family Medicine Programs: A Discussion Paper}

\section{Authors}

Andrew Organek, Jonathan Kerr, Jill Konkin, Ean Parsons, Danielle Saucier, Liz Shaw, David Tannenbaum, Allyn Walsh

Suggested Citation:

Organek A, Kerr J, Konkin J, Parsons E, Saucier D, Shaw L, et al. Triple C implications for enhanced skills training in family medicine programs: a discussion paper. In: Oandasan I, Saucier D, eds. Triple C Competency-based Curriculum Report - Part 2: Advancing Implementation. Mississauga, ON: College of Family Physicians of Canada; 2013. Available from: www.cfpc.ca/uploadedFiles/ Education/_PDFs/TripleC_Report_pt2.pdf. Accessed 2013 Jul 29. 
This paper discusses the changes that family medicine programs offering enhanced skills training might need to make to allow evaluation of their progress in meeting the requirements of the Triple $\mathrm{C}$ Competency-based Curriculum (Triple C). ${ }^{1}$ It is intended to be a discussion paper for the academic community.

\section{INTRODUCTION}

Training in enhanced skills for family medicine comprises a heterogeneous group of opportunities accredited by the College of Family Physicians of Canada (CFPC) and is available to graduates of family medicine residency programs and physicians currently in practice who wish to "upgrade their skills or acquire new skills to meet the needs of the populations they serve." ${ }^{2}$ Enhanced skills programs serve to meet these requirements, and have evolved with the needs of residents, programs, and communities. New opportunities to further develop practising doctors' existing skills within the broad scope of family medicine contributes to the growth and versatility of family medicine.

The successful completion of the core family medicine curriculum is just the beginning for the graduate physician's journey in the practice of family medicine. The first few years in practice is a critical time in the development of graduates' broad-based skills in practice and an ideal point at which to seek out enhanced skills training. Graduates of enhanced skills programs are expected to become comprehensive family physicians who have additional skills in specific areas that they require to meet the needs of the communities they serve.

There are many questions concerning how enhanced skills programs can best be structured and integrated within core family medicine residency training. The introduction of Triple $C$ in postgraduate family medicine training presents an opportunity to address many of these questions, and offers a framework on which not only to build new programs in enhanced skills for family medicine, but to evolve existing ones. This paper will discuss the implications of the shift to Triple $\mathrm{C}$ for these programs, and must be read in the context of the entire report.

\section{CURRENT CHALLENGES}

The CFPC's Working Group on Postgraduate Curriculum Review (WGCR) has noted concerns about enhanced skills programs in a few key areas.*

\section{Professional identity as a generalist family physician}

Enhanced skills programs commonly provide exposure to focused care environments to the exclusion of comprehensive care settings, and to training by teachers who do not include comprehensive family medicine in their professional practice. These environments might not be conducive to supporting the ongoing development of residents as generalists and could promote the development of focused practitioners rather than comprehensive family physicians with added skills.

\section{Continuity of family medicine education and patient care}

The Working Group for Postgraduate Curriculum Review raised several concerns about the continuity of family medicine education and patient care in current enhanced skills programs,

*These concerns may be less relevant to those physicians already experienced in comprehensive family practice who are returning to pursue enhanced skills training. 
in Triple C Report - Part 1. ${ }^{1}$ The CFPC Section of Residents Council summarized many of these issues in a report entitled Current Issues in FM R3 Training: The Resident Perspective (2009). The greatest areas of concern are 1) clinical exposure to family practice and 2) integration with local departments of family medicine.

The CFPC's 2006 "Red Book," in outlining its accreditation standards for family medicine/emergency medicine residency programs, states that training programs must provide "an educational environment which facilitates and encourages residents to maintain an ongoing responsibility in a family practice setting throughout the third year." ${ }^{2}$

Although the CFPC's 2013 "Red Book" has been released ${ }^{3}$ the elements related to enhanced skills programs are yet to be revised. Based on the recommendations of the WGCR, the upcoming need is to consider how to align enhanced skills programs with the vision of Triple $\mathrm{C}$-comprehensive care and continuity of care and education that is centred in family medicine, using a competency-based approach.

Over the years, there have been few opportunities within enhanced skills programs for residents to have regular exposure to family practice clinics, despite program directors' expressed commitment to offer them. The issues surrounding the provision of this training continue to be contentious among stakeholders for a number of reasons.

Arguments from residents and educators against ongoing exposure to clinical comprehensive family medicine exposure during enhanced skills training include the following:

- Current "half-day back" exposure to family practice results in poor continuity experiences

- Family practice time reduces time allocated to attaining skills in the area of enhanced training

- Residents pursuing family practice exposure during enhanced skills training risk being taken less seriously by the trainers

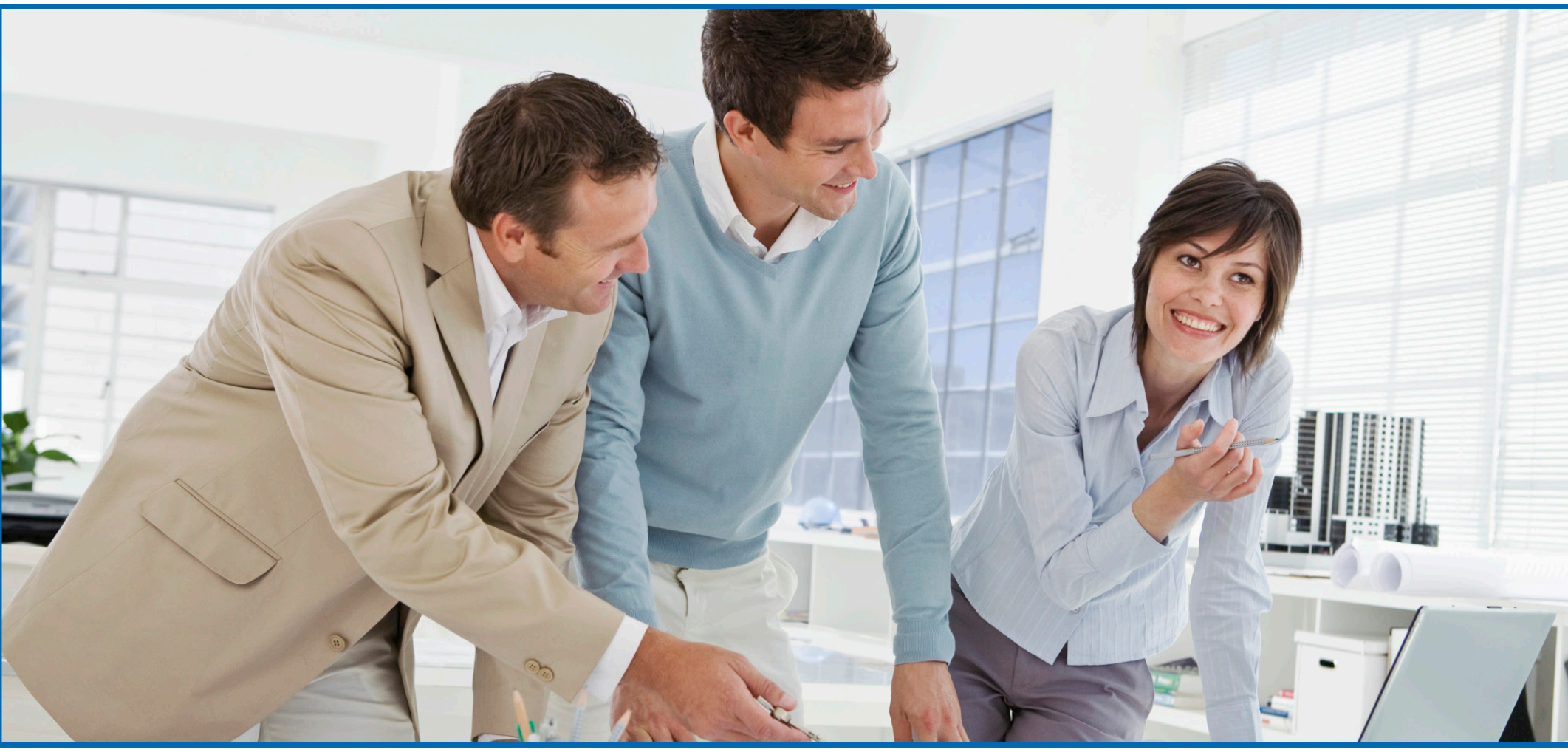


- Residents are not interested in pursuing a career that includes comprehensive family practice

- Residents believe that they do not need further training in comprehensive family practice because they have already completed a family medicine residency program

- Residents are frustrated because they could be "moonlighting" rather than participating in comprehensive family practice experiences as a resident

Those arguing for continuing broad-scope family practice experiences throughout enhanced skills training point to the many benefits of this integration:

- Such training is consistent with the CFPC's goal of training residents to provide comprehensive family practice

- A continuing connection with family practice promotes residents' professional identity as family physicians

- Residents avoid professional isolation from family medicine

- Residents have opportunities to practise family medicine at a more senior level (eg, managing clinic)

- Increased opportunities for teaching in family medicine at a more senior level (eg, monitoring clerks and first- and second-year family medicine residents)

- Such programs encourages and promotes a career inclusive of comprehensive family practice

- Potential to deter residents from entering family medicine residencies with little or no intention of pursuing a career in comprehensive family practice from entering family medicine residencies

\section{TRIPLE C COMPETENCY-BASED CURRICULUM FOR ENHANCED SKILLS PROGRAMS}

The introduction of a competency-based curriculum into enhanced skills programs could help to address many of the criticisms outlined above. A Triple C competency-based enhanced skills program-one that maintains comprehensive care, is focused on continuity, and is centred in family medicine-would have to be delivered using a variety of methods to suit the diverse ways in which the programs are designed.

\section{Comprehensive education and patient care}

To allow participating residents to maintain their competencies in comprehensive family medicine, enhanced skills programs would be required to include exposure to broad-scope family practice through clinical experiences and improved integration with local family medicine residency programs. Expanding residents' professional identity to include the area of enhanced skills is an essential part of these training experiences, but this expansion and development of enhanced skills should not be accomplished at the cost of their primary professional identity as comprehensive family physicians. Those who enter enhanced skills programs after having already practised comprehensive family medicine are likely to have established their identity as family practitioners, and might have less need for training experiences in comprehensive family practice.

The "half-day back" clinic has been the most frequently proposed solution to the problem of supplying continued clinical exposure to family medicine during enhanced skills training. However, we must 
consider other approaches to supporting generalist identity. If we centre enhanced skills programs in family medicine, new opportunities for residents will arise that will not compromise the efficiency or the flow of their learning.

\section{Continuity of education and patient care}

Continuity of both education and patient care are essential in the training of comprehensive family physicians with enhanced skills.

Continuity of education can be accomplished through supervision, the learning environment, and curriculum design. Continuity of supervision and teaching entails assigning a small group of primary preceptors who contribute to the meaningful assessment of learners over time. Continuity of the learning environment requires, wherever possible, placing residents in familiar settings, offering them more opportunities for continuity of patient care, and enhancing their efficiency in acquiring competencies. For example, a resident who attends an enhanced skills program at the same site as his or her core family medicine residency could benefit from a curriculum design that stresses continuity of education. Continuity is achieved through the design of a coherent, well-sequenced, integrated program that optimizes the progressive development and maintenance of the enhanced set of competencies. An integrated curriculum requires a different approach from the traditional rotationbased model and involves more longitudinal programming.

Enhanced skills training programs, while often brief, offer the potential to support family medicine residents in their continuous care of a population of patients, both in the family medicine setting, and within the area of enhanced skills. Opportunities should also be identified within each specific area of training for ongoing care of a patient population, such as following a population of women through their pregnancies and into labour in an obstetrical care enhanced skills program.

\section{Centred in family medicine}

A curriculum centred in family medicine means that family medicine program directors have full control over the curriculum; content is relevant to the needs of family medicine residents; and learning occurs primarily in a family practice context, using teachers who are family physicians or who fully understand the educational and practice needs of family physicians. For enhanced skills programs, this component of Triple $\mathrm{C}$ will require a fundamental shift to training environments where the context of learning is explicitly based on the needs of family physicians.

Improving the integration of residents learning enhanced skills into their local core family medicine training programs would promote professional socialization and assert their identities as comprehensive family physicians. This integration could lead to family medicine graduates' improved attitudes toward comprehensive family medicine and could promote a broader scope of practice. If the educational experience is strongly rooted in family medicine, opportunities for residents to find relevant exposure to comprehensive family medicine will present themselves more naturally.

To achieve a truly family medicine-centred enhanced skills program would involve significant changes to the way the curriculum is delivered. Stakeholders involved in program design and delivery must consider strategies for how best to integrate Triple C concepts into enhanced skills training to achieve the desired outcomes. These strategies could include making changes to program structure, as well as encouraging enhanced skills residents in core family medicine programs to be more involved. Their involvement might take the form of participation in combined academic sessions, where appropriate; 
teaching in the area of their enhanced skills; or invited and encouraged attendance at family medicine social functions.

To provide optimal family medicine role modeling within enhanced skills programs, the learners' primary group of preceptors would ideally include those with an active comprehensive family practice. Such preceptors would be excellent role models, demonstrating the appeal and feasibility of a career that includes comprehensive family medicine. Augmenting residents' experiences through contact with teachers and contexts outside of family medicine might be necessary to achieve certain competencies; in these circumstances, programs should seek consultant teachers with both a clear understanding of the family physician's role and respect for this discipline. The preceptors selected should be able to improve integration with local family medicine departments and training sites.

\section{Competency-based curriculum}

Shifting to a competency-based curriculum in enhanced skills programs seems a natural step on the path to a Triple C competency-based family medicine residency. This approach involves using carefully designed curricular elements to achieve clearly stated desired outcomes, and is supported by educational theories and practical experience.

CanMEDS-Family Medicine ${ }^{\dagger}$ (CanMEDS-FM) defines the seven roles that are common to all family physicians in practice. ${ }^{4}$ This framework is relevant to residents in enhanced skills for family medicine programs. Learning objectives will need to be developed using this framework, building on the competencies acquired in the core program. Acquisition of competencies should be assessed regularly, and the assessment process should be embedded in the curriculum. Promotion should depend on achievement of competency rather than on time in training.

\section{CONCLUSION}

The recommendations of the WGCR propose major changes to the training of family medicine residents in Canada. Programs teaching enhanced skills for family medicine play an important role in meeting the needs of learners, programs, and communities. As family medicine programs take steps to provide Triple $\mathrm{C}$ competency-based curricula, they will need to make changes to ensure that the enhanced skills programs maintain relevance, efficiency, and appropriate focus. The key principles of Triple C can be adapted to enhanced skills programs, allowing for improved continuity of the family practice learning experience, while bringing many other benefits to learners, programs, and society. 


\section{References}

1. Tannenbaum D, Kerr J, Konkin J, Organek A, Parsons E, Saucier D, et al. Triple C Competencybased Curriculum. Report of the Working Group on Postgraduate Curriculum Review - Part 1. Mississauga, ON: College of Family Physicians of Canada; 2011. Available from: www.cfpc. ca/uploadedFiles/Education/_PDFs/WGCR_TripleC_Report_English_Final_18Mar11.pdf. Accessed 2013 Mar 18.

2. College of Family Physicians of Canada. Standards for Accreditation of Residency Training Programs: Family Medicine; Emergency Medicine; Enhanced Skills; Palliative Medicine. Mississauga, ON: College of Family Physicians of Canada; 2006.

3. College of Family Physicians of Canada, Academic Family Medicine Department. Specific Standards for Family Medicine Residency Programs Accredited by the College of Family Physicians of Canada: The Red Book. Mississauga, ON: College of Family Physicians of Canada; 2013. www.cfpc.ca/uploadedFiles/Red\%20Book\%20English.pdf. Accessed 2013 Mar 18.

4. College of Family Physicians of Canada, Working Group on Curriculum Review. CanMEDSFamily Medicine: A Framework of Competencies in Family Medicine. Mississauga, ON: College of Family Physicians of Canada; 2009. Available from: www.cfpc.ca/uploadedFiles/ Education/CanMeds\%20FM\%20Eng.pdf. Accessed 2013 Mar 22. 

The implementation of Triple $\mathrm{C}$ requires a significant investment of time and effort focused on managing change. Curriculum change in family medicine impacts not only learners, but residency dierectors, program planners, department chairs, and deans; clinical preceptors in family medicine and other specialties; funders, including regional health authorities; clinical partners, including hospitals and family practice clinics; and key provincial partners, notably, the provincial regulatory health authorities. Managing expectations and ensuring good communication among these stakeholders as relationships develop and as change proceeds is critical for the success of Triple C.

This section of Triple C Report - Part 2 emphasizes these facets of change and explores resources, policies, and faculty development in "Facilitating Curriculum Change: Moving to a Triple C Competency-based Curriculum" and "Resource Implications for Departments of Family Medicine: A Discussion Paper." These two discussion papers will be of particular interest to those directly involved in the planning and implementation of Triple $\mathrm{C}$ within residency programs as they proactively consider the challenges ahead.

The third paper in this section, "Potential Impact of Triple C on CFPC External Stakeholders: A Discussion Paper," highlights how these changes will affect key stakeholders outside of the residency program. These stakeholders will learn what they need to know about Triple $\mathrm{C}$ and how they can help family medicine educators successfully implement the changes required. The process of implementing Triple $\mathrm{C}$ presents an opportunity for the entire medical education community to collectively support the development of family physicians with the competencies needed to address the ever-changing needs of Canadians. 



\title{
Facilitating Curriculum Change: Moving to a Triple C Competency-based Curriculum
}

\begin{abstract}
Authors
Allyn Walsh, Jonathan Kerr, Jill Konkin, Andrew Organek, Ean Parsons, Danielle Saucier, Liz Shaw, David Tannenbaum
\end{abstract}

Suggested Citation:

Walsh A, Kerr J, Konkin J, Organek A, Parsons E, Saucier D, et al. Facilitating curricular change: moving to a Triple C Competency-based Curriculum. In: Oandasan I, Saucier D, eds. Triple C Competency-based Curriculum Report - Part 2: Advancing Implementation. Mississauga, ON: College of Family Physicians of Canada; 2013. Available from: www.cfpc.ca/uploadedFiles/Education/_ PDFs/TripleC_Report_pt2.pdf. Accessed 2013 Jul 29. 


\section{INTRODUCTION}

As residency programs engage in major transformation, they are faced with many challenges. Samuel Bloom once described medical education as a "history of reform without change." ${ }^{1}$ How, then, to bring about a family medicine residency program's desire for real curricular changes, such as those embodied in the College of Family Physicians of Canada's (CFPC's) Triple C Competency-based Curriculum?

There is an abundance of books and articles on bringing about change; however, much of this literature, while engaging to read, does not represent scientific approaches or analysis. An exception to this is the systematic review published by Carol Bland et al in 2000, which sought to determine which factors were responsible for successful curricular change. ${ }^{2}$ Although the focus of the review was undergraduate medical education, it also considered primary care education, as well as curricular change in general. The framework that resulted from that work might be helpful for those of us engaged in moving family medicine residency education forward. It includes four stages: planning, initiation, implementation, and institutionalization. These stages do not take place in a stepwise manner; rather, every program moves through the stages according to its own priorities and as fits its particular context.

Using Bland et al's framework, and drawing on several other studies on change, ${ }^{3-6}$ and on curricular reform in particular, this paper presents ideas that residency programs might find useful to facilitate their own transitions to a Triple C Competency-based Curriculum.

\section{PLANNING}

During this stage, the program recognizes the need for change, designs a vision for change, and considers the context in which change will happen. A number of actions need to occur during this initial stage and may take place concurrently.

\section{Identify the need to change}

Those in charge of the residency program need to first identify for themselves the need to make changes before they can convince others. It is crucial that the proposed changes are compatible with the program's educational philosophy, missions, and goals and that they clearly address problems that people involved in the program experienced. Those leading the charge need a thorough understanding of the Working Group on Postgraduate Curriculum Review's (WGCR's) recommendations for curricular change, identified in the Triple C Report - Part 1, ${ }^{7}$ before they conduct a program review to pinpoint which aspects of the program need maintaining, enhancing, or developing. This review needs to identify those elements of the program that do not significantly contribute to developing the desired competencies in the majority of residents. Sources of program evaluation will be important, and if tools are not available, they might need to be developed (eg, encounter data, resident and teacher surveys, resident evaluations).

This review process involves evaluating each residency program and clinical teaching site on the implementation of the key elements of the Triple C curriculum ${ }^{7}$ :

1. Comprehensive care and education: Are programs designing their cirriculum to provide learning that exposes residents to comprehensive care that spans the life cycle and clinical settings, with experiences that cover the range of clinical responsibilities across defined populations including underserved populations? Are the clinical settings modeling the delivery of comprehensive care for its learners? 
2. Continuity of care and education: Are programs providing learning opportunities to enable learners to follow patients over time and in different settings in order for them to experience the importance of developing relationships with their patients and feel responsible for their care? Are learners provided with continuity of supervision that enables progressive assessment of their competency development, and with continuity of education that enables learners to have a curriculum that is cohesive, continuous, and integrated despite the multiple learning environments that they might encounter?

3. Centred in family medicine: Are family medicine residents given relevant learning experiences that enable them to achieve their competencies? Does the residency program feel that they are able to maintain control on the goals and curricular elements specific for family medicine? Are learners given opportunities to develop their professional identity as family physicians?

4. Competency-based education: Are expected outcomes or competencies defined and used in designing the residency program curriculum and matched with learning experiences and assessment strategies for learners?

\section{Ideas:}

1. Ensure residency program leaders and key stakeholders read relevant sections of the Triple $C$ Competency-based Curriculum Report - Part 1 and Part 2 to ensure the recommendations and implementation strategies for Triple $\mathrm{C}$ are understood and acted upon. Identify opportunities for communicating the Triple $\mathrm{C}$ recommendations and implementation strategies to all stakeholders.

2. Review program curriculum, identifying elements that are consistent with a Triple $C$ curriculum and leveraging the use of tools such as the "Guide for Translating the Triple C Competency-based Recommendations Into a Residency Curriculum.."

3. Look for "best practices" in different sites and contexts across programs to facilitate sharing of strategies and approaches.

4. Set priorities for change. Not all changes need to happen at the beginning. Changes that are most likely to succeed or that are most vital should be selected for the initial work.

\section{Build alliances at the top}

Family medicine education is an endeavour that is conducted collaboratively with many other disciplines and professions and in a wide variety of contexts. Traditionally, at the residency level, it has been built on the model of the rotating internship, and often on the provision of service to other parts of the hospital and health care system. Curricular changes could have a strong effect on these partners and might engender resistance. Helping institutional leaders to understand the reasons change is required will undoubtedly smooth the way. Deliberately engaging these partners and seeking agreement on principles before discussing actions will facilitate this understanding. Accordingly, it is important to foster open communication during this stage and to encourage key stakeholders to express any concerns or describe barriers they foresee, so that the program can address them at the outset. It is essential to seek the support of influencers within organizations and to identify and communicate the benefits that enable change ahead. For example, the importance of educating physicians to work in contexts similar to their future practices is a message that appeals to educators, but some might need to understand the rich variety of contexts and skilled teachers/practitioners available in family medicine settings. 


\section{Ideas:}

1. Identify stakeholders whose early support is key to bring about curricular change (eg, the postgraduate dean, program directors, consulting specialty colleagues who teach family medicine residents, and regional health authorities) and utilize and create opportunities to discuss Triple $\mathrm{C}$ to ensure their clear understanding of its principles and impact.

2. Look for those outside the residency program who might be affected by the planned changes. Identify as many win-win opportunities as possible, but be prepared to stand firm on nonnegotiable points. (See the discussion paper on resource implications ${ }^{9}$ later in this section.)

3. Engage the support of external stakeholders, including the regulatory authorities, the medical associations, government, and other funders, as well as other medical education organizations, to ensure that the intent and value of Triple $\mathrm{C}$ is understood.

\section{Build consensus from the grass roots}

A major shift in direction demands respected and powerful champions, who can provide a vision for why change is needed and what is expected. Effective change leaders are able to encourage and inculcate in others new organizational behaviours and cultures, motivating and mobilizing them to maintain the change momentum. These influential figures communicate and promote the shared vision for curricular change to residents, teachers, and other faculty, as well as to administrative staff.

\section{Ideas:}

1. Identify champions able to articulate and lead the changes proposed. These champions need not be the same people responsible for the administrative leadership of the program/site. They must have a good understanding of, and be enthusiastic about, the Triple C concepts; credibility within and external to the residency program; and strong communication skills, both formal (presentations) and informal (dialogue and discussion).

2. Provide champions with opportunities to develop networks or communities of practice that enable stakeholders to be engaged in the process of change. Stakeholders including residents, teachers within the department and family medicine contexts, teachers from other disciplines and settings, administrative staff, and patients can be powerful influencers of change. Finding ways to bring key teams together in a cohesive way to advance the vision for change forward will be critical.

\section{Ensure strong leadership}

Successful change efforts are led by a strong influential advocate at the forefront of the activity. It is important to identify a champion to lead the change, someone who will be a strong and influential advocate for the change, who can gain support from the grass roots as well as from institutional leaders, such as the dean and postgraduate dean. Communication must be frequent, timely, substantive, and forthright, and will need to be shared in a variety of verbal and written forms, both formal and informal. The leader needs to be both visible and proactive, and he or she must model enthusiasm and commitment. The quality of leadership is a predictor of successful change.

\section{Ideas:}

1. The change leader needs to maintain bidirectional communication with institutional leaders in order to identify win-win opportunities and address concerns at the earliest possible opportunities.

2. The change leader must identify any external sources of potential resistance at this planning 
stage, so that there is time to muster support and develop strategies for overcoming resistance.

3. This initial champion should be carefully selected for his or her credibility and communication skills.

\section{INITIATION}

In the initiation stage, old organizational patterns are unlocked and the innovations are introduced into the environment. Understanding the context of the organization is important during this stage.

\section{Value context}

The Triple C Competency-based Curriculum will necessarily be implemented differently both between programs and from site to site as the opportunities and educational resources available vary. It is important to value and build on this diversity, allowing flexibility in implementation, while maintaining consistent program policy. Learning from the experiences of different sites can help to more quickly build the change.

\section{Ideas:}

1. Doing things differently at different sites is natural because the sites have different resources and contexts. However, communicating about activities across the institution, as well as sharing and learning from successes and mistakes, should be evident. The systems to make this communication possible, such as networks, committees, and demonstration projects, must be built and reinforced (eg, networks, committees, demonstration projects), supported by individual residency programs nationwide through the CFPC.

2. A history of effective change is predictive of future success in innovation. Identify individuals, sites, or programs that have successfully introduced change, and invite them to lead the planning and implementation of projects.

\section{Build strong organizational structures}

Residency programs need to reflect on their organizational structures to consider if they align with the needs of Triple $\mathrm{C}$. The relationship between the university residency program base and its clinical teaching sites is important. Clear communication strategies should be evident and will likely facilitate changes needed program-wide.

\section{Ideas:}

1. Build opportunities for shared learning, and create teams within residency programs that leverage members from different clinical teaching sites. Recognizing that different clinical teaching sites might be implementing different elements of Triple C, what we learn from each other's experiences will be helpful in advancing change as a whole for the program.

2. Ensure that university residency program governance includes strong connections across teaching sites to support change needed for Triple $C$ and to ensure that it occurs across the program with equity, despite variation in how change is implemented in the different sites.

3. Consider how to best align the funding within the department to support the change process.

4. Consider how the departmental awards and honours system could help advance change. 


\section{Select initial change projects carefully}

Advancing change requires strategic choices. Selecting what types of change initiatives to undertake is important. Discussing the size of the project to be undertaken with recognition of level of engagement is paramount. If change is too large and ambitious there is a risk of overwhelming program

participants. However, choosing to undertake smaller projects runs the risk of lack of sustainability and uptake across the program. It is helpful to begin with "the low-hanging fruit," finding opportunities that are most likely to succeed, as these successes will build confidence and motivation.

\section{Ideas:}

1. Use the "Guide for Translating the Triple C Competency-based Recommendations Into a Residency Curriculum" ${ }^{8}$ to identify where change has already been achieved, where opportunities exist for "quick wins," and where strategic choices can be made.

\section{IMPLEMENTATION}

During implementation, the innovations continue to be put into practice across the program, with modifications and adjustments. As in the other stages, clear and regular communication is critical.

\section{Allow all views to be heard}

Those who oppose change should be invited to air their concerns. Allowing their participation establishes trust and affirms risk taking. Their voices are often representative of common sentiments that need to be heard and can uncover issues that must be addressed.

\section{Ideas:}

1. Be open to all views, including those views that might be resistant to the changes proposed. Find venues to enable perspectives to be shared in constructive ways. Consider inviting those with opposing views to contribute to the planning and implementation of projects.

\section{Enhance support}

As those involved in the change (residents, teachers, administrators) move through the change process, it is important to be attentive to their needs, providing appropriate support to enable individuals to enact the changes in progress. Because people tend to revert to old patterns of behaviour when learning new ones, particularly when difficulties arise, reinforcement, support, and coaching processes should be put into place.

\section{Ideas:}

1. Faculty development strategies are critical to help leaders and teachers understand what they need to know about Triple C. Tools provided by the CFPC, as well as material from other programs and clinical sites, should be readily available to be used and adapted to meet local needs. Programs should also implement ongoing strategies to ensure learning and coaching can be provided on an ongoing basis. Presenting frequent opportunities to reflect on the needs of the various stakeholders will help programs consider ways to address needs that emerge over time. 
2. Residents also need to be prepared for the changes they will encounter; they must be well informed about the changes ahead, as well as involved in the planning and implementation processes.

3. Consider the use of focused retreats, meetings, and other sessions that tailor learning and support for key stakeholders. This ongoing initiative requires a perspective that all those engaged in the implementation of change should be supported in one way or another.

\section{Build in evaluation}

As innovations involve some degree of risk, it is important to evaluate both learners and programs to identify successes and false starts. Evaluations of learners should be based on demonstration of competency achievements, and program evaluations should also look at a variety of outcomes, as appropriate for the program's overall mission and goals. The evaluations should involve methods that the faculty regard as meaningful and important. Evaluation is a collaborative activity and so can help to build commitment to the process.

\section{Ideas:}

1. Build on previous program evaluation methods to assess impact of change.

2. Consider both short-term and long-term evaluations.

3. Use focus groups as tools not only to evaluate but to build engagement and accountability.

4. Take corrective action to improve and reinforce change efforts.

5. Refer to the CFPC's Triple C evaluation plan ${ }^{8}$ to identify key areas of evaluation.

\section{Reinforce a positive work environment}

Successful curricular change requires a respectful and positive work environment. Innovation demands a steady stream of creative ideas, and an atmosphere in which colleagues practise new behaviours. This atmosphere has been described as "creative, supportive tension." ${ }^{9}$ Change involves uncertainty and discomfort; the work climate needs to be cooperative, with mechanisms for successful conflict resolution.

\section{Ideas:}

1. Acknowledge the uncertainty and discomfort of change and the inevitability of mistakesframed as organizational learning.

2. Recognize that there is usually a "performance dip" at the initiation of a major change, but that the dip corrects itself.

3. Recognize and reward people for their efforts, formally and informally.

4. Consider seed grants or pilot funds to encourage innovative projects aligned with the change process. 


\section{INSTITUTIONALIZATION}

This term refers to the stage at which innovations have become the accepted way of doing things in the organization. Institutionalization is reached when the innovations that have been put into place have become incorporated as the "the new way" of doing things. Broad participation is required to ensure permanence of change. If the previous stages have been addressed with wide engagement, institutionalization is likely.

\section{SUMMARY}

Bringing about significant curricular change requires long-term commitment on the part of both the program and the clinical teaching sites affiliated with the residency program. Leadership, communication, and commitment from all those concerned need to be fostered so that positive changes can be institutionalized. Ensuring early engagement with all stakeholders is critical.

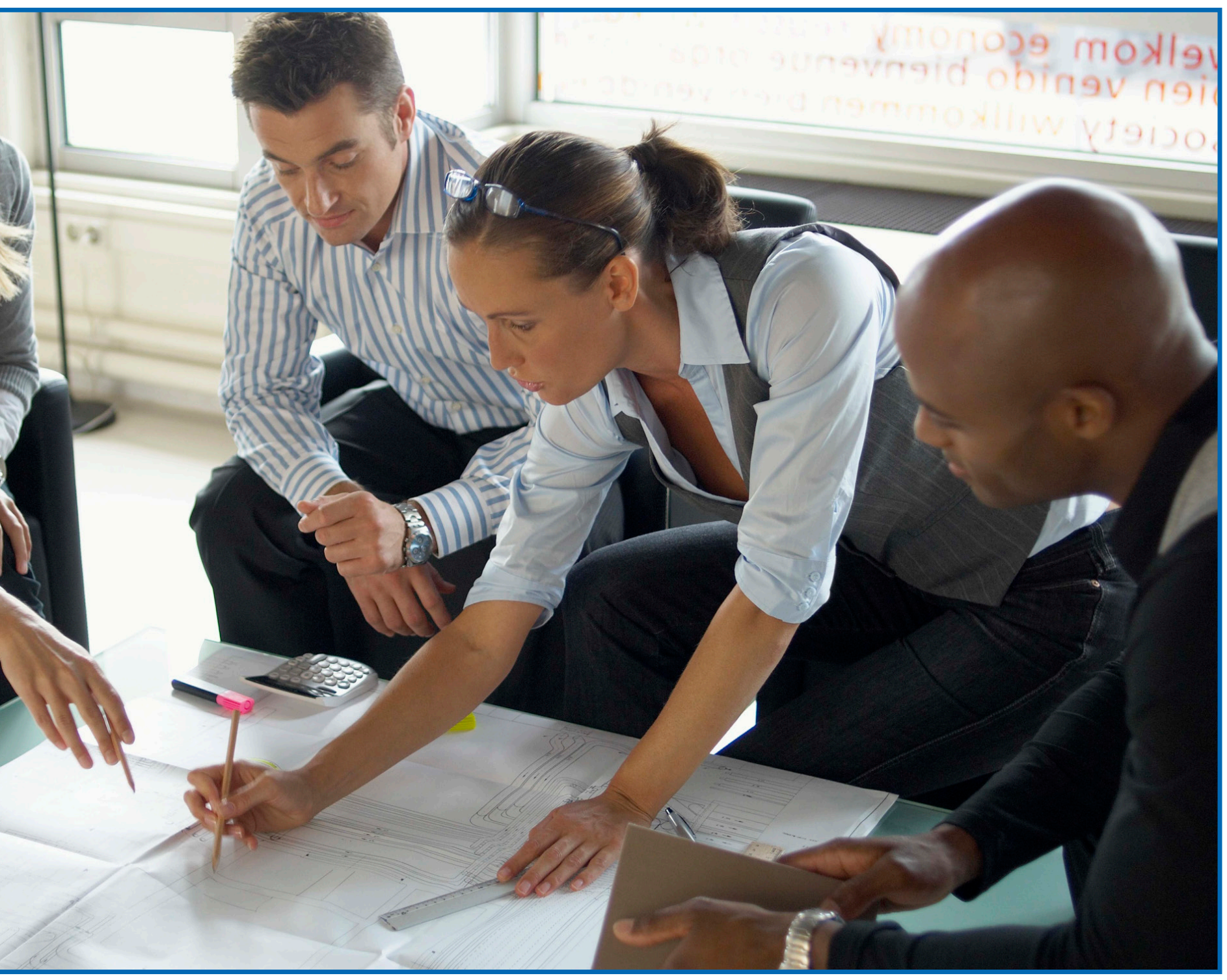




\section{References}

1. Bloom SW. Structure and ideology in medical education: an analysis of resistance to change. J Health Soc Behav 1988;29(4):294-306.

2. Bland CJ, Starnamen S, Wersal L, Moorhead-Rosenberg L, Zonia S, Henry R. Curricular change in medical schools: how to succeed. Acad Med 2000;75:575-594.

3. Carraccio C, Wolfsthal SD, Englander R, Ferentz K, Martin C. Shifting paradigms: from Flexner to competencies. Acad Med 2002;77:361-367.

4. Farris KB, Demb A, Janke KK, Kelley K, Scott SA. Assessment to transform competency-based curricula. Am J Pharm Educ 2009;73(8):158.

5. Genn, JM. AMEE Medical Education Guide No. 23 (Part 1): Curriculum, environment, climate, quality and change in medical education - a unifying perspective. Med Teach 2001;23:337-344.

6. Kotter JP. Leading change: Why transformation efforts fail. In: The Tests of a Leader. Harvard Business Review Paperback Series. New York: Harvard Business Review Press; 2007:96-103.

7. Tannenbaum D, Kerr J, Konkin J, Organek A, Parsons E, Saucier D, et al. Triple C Competencybased Curriculum. Report of the Working Group on Postgraduate Curriculum Review - Part 1. Mississauga, ON: College of Family Physicians of Canada; 2011. Available from: www.cfpc. ca/uploadedFiles/Education/_PDFs/WGCR_TripleC_Report_English_Final_18Mar11.pdf. Accessed 2013 May 30.

8. Saucier D, and the Working Group on Postgraduate Curriculum Review. A guide for translating the Triple $C$ Competency-based recommendations into a residency curriculum. In: Oandasan I, Saucier D, eds. Triple C Competency-based Curriculum Report - Part 2: Advancing Implementation. Mississauga, ON: College of Family Physicians of Canada; 2013. www.cfpc.ca/uploadedFiles/Education/_PDFs/TripleC_Report_pt2.pdf. Accessed 2013 Jul 29.

9. Shaw L, Walsh A, Oandasan I, Kerr J, Konkin J, Organek A, et al. Resource implications for departments of family medicine: a discussion paper. In: Oandasan I, Saucier D, eds. Triple C Competency-based Curriculum Report - Part 2: Advancing Implementation. Mississauga, ON: College of Family Physicians of Canada; 2013. www.cfpc.ca/uploadedFiles/Education/_PDFs/ TripleC_Report_pt2.pdf.

10. Oandasan I, on behalf of the Triple C Competency Based Curriculum Task Force. A national program evaluation approach to study the impact of Triple C. In: Oandasan I, Saucier D, eds. Triple C Competency-based Curriculum Report - Part 2: Advancing Implementation. Mississauga, ON: College of Family Physicians of Canada; 2013. www.cfpc.ca/uploadedFiles/ Education/_PDFs/TripleC_Report_pt2.pdf. Accessed Jul 29.

11. Pelz DC, Andrews FM. Scientists in Organizations: Productive Climates for Research and Development. New York: John Wiley \& Sons; 1966. 



\title{
Resource Implications
} for Departments of Family Medicineः A Discussion Paper

\author{
Authors \\ Liz Shaw, Allyn Walsh, Ivy Oandasan, \\ Jonathan Kerr, Jill Konkin, Andrew Organek, Ean Parsons, \\ Danielle Saucier, David Tannenbaum
}

Suggested Citation:

Shaw L, Walsh A, Oandasan I, Kerr J, Konkin J, Organek A, et al. Resource implications for departments of family medicine: a discussion paper. In: Oandasan I, Saucier D, eds. Triple C Competency-based Curriculum Report - Part 2: Advancing Implementation. Mississauga, ON: College of Family Physicians of Canada; 2013. Available from: www.cfpc.ca/uploadedFiles/Education/_PDFs/ TripleC_Report_pt2.pdf. Accessed 2013 Jul 29. 
The growth and development of teaching in family medicine has always been challenging, representing a culture shift for communities, patients, and health care providers. Although many issues have resource implications, there are some that could arise specifically as a result of the shift to the Triple C Competency-based Curriculum (Triple C) in terms of human and clinical resources, and could have faculty development implications.

\section{RESOURCE IMPLICATIONS}

With a shift to a family medicine-centred curriculum, ${ }^{1}$ it is projected that in many programs, residents will be spending less time in settings with consulting specialists and more time with family physicians. In addition, there will be an increased focus on family physician teachers within the academic program. This could result in an increased need for family physician teachers, faculty time, and exposure to patients and clinical space (examination rooms, computers, formal teaching space, etc.).

Programs will have to pay attention to comprehensiveness of teaching sites and family physician supervisors. While each resident will require continuity of education and a family practice "home," no single location will suffice to provide all of the relevant learning experiences that address the competencies required for comprehensive family practice; strategies for collaboration between sites to complement resident exposure will need to be explored. The ongoing search for teaching settings and family medicine supervisors who provide comprehensive clinical and educational experiences individually or in teams will only be heightened by the move to a Triple C Competency-based Curriculum. Finding a balance between exposure to different aspects of comprehensive care and a strong experience of continuity of care will be challenging. The Patient's Medical Home model ${ }^{2,3}$ supports the concept of comprehensive and collaborative care and, when resourced and structured appropriately, will provide excellent educational opportunities.

Learning experiences must be carefully selected in order to support the family medicine-centred curriculum, and to ensure that residents have relevant learning experiences to enable the development of the required competencies. Finding such learning environments can be challenging, particularly in the face of competition arising from both undergraduate and postgraduate family medicine expansion locally and nationally.

The types of patients and problems relevant to family medicine are most often seen in ambulatory care, sometimes in hospitals and long-term care facilities, but very often in private offices of both

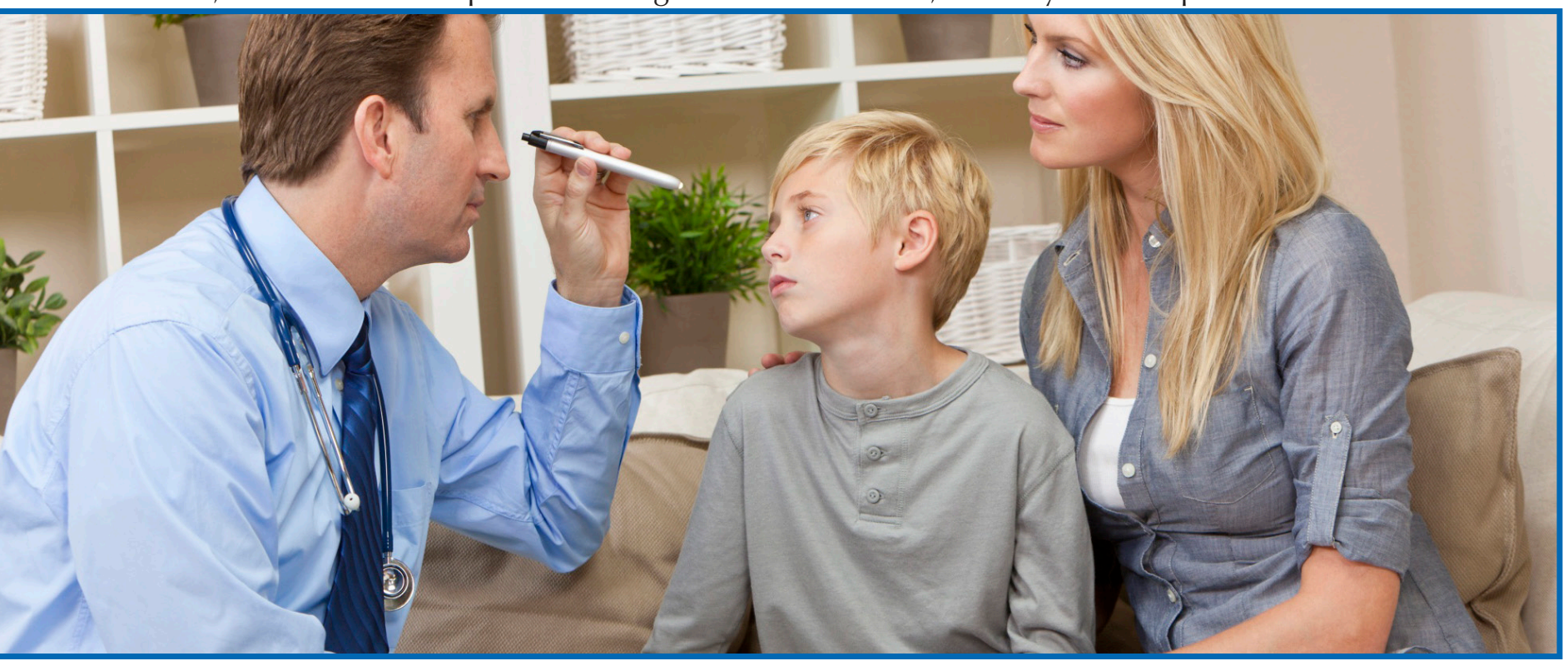


family physician teachers and those in other disciplines. The clinical-educational financial system is not organized to facilitate resident learning in these environments, and most commonly clinical spaces in private offices are not planned to accommodate learners.

In order to meet new assessment requirements, clinical space will need to be adapted to enable direct observation of residents as they provide care to patients. Methods to track resident experiences need to be developed and implemented at the program level and could be leveraged through the use of technology such as electronic medical records (EMRs). The use of EMRs has already been shown to be helpful in tracking the types of patients and clinical situations residents have already seen and mastered, in order to augment learning exposure in gap areas. E-learning, through cases and simulations, can be used to further enhance learning so that learners can gain, and be assessed for, competencies. The benefits gained from the use of advanced technology need to be weighed against the incurred costs associated with it.

In considering the issues surrounding competency-based assessment, learners will require more direct and intentional work-place assessment throughout their training. Structured time will need to be set aside for preceptors and residents for coaching and guided reflection. Faculty will need to be prepared to take on this role and feel confident and competent to carry out their supervisory tasks. Residents' roles will also be enhanced with increasing responsibility laid upon them. Residents will be expected to be more self-reflective and proactive, understanding their own learning gaps and initiating ways to shape their needed learning experiences. With preceptors acting as coaches to help learners recognize more fully their competence achievements, the relationships between residents and preceptors will be different than in the current system. For some, this shift might be significant, but it is believed the change will strengthen learning. Managing this change will need to be facilitated carefully.

The experience of different programs in advancing various components of Triple $C$ has shown an increased demand for administrative staff support around two activities: a) managing residents' schedules, reflecting a more individualized approach to enhancing competency achievement, with complementary learning experiences provided in tandem with the learner's main family medicine experience; and b) managing a competency-based assessment system, because of increased data/ evidence gathering and accountability requirements.

Finally, with an emphasis on outcomes and their relationship to quality and social accountability, residency programs will be called upon to examine whether their programs are able to produce the type of residents/graduates expected to address the health care needs of the country. New accreditation standards, new accountabilities put into place by governments, and expectations by residents and patients will apply pressure to residency programs to evaluate their impacts. Both the operational aspects of the residency programs and the family medicine graduates they produce will be assessed in relation to their ability to successfully address health system needs. Program evaluation will become an integral part of residency programs. As noted in the section "A National Program Evaluation Approach to Study the Impact of Triple $C^{\prime \prime 4}$ of this Report, program evaluation will provide a means to describe impact. The value of surveying graduates and analyzing implementation progress of Triple $C$ through more structured program evaluation processes will undoubtedly lead to new resource requirements. Yet, it might also reveal research opportunities, enabling external funding opportunities. The use of comparative data obtained across residency programs might be helpful to chairs in their advocacy efforts to negotiate for more resources, especially if the purpose and the evidence provided are aimed at enhancing academic excellence and social accountability. With fiscal restraints faced by all university programs, family medicine's strength can lie in opportunities to work together collaboratively, sharing success stories and collectively strategizing to support all programs during this transition period. 


\section{FACULTY DEVELOPMENT IMPLICATIONS}

As with any significant development in educational programs, preparing family medicine teachers for change is crucial; this is particularly important with the transformational scope of Triple C. Ongoing faculty development activities, in addition to repeated communication, will be required. Early and broad involvement of faculty members in the planning stage is important, in appreciation of the need for faculty development among all members of the interprofessional clinical and academic team.

Some of the areas of focus for faculty development are relatively well understood, due to a solid literature and many available tools (eg, assessment in competency-based education), while others will require new ideas and innovation (eg, enabling learners to take a higher level of responsibility for their learning). In addition, clinical teachers will need a better understanding of the CanMEDS-Family Medicine (CanMEDS-FM) roles, ${ }^{5^{*}}$ the Domains of Clinical Care, ${ }^{6}$ and the Evaluation Objectives. ${ }^{7}$ They must understand the relationships among these three frameworks and how they play out in practice. This relationship is described in "Triple C: Linking Curriculum and Assessment," ${ }^{18}$ found in this report. More and more family physician teachers will be expected to model the family physician role, to coach, and to teach in their day-to-day practices.

Departments will need to invest in faculty development to make their Triple C transformations happen. Programs will also need to consider creative ways to engage teachers to progressively learn new teaching and assessment skills while working in their busy clinical practices. Developing local champions to support teachers to assist in peer consultation and teaching could prove an effective faculty development strategy for residency programs.

To ease understanding, the goal of having more family physicians teaching competencies that can be ably taught by family physicians but that have been historically taught by consultant specialists will require renewed emphasis on continuing professional development in order to ensure what is being taught and modeled is based on up-to-date, evidence-based, yet family medicinecontextualized, approaches. The use of CanMEDS-FM roles ${ }^{5}$ as a guide to lifelong learning for family physicians enables a mesh of both continuing professional development and faculty development as the future evolves.

Investment in renewed efforts to recruit family medicine faculty might be needed to ensure departments and clinical teaching units can count on family medicine teachers who represent the diverse and comprehensive scope of family medicine as described by the Domains of Clinical Care. ${ }^{6}$ Programs might also need to consider new recruitment strategies with compelling incentives. Universities will then be required to support these strategies, particularly in providing the educational resources and funding to reach the expanded, distributed faculty teachers needed.

\section{CONCLUSION}

At a time when all university-based residency programs are facing curriculum reform, a clear opportunity presents itself. Necessary recruitment strategies, expanded clinical resources, faculty development tools, assessment methodologies, and program evaluation methodologies are being developed in different ways, at different times, and with different resources across all 17 universities in Canada. With the support of the CFPC, family medicine programs could help one another to develop strategies to find the resources needed to transform into a Triple C Competency-based Curriculum and to collaborate in developing materials to benefit all.

A consistent approach to, and messaging surrounding, Triple $\mathrm{C}$ across the country is important, and

\footnotetext{
*Adapted from Frank JR, ed. The CanMEDS 2005 Physician Competency Framework. Better standards. Better physicians. Better care. Ottawa: The Royal College of Physicians and Surgeons of Canada; 2005. Available from: www.royalcollege.ca/portal/page/portal/rc/canmeds/resources/publications. Accessed 2013 Mar 3.
} 
can be facilitated with national coordination, some common tools and strategies, and repeated sharing. The implementation of Triple $\mathrm{C}$ requires family physicians to play a larger role in the education of residents in their discipline, and clinical settings will need to be appropriately resourced. Preparation of both teachers and residents for their roles in the new curriculum will need to be well planned and implemented. The resource implications of this transformation are significant; however, departments of family medicine in Canada have demonstrated strengths to meet these challenges. Success has already been established in the last number of years. . With the multiple program director retreats; large national meetings with the academic teachers; meetings with assessment coordinators, faculty development coordinators, and academic coordinators; and upcoming meetings with the chairs of the departments of family medicine, collaboration has been the driving success factor for Triple C. As resource implications become more apparent, collaboration must continue to be in the forefront of the academic community.

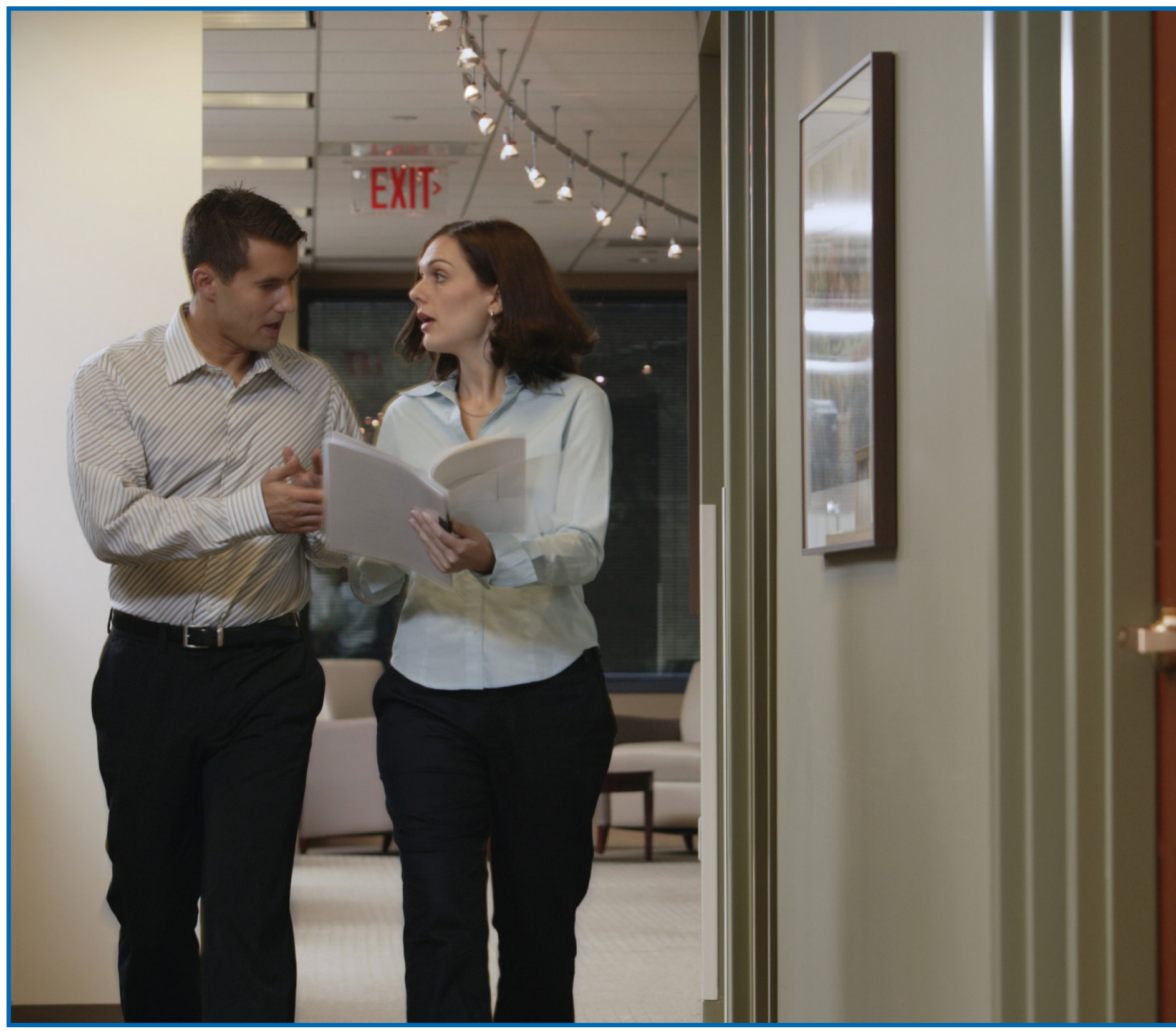




\section{References}

1. Shaw E, Walsh AE, Saucier D, Tannenbaum D, Kerr J, Parsons E. The last C: centred in family medicine. Can Fam Physician 2012;58:346-348. Available from: www.cfp.ca/content/58/3/346. full.pdf+html. Accessed 2013 Feb 1.

2. College of Family Physicians of Canada. Patient-centred primary care in Canada: bring it on home. [Discussion paper.] Mississauga, ON: CFPC; 2009 Oct. 27 Available from: www.cfpc. ca/uploadedFiles/Resources/Resource_Items/ Bring20it20on20Home20FINAL20ENGLISH.pdf. Accessed 2013 Feb 19.

3. College of Family Physicians of Canada. A Vision for Canada: Family Practice - The Patient's Medical Home. Mississauga, ON: College of Family Physicians of Canada; 2011. Available from: www.cfpc.ca/A_Vision_for_Canada_Family_Practice_2011/. Accessed 2013 Feb 19.

4. Oandasan I, on behalf of the Triple C Competency Based Curriculum Task Force. A national program evaluation approach to study the impact of Triple C. In: Oandasan I, Saucier D, eds. Triple C Competency-based Curriculum. Report - Part 2: Advancing Implementation. Mississauga, ON: College of Family Physicians of Canada; 2013. Available from: www.cfpc.ca/ uploadedFiles/Education/_PDFs/TripleC_Report_pt2.pdf. Accessed 2013 Jul 29.

5. College of Family Physicians of Canada, Working Group on Postgraduate Curriculum Review. CanMEDS-Family Medicine: A Framework of Competencies in Family Medicine. Mississauga, ON: College of Family Physicians of Canada; October 2009. Available from: www.cfpc.ca/ uploadedFiles/Education/CanMeds\%20FM\%20Eng.pdf. Accessed 2013 Feb 19.

6. Tannenbaum D, Kerr J, Konkin J, Organek A, Parsons E, Saucier D, et al. The Scope of Training for Family Medicine Residency: Report of the Working Group on Postgraduate Curriculum Review. Mississauga, ON: College of Family Physicians of Canada; 2011. Available from: www.cfpc.ca/uploadedFiles/Education/_PDFs/8\%20The\%20Scope\%20of\%20Training\%20 for $\% 20$ Family $\% 20$ Medicine $\% 20$ Residency_Domains $\% 20$ of $\% 20$ Clinical $\% 20$ Care $\% 20$ and $\% 20$ Evolving\%20Professional\%20Competencies.pdf. Accessed 2013 Feb 19.

7. College of Family Physicians of Canada, Working Group on Certification Process. Defining Competence for the Purposes of Certification by the College of Family Physicians of Canada: The Evaluation Objectives in Family Medicine. Mississauga, ON: College of Family Physicians of Canada; 2010. www.cfpc.ca/uploadedFiles/Education/Definition\%20of\%20Competence\%20 Complete\%20Document\%20with\%20skills\%20and\%20phases\%20Jan\%202011.pdf. Accessed 2013 Feb 19.

8. Oandasan I, Wong E, Saucier D, Donoff M, Iglar K, Schipper S. Triple C: linking curriculum and assessment. Can Fam Physician 2012;58:1165-1167. Available from: www.cfp.ca/ content/58/10/1165.full.pdf+html. Accessed 2013 Feb 19.

9. Kerr J, Saucier D, Wong E, Konkin J, Organek A, Parsons E, et al. Transitioning to Triple C: residency program perspectives from 2009 to 2010. In: Oandasan I, Saucier D, eds. Triple C Competency-based Curriculum Report - Part 2: Advancing Implementation. Misssissauga, ON: College of Family Physicians of Canada; 2013. www.cfpc.ca/uploadedFiles/Education/_PDFs/ TripleC_Report_pt2.pdf. Accessed 2013 Jul 29. 


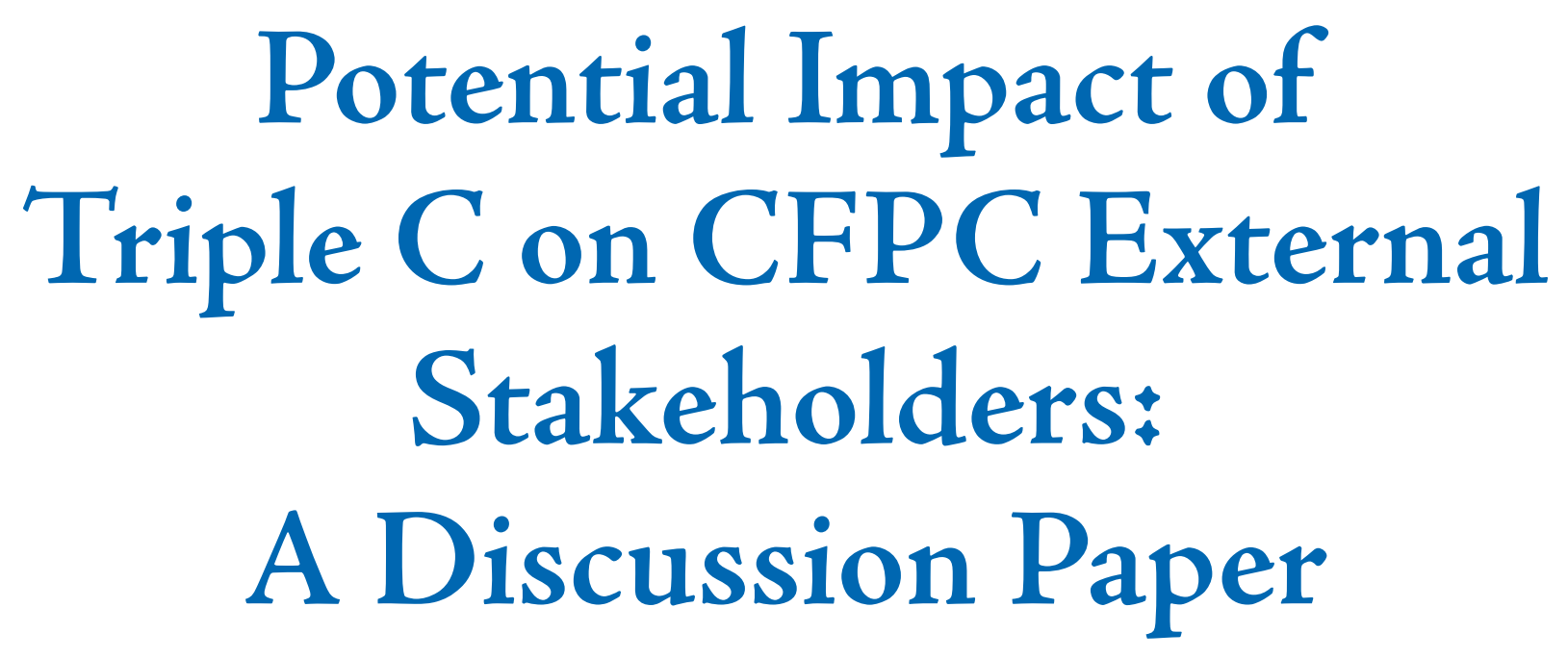

Authors

Ivy Oandasan, Eric Wong, Danielle Saucier, Ean Parsons, Jonathan Kerr, Jill Konkin, Andrew Organek, Liz Shaw, David Tannenbaum, Allyn Walsh

Suggested Citation:

Oandasan I, Wong E, Saucier D, Parsons E, Kerr J, Konkin J, et al. Potential impact of Triple C on CFPC external stakeholders: a discussion paper. In: Oandasan I, Saucier D, eds. Triple C Competencybased Curriculum Report - Part 2: Advancing Implementation. Mississauga, ON: College of Family Physicians of Canada; 2013. Available from: www.cfpc.ca/uploadedFiles/Education/_PDFs/ TripleC_Report_pt2.pdf. Accessed 2013 Jul 29. 


\section{INTRODUCTION}

As the Triple C Competency-based Curriculum ${ }^{1}$ (Triple C) is introduced to train new family physicians according to CanMEDS-Family Medicine (CanMEDS-FM) ${ }^{2 *}$ and across the Domains of Clinical Care, ${ }^{3}$ significant implications will arise for a number of the College of Family Physicians of Canada (CFPC) stakeholders involved in medical education. This section highlights some important considerations for these groups.

\section{UNDERGRADUATE MEDICAL EDUCATION AND SCHOOLS OF MEDICINE}

Triple $\mathrm{C}$ is very much in sync with recommendation nine of The Future of Medical Education in Canada (FMEC): A Collective Vision for MD Education (FMEC MD): "Adopt a competency-based and flexible approach" ${ }^{4}$ :

Physicians must be able to put knowledge, skills, and professional values into practice. Therefore, in this first phase of the medical education continuum, MD education must be based primarily on the development of core foundational competencies and complementary broad experiential learning. In addition to pre-defined curriculum requirements, $M D$ education must provide flexible opportunities for students to pursue individual scholarly interests in medicine.

As schools of medicine gradually adopt a competency-based curriculum, learners and faculty will get acquainted early on with competency-based educational strategies, such as increased feedback, competency-based assessment, and ongoing monitoring of progression. This will impact positively on the implementation of Triple $\mathrm{C}$ programs over the coming years, as competency-based medical education increasingly becomes the general culture. Expertise and tools developed for family medicine residency programs around competency-based education might be helpful for each local school of medicine.

The introduction of CanMEDS-FM has given undergraduate family medicine educators a framework to organize their curricular content and its assessment. The Undergraduate Committee of the CFPC developed CanMEDS-FMU ${ }^{5}$ (CanMEDS-Family Medicine Undergraduate) to provide level-appropriate competencies organized under the CanMeds-FM roles. Medical students will benefit from having learning activities across specialties organized under the CanMEDS-based framework. ${ }^{6}$ There will also be added continuity of educational language and educational consistency from undergraduate through postgraduate medical education. This develops a learner who is well grounded in a generalist view that is consistent with the FMEC Postgraduate Project report (FMEC PG) ${ }^{7}$ recommendation five: "Ensure effective integration and transitions along the educational continuum."

Coordination of clinical resources for longitudinal experiences in undergraduate and postgraduate education, both at teaching hospitals and, particularly, community sites, becomes even more important in a competency-based medical educational system.

\section{POSTGRADUATE MEDICAL EDUCATION OFFICES}

The implementation of Triple $\mathrm{C}$ comes at a time when the postgraduate medical education system has endorsed the FMEC-PG. ${ }^{7}$ Triple $C$ aligns with the directions laid out by the FMEC PG report ${ }^{7}$ and indeed is one of the first specialty programs in Canada that is demonstrating a true competency-based approach to curriculum and assessment.

*Adapted from Frank JR, ed. The CanMEDS 2005 Physician Competency Framework. Better standards. Better physicians. Better care. Ottawa: The Royal College of Physicians and Surgeons of Canada; 2005. Available from: www.royalcollege.ca/portal/page/portal/rc/canmeds/resources/publications. Accessed 2013 Mar 3. 
The postgraduate deans have all advocated strongly in favour of all 10 of the recommendations of the FMEC PG report ${ }^{7}$ and thus will need to partner with residency programs such as family medicine to facilitate implementation of the recommendations. Two of the most critical changes that will be affected relate to the implementation of competency-based curriculum and competency-based assessment. The following are some key areas of potential impact that warrant further consideration by postgraduate deans and their offices in transitioning and adopting a competency-based approach to medical education in family medicine and across all specialties:

1. Policies on assessment, evaluation, remediation, and appeals that might have been based on time-based approaches to training will need to be reviewed. Some key questions for consideration might include the following:

- What evidence is required to support learner competence?

- How does the university and its programs define normal progression of achievement of competencies?

- What accommodations could be necessary to account for variations in time for learner acquisition of competence?

- What criteria should lead to permission to extend training in a competency-based curriculum?

- What criteria should lead to a decision for dismissal, based on lack of progression or major insufficiencies in one or more of the CanMEDS/CanMEDS-FM roles?

- How long should training be extended and what evidence must a resident demonstrate to justify extension?

- What are the key components, standards, and policies required of a competency-based assessment system supported by the university's postgraduate medical education dean's office?

2. Organizational structures, committees, and other educational policies in the postgraduate offices will need to be reviewed to align with competency-based medical education approaches. Impacts might vary from one school to another.

3. The relative importance of in-training assessments and summative assessments given by certification and licensing bodies as measures of the readiness to practise will need to be reconsidered. Those engaged in postgraduate medical education will need to reflect on their role in rendering judgment of competence and on how they can do so in a rigorous fashion, in a way that could stand up to legal challenge. Accountability becomes the basic expectation.

4. Resources for faculty development to help shift the type of teaching, learning, and assessment provided might require particular support from postgraduate medical education deans and offices during the start-up phases implementing Triple C. Coherence and collaboration with similar faculty development efforts in undergraduate medical education is recommended.

5. Since competency-based medical education will result in rigorous assessment of learners, the implementation of Triple $\mathrm{C}$ at a system level might result in a greater proportion of learners needing additional or specific exposure to various educational experiences in order to achieve required competencies. This will require careful planning of educational resources and perhaps the development of new resources to allow greater flexibility in the 
postgraduate education system. Coordination between undergraduate and postgraduate stakeholders using the same resources will become essential, especially in an era of increasing cohorts of students.

Given that family medicine is the largest, yet shortest and most dispersed, training program in postgraduate medical education across universities, there will be significant challenges in the implementation of competency-based medical education. Thus, it is critical to underscore the importance of the alignment of our program directors, department chairs, and postgraduate medical education deans toward Triple C, which reflects and shares the vision of competency-based medical education as described in the FMEC PG report. ${ }^{7}$ The timing of the implementation of Triple $C$ also aligns with that of the FMEC PG recommendations. It would be helpful for family medicine educators committed to Triple $\mathrm{C}$ to become familiar with the FMEC PG recommendations as the need for resources and policy change become apparent. The success of FMEC PG and Triple C are co-related. One of the first residency programs to truly adopt the competency-based medical education approach, the family medicine residency program will see issues with this competency-based approach, flagged first by many of the family medicine departments. The ability to strategize a collective movement for change, one supported nationally by medical educators and leaders, including the postgraduate deans, will be helpful in the coming years.

\section{LICENSING AUTHORITIES}

With the advancement of competency-based medical education, much development is being done on advanced processes for assessment throughout and at the end of residency. The advancement of competency-based medical education and developments in assessment should strengthen the licensing authorities' understanding of the rigour associated with the CFPC's certification process; they are also made to enhance social accountability for ensuring that family medicine residents have the ever-evolving competencies required for their specialty training to match the needs of the public. The FMEC PG report echoes this concept in its second recommendation: "Cultivate social accountability through experience in diverse learning and work environments." ${ }^{7}$

Ongoing dialogue will need to occur to apprise the licensing authorities of the integrated method of achieving competencies instead of one that just counts completed rotations to make judgments on training completion. Even learners without major academic difficulties might need further time to achieve a few competencies to be ready for independent practice. Within a competency-based medical education approach the notion of extended time does not necessarily equate to remediation. Rather, the length of program might vary from individual to individual and will need to be decided based on evidence of a learner's continued progression in attaining competence, even if at a slower rate. This shift might require review of policy and language at the level of each provincial and territorial licensing authority. The CFPC can help raise awareness of these issues at the national level, but specific discussions will also need to happen at a provincial level, led by academic departments of family medicine.

\section{PRACTISING FAMILY PHYSICIANS: CONTINUING PROFESSIONAL DEVELOPMENT AND TEACHING ROLES}

Through the definition of CanMEDS-FM roles, ${ }^{2}$ continuity and coherence of developing competence becomes even more important. The Triple C Competency-based Curriculum encourages learning along the continuum of undergraduate and postgraduate medical education and into practice, continually developing as physicians follow along their personal "trajectories" of professional competencies. The CanMEDS-FM roles help describe the unique professional identity of family physicians over their lifetimes. 
Offices of continuing professional development (CPD) should adopt the CanMEDS-FM roles framework $^{2}$ to develop their educational programs for family physicians. There is a role for CPD to help in developing programs for the use of chronic disease management tools; developing quality improvement tools; enhancing professionalism in practice; and expanding the family physician's medical expert role, especially in the evolving competencies highlighted in the paper on the Domains of Clinical Care. ${ }^{3}$ These are examples of how the CanMEDS-FM roles framework can help family physicians in practice. Increased competence in all CanMEDS-FM roles ${ }^{2}$ for the overall population of family physicians will definitely contribute to their role as clinical teachers, enabling them to become better role models, and to be fluent in the underlying concepts and skills.

\section{IMPACT ON FUNDERS OF FAMILY MEDICINE RESIDENCY EDUCATION}

At present, most residency programs are funded for a period of two years of training. Although this is the expected average period of training for most residents in order to achieve competencies, some trainees might require a further period of educational or clinical experiences to achieve readiness for practice. In Quebec, residents are funded to completion of their programs. The program can go beyond 24 months and is determined according to a series of specific criteria administered directly by program directors and overseen by the postgraduate dean's office and Collège des médecins du Québec, on behalf of the government. This working model could serve as an example for other provinces.

The chairs of family medicine, working closely with the program directors, must become keenly aware of the potential resource implications related to changes made to successfully implement Triple C. In

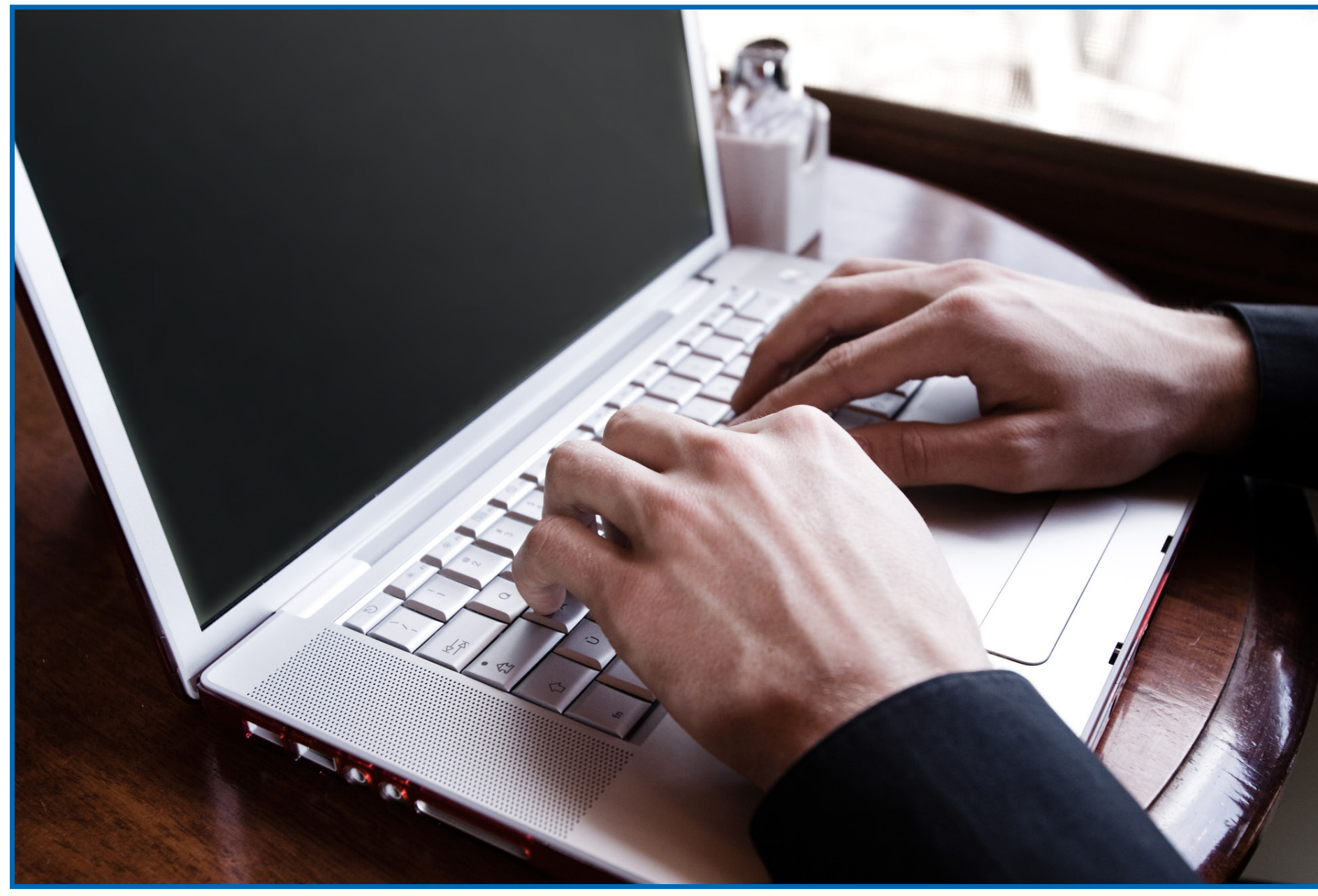


frameworks used, it will be important for the various organizations and universities to reflect on both the uniqueness and the commonalities among the specialties and certifying College approaches. Key principles for best practices for medical education can be created collectively, with collaboration, for implementation at the university program levels. Canada has an unprecedented opportunity to advance cutting-edge scholarship in the area of competency-based education with the work being done across the country by specialty colleagues and family medicine colleagues working both together and independently.

\section{IMPACT ON SOCIETY}

Both the FMEC MD ${ }^{4}$ and the FMEC $\mathrm{PG}^{7}$ emphasize the need for socially relevant and accountable medical education. For example, the first recommendation in the FMEC MD report, "Address individual and community," ${ }^{4}$ aligns with FMEC PG recommendation one, "Ensure the right mix, distribution and number of physicians to meet societal needs," and recommendation two, "Cultivate social accountability through experience in diverse learning and work environments." ${ }^{\prime 7}$ The FMEC MD report highlights that for medical education as a whole ${ }^{4}$ :

Social responsibility and accountability are core values underpinning the roles of Canadian physicians and Faculties of Medicine. This commitment means that, both individually and collectively, physicians and faculties must respond to the diverse needs of individuals and communities throughout Canada, as well as meet international responsibilities to the global community.

The Triple C curriculum was developed with these priorities in mind. The best training to prepare the family physicians needed by Canadians across the country will require adequate resources. Access to clinical models that allow family physicians to practise in an optimum, broad-based, interprofessional model will be critical for the future of family medicine. In order to make this possible, further work is needed in developing academic/clinical funding models that enable family medicine education to be provided in a competency-based manner in diverse communities. Triple $\mathrm{C}$ is a curriculum designed to produce family physicians who will be ready to work in Patient's Medical Home Models. ${ }^{11}$ Considering the vision of how family medicine should be practised in the future, the Patient's Medical Home model reflects an approach to care that is founded on the principles of comprehensiveness and continuity of patient-centred care. As the CFPC moves forward with the Patient's Medical Home, Triple C curriculum will ensure that family physicians are trained to work in such a model. CFPC's goal is to provide those advocating for a strong primary care system with a progressive approach, one that aligns both education and practice changes to reflect and meet the ever-changing needs of Canadians. 


\section{References}

1. Tannenbaum D, Kerr J, Konkin J, Organek A, Parsons E, Saucier D, et al. Triple C Competency-based Curriculum. Report of the Working Group on Postgraduate Curriculum Review - Part 1. Mississauga, ON: College of Family Physicians of Canada; 2011. Available from: www.cfpc.ca/uploadedFiles/ Education/_PDFs/WGCR_TripleC_Report_English_Final_18Mar11.pdf. Accessed 2013 Mar 3.

2. College of Family Physicians of Canada, Working Group on Postgraduate Curriculum Review. CanMEDS-Family Medicine: A Framework of Competencies in Family Medicine. Mississauga, ON: College of Family Physicians of Canada; October 2009. Available from: www.cfpc.ca/uploadedFiles/ Education/CanMeds\%20FM\%20Eng.pdf. Accessed 2013 Mar 3.

3. Tannenbaum D, Kerr J, Konkin J, Organek A, Parsons E, Saucier D, et al. The Scope of Training for Family Medicine Residency: Report of the Working Group on Postgraduate Curriculum Review. Mississauga, ON: College of Family Physicians of Canada; 2011. Available from: www.cfpc.ca/ uploadedFiles/Education/_PDFs/8\%20The\%20Scope\%20of\%20Training\%20for\%20Family\%20 Medicine\%20Residency_Domains\%20of\%20Clinical\%20Care\%20and\%20Evolving\%20 Professional\%20Competencies.pdf. Accessed 2013 Mar 3.

4. Association of Faculties of Medicine of Canada. The Future of Medical Education in Canada (FMEC): A Collective Vision for MD Education. Ottawa, ON: Association of Faculties of Medicine of Canada; 2010. Available from: www.afmc.ca/fmec/pdf/collective_vision.pdf. Accessed 2013 Mar 3.

5. College of Family Physicians of Canada, Undergraduate Education Committee. CanMEDS-FMU: Undergraduate Competencies from a Family Medicine Perspective. Mississauga, ON: College of Family Physicians of Canada; November 2009. Available from: www.cfpc.ca/uploadedFiles/ Education/CanMEDS-FMU_Feb2010_Final_Formatted.pdf. Accessed 2013 Mar 3.

6. Frank JR, ed. The CanMEDS 2005 Physician Competency Framework. Better standards. Better physicians. Better care. Ottawa: The Royal College of Physicians and Surgeons of Canada; 2005. Available from: http://www.royalcollege.ca/portal/page/portal/rc/canmeds/resources/publications. Accessed 2013 Mar 3.

7. Association of Faculties of Medicine of Canada. Future of Medical Education in Canada (FMEC) Postgraduate Report. A Collective Vision for Postgraduate Medical Education in Canada. Ottawa, ON: Association of Faculties of Medicine of Canada; 2012. Available from: http://www.afmc.ca/future-of-medical-education-in-canada/postgraduate-project/pdf/FMEC_ PG_Final-Report_EN.pdf. Accessed 2013 Mar 8.

8. Shaw L, Walsh A, Oandasan I, Kerr J, Konkin J, Organek A, et al. Resource implications for departments of family medicine: a discussion paper. In: Oandasan I, Saucier D, eds. Triple C Competency-based Curriculum Report - Part 2: Advancing Implementation. Mississauga, ON: College of Family Physicians of Canada; 2013. Available from: www.cfpc.ca/uploadedFiles/Education/_PDFs/TripleC_Report_pt2. pdf. Accessed 2013 Jul 29.

9. College of Family Physicians of Canada, Working Group on Certification Process. Defining Competence for the Purposes of Certification by the College of Family Physicians of Canada: The Evaluation Objectives in Family Medicine. Mississauga, ON: College of Family Physicians of Canada; 2010. Available from: www.cfpc.ca/uploadedFiles/Education/Definition $\% 20$ of $\% 20$ Competence $\% 20$ Complete\%20Document \%20with\%20skills\%20and\%20phases\%20Jan\%202011.pdf. Accessed 2013 Mar 3.

10. Oandasan I, Wong E, Saucier D, Donoff M, Iglar K, Schipper S. Triple C: linking curriculum and assessment. Can Fam Physician 2012;58:1165-1167. Available from: www.cfp.ca/ content/58/10/1165.full.pdf+html. Accessed 2013 Mar 3.

11. College of Family Physicians of Canada. A Vision for Canada. Family Practice - The Patient's Medical Home. Mississauga, ON: College of Family Physicians of Canada; 2011. Available from: http://www. cfpc.ca/A_Vision_for_Canada_Family_Practice_2011/. Accessed 2013 Mar 3. 
With the investment of time, resources, and energy toward implementing an enhanced approach to family medicine postgraduate education, it is imperative for the College of Family Physicians of Canada (CFPC) to evaluate the impact of the Triple C Competency-based Curriculum (Triple C). The CFPC and the 17 university family medicine residency programs have joint responsibility to help ensure that we have the right number of family physicians ready to practise comprehensive family medicine in any community in Canada. To this end, the CFPC has invested in the development and implementation of a longitudinal program evaluation plan. This section describes this plan in depth, in "A National Program Evaluation Approach to Study the Impact of Triple C." This discussion paper shares a logic model intended to help tell the story of implementation and impact, and includes the methods to be carried out through partnerships across the country. 



\title{
A National Program Evaluation Approach to \\ Study the Impact of Triple C
}

\author{
Authors \\ Ivy Oandasan, \\ on behalf of the \\ Triple C Competency Based Curriculum Task Force
}

Suggested Citation:

Oandasan I, on behalf of the Triple C Competency Based Curriculum Task Force. A national program evaluation approach to study the impact of Triple C. In: Oandasan I, Saucier D, eds. Triple C Competency-based Curriculum Report - Part 2: Advancing Implementation. Mississauga, ON: College of Family Physicians of Canada; 2013. Available from: www.cfpc.ca/uploadedFiles/Education/_PDFs/ TripleC_Report_pt2.pdf. Accessed 2013 Jul 29. 


\section{BACKGROUND}

Family medicine is prepared to evaluate whether or not the Triple C Competency-based Curriculum (Triple C) is meeting the mark. The goal of family medicine residency programs in Canada is to ensure that graduates are ready to begin practice in the specialty of family medicine in any community in Canada. The College of Family Physicians of Canada (CFPC), in partnership with the 17 universitybased family medicine residency programs in Canada, has started to implement Triple C. Triple C aims to provide education to family medicine residents that is comprehensive in scope, focused on continuity of care and education, and through learning that is centred in family medicine. ${ }^{1}$ Its intent is to ensure that new family physicians entering practice are ready to meet the evolving needs of Canadians.

To fulfill its social accountability to produce family physicians who meet the needs of the Canadian population, it is important that the academic family medicine community determine what role Triple $\mathrm{C}$ can have in influencing the type of family physicians produced, their type of practice patterns, and their location of practice. Family physicians who are able to provide comprehensive care and continuity of care focused on quality, and who are working in models of care that improve access and efficiencies, are key to the future of the health care system. This discussion paper provides a description of the program evaluation plan and logic model developed and approved in 2012 to describe the influence and impact of Triple C.

\section{THE CONTEXT OF FAMILY MEDICINE EDUCATION IN CANADA}

The role of the postgraduate education system in Canada is to ensure that we have sufficient numbers of family physicians and other specialists who are distributed across the country and ready to provide care that responds to the ever-changing needs of Canada's dispersed population. The 17 universitybased family medicine residency programs have collaborated extensively with the CFPC to provide family medicine education to more than 2,300 residents annually in more than 150 clinical training sites across Canada. Family medicine is the largest postgraduate residency program housed in each of the universities' faculties of medicine in Canada.

\section{Impact of family medicine on care}

Evidence indicates that a strong primary care system that provides the population with access to effective primary care providers is correlated with better population health outcomes, ${ }^{2}$ lower overall costs for patients with chronic disease, ${ }^{3}$ reduced morbidity for patients who have multiple providers, ${ }^{4}$ and enhanced ways to mitigate some of the negative impacts of social inequities. ${ }^{4}$ Starfield and Shi (2004) found that medical services provided and coordinated by the patient's own personal primary care provider and team produces better health outcomes. ${ }^{2}$ With this and other evidence in mind, the CFPC launched A Vision for Canada, ${ }^{5}$ which strives for every person in Canada to have access to a family practice/primary care setting that serves as their medical home. The Patient's Medical Home (PMH) concept reflects the CFPC's goal to ensure that every Canadian has access to quality, focused health care through teams of health care professionals working collaboratively with family physicians in practices modeled after the $\mathrm{PMH}$ concept. ${ }^{5}$ The $\mathrm{PMH}$ is the central hub for the timely provision and coordination of the comprehensive menu of health and medical services patients need. ${ }^{5}$ The move toward the PMH comes at the same time as the CFPC advances its enhanced approach to family medicine residency education training. Triple $\mathrm{C}$ aims to ensure graduates are ready to begin the practice of comprehensive family medicine, ideally within a health care system that enables them to provide this type of care. From a practice level, the vision of the $\mathrm{PMH}$ provides one solution that can help support graduates of tomorrow. 


\section{Family medicine education and its role in social accountability}

Triple C was born from the need to identify the future needs of Canadians and to create a competencybased curriculum that would reflect and respond to these needs. ${ }^{1}$ With the dedication of significant time and financial resources to the implementation of this new approach to education, it is critical to determine its impact. In an era that requires evidence more than rhetoric, a robust program evaluation is essential. With this in mind, the CFPC has launched an implementation plan based upon a logic model presented in this paper.

\section{DEVELOPING THE PROGRAM EVALUATION PLAN}

The Triple C Competency Based Curriculum Task Force (Triple C Task Force), reporting to the CFPC's Section of Teachers Council, was charged with overseeing the development and implementation of a program evaluation plan for Triple C. Program evaluation implies the rigorous collection of valid, reliable, and useful information about a program for the purposes of one or more of the following: program and organizational improvement, oversight and compliance, assessment of merit or worth, and knowledge development. ${ }^{6}$ The overarching purpose of Triple $C$ program evaluation is to help the CFPC make decisions related to ongoing support for this enhanced approach to family medicine residency education. For this reason, a utilization-focused program evaluation plan ${ }^{7}$ is being used with a threefold purpose:

1. To inform decisions about the Triple $C$ curriculum as it is implemented

2. To understand the impact of Triple $C$ on residents, faculty, departments, and the discipline of family medicine in Canada

3. To share lessons learned from implementation of a competency-based curriculum

Cathexis Consulting Inc. (http://cathexisconsulting.ca/) was hired to help create the plan with the Triple C Competency Based Curriculum Task Force (Triple C Task Force). It undertook a series of steps to create the recommended evaluation plan outlined in this paper.

\section{PROGRAM ACTIVITIES}

Family medicine residency programs have already begun to transform their curricula and assessment methodologies across the country. Figure 1 provides a visual depiction of this process. Three basic building blocks exist for successful implementation of Triple C, which should be integrated and aligned:

1. Defining the educational outcomes that residents must achieve in order to successfully complete their programs. Educational outcomes should be based on the CanMEDS-Family Medicine (CanMEDS-FM) Roles*8 and/or the Evaluation Objectives ${ }^{9}$ (ie, skills dimensions, phases of clinical encounter, priority topics, and key features).

2. Developing a full range of learning opportunities and contexts that will enable residents to achieve the defined educational outcomes. The opportunities and contexts should be intentional and should be comprehensive, allow for continuity of care and education, and be centred in family medicine. They should also reflect the clinical domains of family medicine.

*Adapted from Frank JR, ed. The CanMEDS 2005 Physician Competency Framework. Better standards. Better physicians. Better care. Ottawa: The Royal College of Physicians and Surgeons of Canada; 2005. Available from: http://www.royalcollege.ca/portal/page/portal/rc/canmeds/resources/publications Accessed 2013 Apr 21. 
3. Establishing and embedding competency-based assessment processes into the curriculum that allow for ongoing formative assessment of learners. This step supports reflective learning and enables the resident and preceptors to identify and fill learning gaps early on in the resident's experience. It also supports a meaningful assessment of the resident's competence defined the end of residency.

In addition to these three basic building blocks, several factors have been identified as critical to implementation:

- Building institutional support from senior leaders in the organization ensures that adequate resources are available to facilitate the change

- Faculty development will enable clinical teachers to fulfill expectations and enhance teaching methods that align with a competency-based approach

- As active learners, residents can take on enhanced responsibility for their learning, with teachers functioning more as guides or coaches

- Partnerships and networks within and between programs will ease sharing of knowledge and tools, which will facilitate the development and spread of effective practices

As shown in Figure 1, implementation of Triple $C$ is neither a one-time event nor a linear process. It is an iterative, cyclical process of planning, implementing, evaluating, and course correcting that will occur over time. It also involves sharing successes and lessons learned with the broader family medicine education community.

\section{Figure 1. Process for Triple $C$ implementation within family medicine residency programs}




\section{ANTICIPATED OUTCOMES OF TRIPLE C}

Figure 2 shows a "logic model" for Triple C, which demonstrates how the activities of the CFPC and the postgraduate family medicine programs are intended to produce specific short- and longer-term outcomes. The logic model provides a framework for what an activity aims to achieve. In creating the logic model for Triple $\mathrm{C}$, interviews were conducted with key stakeholders including leaders at the CFPC, university program directors, postgraduate deans, family medicine residents, and CFPC education committee members. A limited literature review on evaluation of competency-based curriculum and curriculum change was conducted. ${ }^{10-17}$ Finally, the authors undertook an extensive review of the CFPC documents related to elements of Triple C.

With respect to changes in programming, the short-term outcomes identified in the logic model reflect the immediate benefits anticipated for residents, new graduates, and faculty. These outcomes will likely start to be seen between 2014 and 2017, as the programs begin to change and the first cohorts of Triple $\mathrm{C}$ residents graduate. It is anticipated that these short-term outcomes will have positive impacts on the practice of family physicians, the CFPC, and the broader discipline of family medicine.

Along with other CFPC initiatives, Triple C should ultimately support CFPC's end goal of family physicians practising quality-focused comprehensive and continuing care through models like the Patient's Medical Home. Influenced by system factors (highlighted in yellow in the outer edges of Figure 2), the CFPC recognizes that Triple $C$ is being developed and implemented within a broader context with factors beyond its control. Some of these factors include trends in medical education, availability of resources, the culture of current family practice settings, the regulatory environment, changes in the needs and expectations of the Canadian public, and trends in Canadian health care. These factors must be taken into consideration when interpreting potential outcomes related to Triple C. Although there will not be a way to show causation, the hope is that program evaluation will help to provide evidence of attribution related to Triple C. It is expected that over time, the outcomes might become more refined, and that the present logic model and program evaluation plan could change in response to further input from stakeholders. 
Figure 2. Triple C logic model: A living document

CONTEXTUAL FACTORS SUCH AS

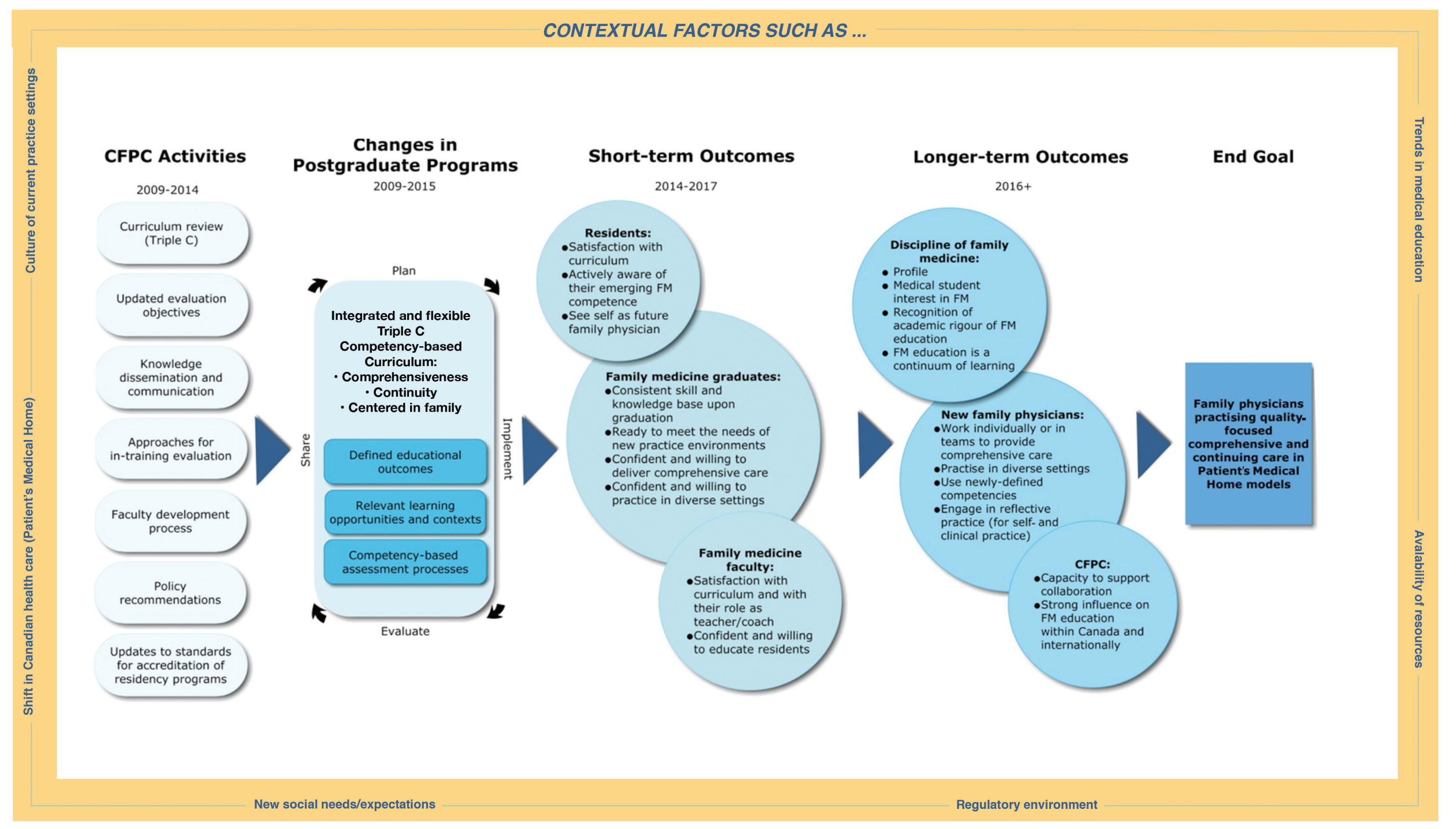




\section{THE PROGRAM EVALUATION PLAN}

The evaluation plan for Triple $\mathrm{C}$ was created to provide an understanding of the following:

1. The process of implementing Triple C: critically assessing its implementation in order to make further decisions about Triple C, improve elements of the curriculum, and fill knowledge gaps about competency-based education

2. Impact of Triple C: considering both short- and long-term outcomes on learners, faculty, the discipline, and the College itself

The program evaluation plan is national in scope; it aims to look for patterns and trends across all of the 17 family medicine programs and their clinical sites. It will not evaluate any of the programs or sites individually, although it will provide tools and generate data that the individual programs or sites can use for quality improvement.

The questions in Box 1 were approved by the Triple C Task Force to help guide the evaluation design, data collection, analysis, and reporting.

\section{Box 1. Triple $C$ program evaluation questions}

1. How has the Triple $C$ curriculum been implemented at each of the 17 family medicine programs and clinical sites?

2. What implementation supports were provided by the CFPC, and how useful were they?

3. What lessons have been learned about effective implementation of Triple C?

4. What more is needed to support full implementation and sustainability of Triple C across Canada?

5. To what extent are intended short-term outcomes achieved for the following:
a) Residents?
b) Family medicine faculty?
c) Family medicine graduates?

6. To what extent are intended longer-term outcomes achieved for the following:
a) New family physicians?
b) The discipline of family medicine?
c) CFPC?

7. To what extent has Triple $C$ contributed to changes in the intended outcomes?

8. What unintended outcomes have been observed?

\section{Data collection}

Data for the program evaluation process is to be collected from a variety of stakeholders using a mixed-methods approach ${ }^{18}$ (see Figure 3). The use of qualitative approaches to enable a dialogue with stakeholders is planned and should address evaluation questions 1 to 4 . A process will be needed that 
helps to uncover levels of implementation of the various elements of the Triple C by program. Use of the process on an ongoing basis by the family medicine programs will determine how and when Triple $C$ is fully implemented by each program. The development of a "Triple C Residency Program Implementation Inventory" is being explored at this time.

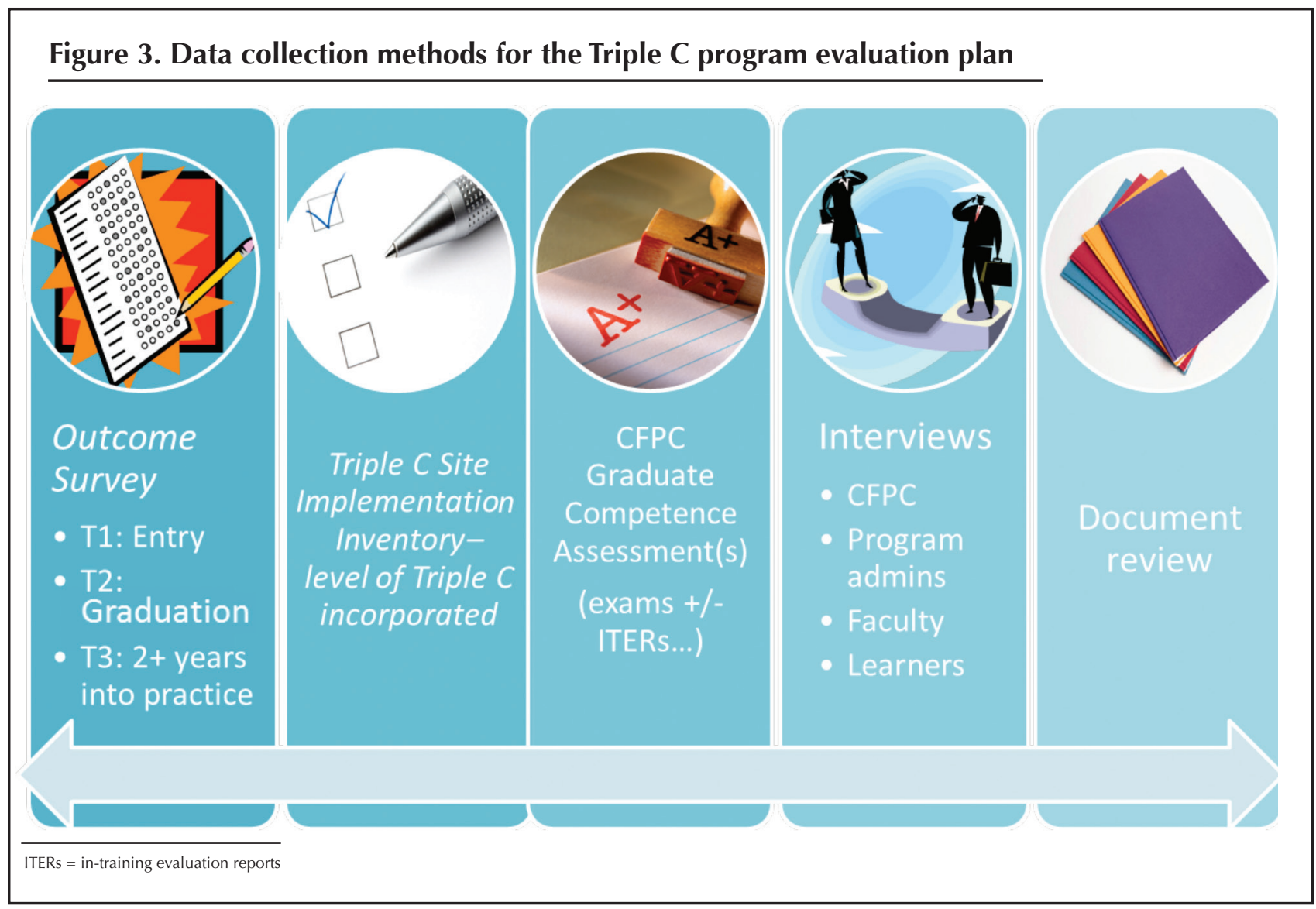

To determine the potential outcomes of Triple C (evaluation questions 5 to 8), a means to track residents longitudinally from entrance into residency, graduation, and through to early independent practice is needed. A longitudinal survey tracking resident perspectives on Triple $\mathrm{C}$ and intentions to practise, starting from entrance into residency through to early independent practice, is currently at the pilot stage. Longitudinal surveys obtain data from learners highlighting potential short- and longterm outcomes. The Triple C Working Group for Survey Development at the CFPC has been initiated to help implement the survey pilot process. The Triple C Working Group for Survey Development will highlight findings of their work in future publications.

Program evaluation of Triple $C$ is expected to be carried out over a 10+ year period. The years 2012 to 2013 will see family medicine programs develop and test the program evaluation methods, with the collection of baseline information anticipated in 2013. Data will continue to be collected periodically until approximately 2022. In the early years of the evaluation, the focus will be primarily on the implementation of Triple C, as well as on shorter-term outcomes. The information needs of CFPC, the family medicine programs, and other stakeholders could evolve over the course of the evaluation. Therefore, the evaluation plan will be developmental in nature. Based on the work of Patton (2008), ${ }^{7}$ the evaluation will evolve so that it can be responsive to the changing context of family medicine and family medicine education. As Triple $\mathrm{C}$ becomes better established, the focus of the evaluation will shift to longer-term outcomes, allowing us to assess the degree to which Triple $\mathrm{C}$ addresses its original goals. 


\section{Analysis}

Because all of the residency programs will be implementing Triple $\mathrm{C}$ at a different pace, an experimental design cannot be used to evaluate its impact. Some programs and clinical sites have already begun to implement aspects of Triple C, while others have not. ${ }^{19}$ An opportunity to describe programs according to level of implementation of Triple $C$ is currently being examined. By clustering programs in this way, we will have a mechanism to compare and contrast differences and similarities across programs and to assess associations with learner outcome data from the longitudinal survey. Hypothetically, improvements in outcomes could be observed from the early adopters, then among the early majority, and finally, among the remaining programs.

Changes in outcomes might be difficult to interpret. Even with examining outcomes by implementation level, it will be challenging to draw conclusions about the impact of Triple C. There are many external factors that will have an impact on the desired outcomes and that will change the interpretation of the findings. For example, many of the contextual factors written around the edge of the logic model (Figure 2) point to paying attention to trends in medical education, funding, culture in current practice settings, regulatory environment, new societal needs and expectations, and shifts in Canadian health care. It will be important to collect information about these factors, and to take them into account when analyzing and interpreting the outcomes data.

Using the data collected from all methods, results will be interpreted with more rigour. Consistent evidence from different sources builds confidence in the results. In contrast, discrepancies among the findings from different sources require further exploration to determine the cause.

\section{FAMILY MEDICINE'S OPPORTUNITY}

The program evaluation plan for the Triple C Competency-based Curriculum is the first that we are aware of to use a national approach to determine the impact of residency programs in family medicine. It is hoped that through what is learned, we will be able to identify what influence Triple C might have on education and the health care system in general. These success factors will need to be shared. Where critical challenges surface, the CFPC welcomes the opportunity to attempt to address them, in order to correct the course of Triple $C$ and support our colleagues across the country who are committed to enhancing family medicine education. The opportunity to assess the influence of this curriculum on graduates, through the longitudinal survey, allows the CFPC and its university partners to understand the impact of education on the type of family physicians developed. The practice patterns can help us better understand if curriculum is able to influence both the type of family medicine practised (comprehensive vs focused) and the location of practice (any community in Canada). Ultimately, the data collected will provide perspectives on the impact of family medicine education on patient outcomes and system efficiencies.

\section{ACKNOWLEDGEMENTS}

The author wishes to acknowledge the contributions of Cathexis Consulting, Inc.and the individual members of the Triple C Competency Based Curriculum Task Force involved in the development and implementation of the national program evaluation plan: Eric Wong (Chair), Elaine Blau, Fraser Brenneis, Teresa Cavett, Cathy Cervin, Tom Crichton, Nancy Fowler, Roger Ladouceur, David LaPierre, Cathy MacLean, Louise Nasmith, Danielle Saucier, Salvatore Spadafora, David Tannenbaum, and Allyn Walsh. The members of the Triple C Working Group for Survey Development also contributed greatly through their work on the longitudinal survey: Douglas Archibald, Louise Authier, Laura McEwen, María Palacios, Shelley Ross, and Steve Slade. 


\section{References}

1. Tannenbaum D, Kerr J, Konkin J, Organek A, Parsons E, Saucier D, et al. Triple C CompetencyBased Curriculum. Report of the Working Group on Postgraduate Curriculum Review - Part 1. Mississauga, ON: College of Family Physicians of Canada; 2011. Available from: www.cfpc. ca/uploadedFiles/Education/_PDFs/WGCR_TripleC_Report_English_Final_18Mar11.pdf. Accessed 2013 Apr 21.

2. Starfield B, Shi L. The medical home, access to care, and insurance: a review of evidence. Pediatrics 2004;113(5 Suppl):1493-1498.

3. Hollander $\mathrm{M}$, Kadlec $\mathrm{H}$, Hamdi $\mathrm{R}$, Tessaro A. Increasing value for money in the Canadian healthcare system: new findings on the contribution of primary care services. Healthc $Q$ 2009;12(4):32-44.

4. Starfield B, Chang HY, Lemke KW, Weiner JP. Ambulatory specialist use by nonhospitalized patients in US health plans: correlates and consequences. J Ambul Care Manage 2009;32:216-225.

5. College of Family Physicians of Canada. A Vision for Canada: Family Practice - The Patient's Medical Home. Mississauga, ON: College of Family Physicians of Canada; 2011. Available from: http://www.cfpc.ca/A_Vision_for_Canada_Family_Practice_2011/. Accessed 2013 Apr 21.

6. Mark M, Henry G, Julnes G. Evaluation: An Integrated Framework for Understanding, Guiding, and Improving Policies and Programs. San Francisco, CA: Jossey-Bass; 2000.

7. Patton MQ. Utilization Focused Evaluation. 4th ed. Los Angeles, CA: Sage Publications; 2008.

8. College of Family Physicians of Canada, Working Group on Curriculum Review. CanMEDSFamily Medicine: A Framework of Competencies in Family Medicine. Mississauga, ON: College of Family Physicians of Canada; October 2009. Available from: www.cfpc.ca/ uploadedFiles/Education/CanMeds\%20FM\%20Eng.pdf. Accessed 2013 Apr 21.

9. College of Family Physicians of Canada, Working Group on Certification Process. Defining Competence for the Purposes of Certification by the College of Family Physicians of Canada: The Evaluation Objectives in Family Medicine. Mississauga, ON: College of Family Physicians of Canada; 2010. Available from: www.cfpc.ca/uploadedFiles/Education/Definition\%20 of $\% 20$ Competence $\% 20$ Complete $\% 20$ Document $\% 2$ with $\% 20$ skills $\% 20$ and $\% 20$ phases $\% 20$ Jan\%202011.pdf. Accessed 2013 Apr 21.

10. Hodges BD. A tea-steeping or i-Doc model for medical education? Acad Med 2010;85(9 Suppl): S34-S44.

11. Talbot M. Monkey see, monkey do: a critique of the competency model in graduate medical education. Med Educ 2004;38:587-592.

12. The Royal Australian College of General Practitioners. The RACGP Curriculum for Australian General Practice 2011. Available from: http://www.racgp.org.au/curriculum. Accessed 2011 Feb 17.

13. Rees CE. The problem with outcomes-based curricula in medical education: Insights from educational theory. Med Educ 2004;38:593-598. 
14. Miller GE. The assessment of clinical skills/competence/performance. Acad Med 1990;65 (9 Suppl): S63-S67.

15. Allan GM, Korownyk C, Tan A, Hindle H, Kung L, Manca D. Developing an integrated evidence-based medicine curriculum for family medicine residency at the University of Alberta. Acad Med 2008;83:581-587.

16. Epstein RM, Hundert EM. Defining and assessing professional competence. J Am Med Assoc 2002;287:226-235.

17. Bland CJ, Starnaman S, Wersal L, Moorhead-Rosenberg L, Zonia S, Henry R. Curricular change in medical schools: How to succeed. Acad Med 2000;75:575-594.

18. Creswell JW, Plano Clark VL. Designing and Conducting Mixed Methods Research. 2nd ed. Thousand Oaks, CA: Sage; 2011.

19. Wong $\mathrm{E}$, on behalf of the Triple C Competency Based Curriculum Task Force. Reflections from the Triple C Task Force. In: Oandasan I, Saucier D, eds. Triple C Competency-based Curriculum Report - Part 2: Advancing Implementation. Mississauga, ON: College of Family Physicians of Canada; 2013.Available from: www.cfpc.ca/uploadedFiles/Education/_PDFs/ TripleC_Report_pt2.pdf. Accessed 2013 Jul 29. 
After nearly a decade of planning, the Triple C Competency-based Curriculum (Triple C) was officially launched in 2011. The first paper in this section, entitled "Transitioning to Triple C: Residency Program Perspectives From 2009 to 2010," provides evidence of family medicine residency programs already moving toward Triple $C$ even before the official recommendations were released in Triple C Competency-based Curriculum Report - Part 1.

By 2013, it was clear that implementation of the curriculum had begun across all 17 university-based family medicine programs in Canada. The success of this implementation can be attributed to the leadership from the Triple C Competency Based Curriculum Task Force (Triple C Task Force), which reports to the College of Family Physicians of Canada's (CFPC's) Section of Teachers Council. In this section, "Reflections From the Triple C Task Force" highlights the four-year mandate and activities of the Task Force. The accomplishments of the Triple C Task Force to date, along with its plans for the last two years of its mandate, are also shared in this paper. It is clear that ongoing curriculum review will be needed to ensure that family medicine fulfills its role in developing family physicians who meet the needs of Canadians on a yearly basis.

The changes made by the introduction of Triple $C$ will be longstanding. In the final paper of Triple C Report - Part 2, reflections are provided by the editors as an epilogue in "Triple C: Looking Ahead." This paper discusses the impact on medical education and the health care system in general, in Canada and beyond. The strength of the collaboration between the CFPC and the 17 departments of family medicine is unprecedented. Discussing the scholarly approach to leveraging the use of a program evaluation plan, the attention to stakeholder buy-in with an emphasis on change management strategies, and the opportunity to communicate the uniqueness of the discipline of family medicine through Triple C - this final chapter summarizes the story of implementing curriculum reform in Canada, with a call for continued action. The commitment to ongoing quality enhancements to family medicine education is evidenced in the sustainable processes that are being put into place. Triple $C$ is a critical part of the evolution of family medicine in Canada and demonstrates the CFPC's continued contribution to the provision of excellence in care offered to Canadians. 



\title{
Transitioning to Triple C: Residency Program
} Perspectives

From 2009 to 2010

Authors

\author{
Jonathan Kerr, Danielle Saucier, Eric Wong, \\ jill Konkin, Andrew Organek, Ean Parsons, \\ Liz Shaw, David Tannenbaum, Allyn Walsh
}

Suggested Citation:

Kerr J, Saucier D, Wong E, Konkin J, Organek A, Parsons E, et al. Transitioning to Triple C: residency program perspectives from 2009 to 2010. In: Oandasan I, Saucier D, eds. Triple C Competencybased Curriculum Report - Part 2: Advancing Implementation. Mississauga, ON: College of Family Physicians of Canada; 2013. Available from: www.cfpc.ca/uploadedFiles/Education/_PDFs/ TripleC_Report_pt2.pdf. Accessed 2013 Jul 29. 


\section{INTRODUCTION}

Creating change is rewarding but demanding, a process that moves through many stages. To facilitate and monitor the complex process of curricular change in family medicine programs across Canada, the College of Family Physicians of Canada's (CFPC's) Working Group on Postgraduate Curriculum Review (WGCR) carried out two surveys of family medicine program directors. The first survey was conducted in 2009, before the publication of the WGCR's first report ${ }^{1}$ on Triple C Competency-based Curriculum (Triple C). The second survey followed in 2010, after the report had been released to the program directors.

In this discussion paper, we present summaries of the surveys' results, which show the significant progress Canadian family medicine programs have made in implementing the Triple $\mathrm{C}$ concepts.

\section{SCANNING THE LANDSCAPE: 2009 SURVEY}

To determine the extent to which Triple C competency-based concepts were already embodied within the curricula of Canadian family medicine residency programs, the WGCR surveyed program directors in the fall of 2009, before it released the Triple C Report - Part 1. ${ }^{1}$ (See Appendix A for the survey's methodology and data.)

The results provide evidence that prior to 2009 many family medicine residency programs in Canada had already implemented some curricular elements directly aligned with the $\underline{\mathrm{C}}$ of the Triple C:

comprehensiveness, continuity of care and education, and centred in family medicine. ${ }^{1}$ The alignment most frequently reported was the regular offering of family medicine-oriented clinical experiences with positive role models, either family physicians or family medicine-friendly consultant specialists. This response indicated that most programs already shared an understanding of the need for the third $\underline{\mathrm{C}}$, that curriculum be centred in family medicine. Involving residents in "comprehensive care" and efforts to offer "continuity of care" also seemed to be regular features in most programs.

Content addressed within academic programming, such as behavioural medicine, demonstrated that family medicine programs also already understood the need to develop residents' competencies within all CanMEDs-Family Medicine (CanMEDS-FM) Roles, ${ }^{* 2}$ and to not limit their focus to clinical expertise. Many content-specific areas focused on developing competencies defined by the same frameworks on which Triple $\mathrm{C}$ is built, and these areas emerged as the most widespread evidence of "competency-based" elements being taught in 2009, before the actual launch of Triple C.

These findings suggest that some of the characteristics of the Triple $C$ concepts, though not yet propagated as a formal curriculum, were recognized by programs and their directors as ways to advance family medicine education. This synchronicity is not surprising because the Four Principles of Family Medicine ${ }^{3}$ have guided all curricular recommendations in the past, and continue to do so, with enhancements as suggested by Triple C.

Some programs were already actively moving toward a competency-based approach to family medicine curriculum in 2009. Pilot projects in competency-based assessment were under way and a few programs were planning an academic curriculum based on competencies. The reorganizing of a competency-based curriculum rarely included changes to program structure. Experimentation with integrated curricula occurred at individual sites rather than throughout entire programs. Terms like "comprehensiveness of education" and "continuity of education" were never mentioned explicitly as critical components of family medicine education, though some reports alluded to these characteristics.

Overall, the data shared in the survey describe the starting point of the residency programs in family medicine in Canada in 2009.

*Adapted from: Frank JR, ed. The CanMEDS 2005 Physician Competency Framework. Better standards. Better physicians. Better care. Ottawa: The Royal College of Physicians and Surgeons of Canada; 2005. Available from: http://www.royalcollege.ca/portal/page/portal/rc/canmeds/resources/publications. Accessed 2013 May 31. 


\section{LAUNCHING TRIPLE C}

Against this setting, the Triple C Competency-based Curriculum was formally launched in 2010 by the CFPC, beginning a new era of change.

In 2009, the College released Part 1 of the WGCR's interim report ${ }^{4}$ on Triple C, and began a fouryear process (2009 to 2012) of presenting Triple C to all family medicine residency program directors during their annual national meetings. The College expected the programs to engage in significant curricular transformations, in keeping with the directions for change indicated in the report and endorsed by the CFPC. Revised accreditation guidelines for postgraduate residency programs in family medicine (an update to the Red Book ${ }^{5}$ ), aligned with the Triple C perspective, were under development and were since published in $2013 .{ }^{6}$ These activities ensured that family medicine residency programs were aware of the CFPC's expectations that they would implement a Triple C curriculum.

As discussed in "Facilitating Curriculum Change: Moving to a Triple C Competency-based Curriculum," engaging in curricular change represents a complex endeavour. One year after the official start of the national Triple C process, the WGCR planned to survey family medicine residency programs again, to assess their progress in implementing Triple C.

\section{RESHAPING THE LANDSCAPE: 2010 SURVEY}

At the second CFPC Program Directors' Retreat (Mississauga, Ont., December 2010), all participants (key educational leaders, as well as most family medicine residency program directors) were invited to self-assess their programs' level of change to Triple C. Each respondent completed a standardized survey (Appendix B) adapted from Dannefer and Henson's questionnaire ${ }^{7}$ measuring institutional adoption of competency-based education, in turn modeled on Prochaska and DiClemente's stages of change. ${ }^{8}$

The respondents were asked to identify their programs, and to indicate if they were the program directors.

\section{Survey data}

This section highlights the findings from residency program directors who completed the questionnaire. Sixteen of the 17 program directors provided a response. Figure 1 shows a summary of results. Please see Table 1 for a brief description of each stage of progression. According to this survey, as of December 2010, the majority of Canadian family medicine residency programs were actively engaged in design and development (stage 3 change), with some in an early phase and some in an advanced stage. One program was considered by its program director to be at the resistance stage (stage 1), and one program self-assessed as being engaged in initiation (stage 2). Two programs considered themselves to be engaged in the implementation (stage 4). 


\section{Figure 1. Program directors' response to Triple $C$ change}

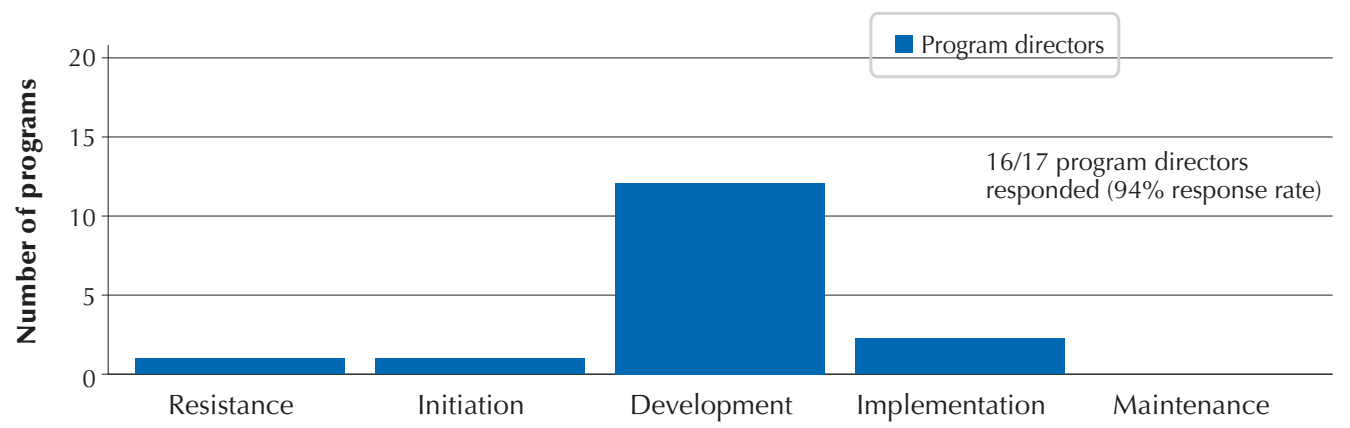

Table 1. Stages of institutional progression toward competency-based education

\begin{tabular}{ll} 
Stage & Description \\
\hline 1 & Resistance \\
2 & Initiation \\
3 & Design and development \\
4 & Implementation \\
5 & Maintenance and evaluation \\
\hline
\end{tabular}

Adapted from Dannefer E, et al. Workshop presented at AMEE Conference. Glasgow, UK; 2010

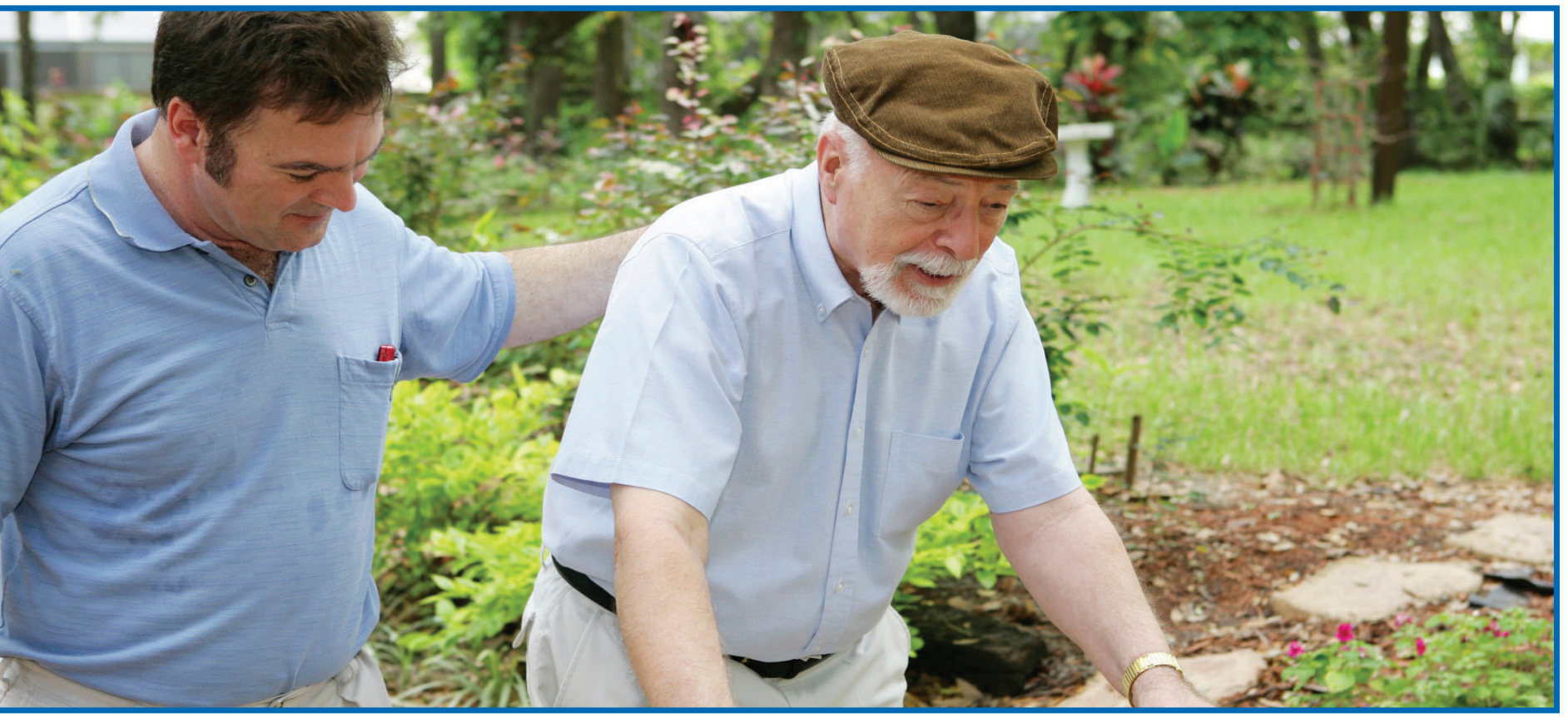




\section{DISCUSSION}

As of December 2010, according to Canadian family medicine residency programs' self-assessment, many programs were actively engaged in implementing a Triple $\mathrm{C}$ competency-based curriculum, making rapid institutional progress.

While changes were occurring at the decisional level of most programs, it was far less certain whether or not the majority of faculty and preceptors were acting on the innovations. Furthermore, it was unclear whether or not the Triple $C$ concepts were understood at the level of desirable but still theoretical objectives, or as a paradigm shift that would require an executable plan affecting daily teaching and learning activities.

These results demonstrate the educational dynamics of Canadian family medicine residency programs and the programs' readiness for change. They also suggest that the Triple $\mathrm{C}$ recommendations were regarded as highly relevant and in accordance with programs' perceived needs for educational change.

Finally, these results provide some evidence of the relevance and effectiveness of CFPC's communication strategies with programs around the Triple $C$ and the WGCR's recommendations. At the time of writing, additional support strategies were being developed by the CFPC to help engage and empower programs to make these institutional changes widespread. The CFPC's Triple C Competency Based Curriculum Task Force was struck in 2010 to carry out the necessary oversight to help residency programs advance the changes required to successfully implement Triple $C$ ("Reflections From the Triple C Task Force" describes the oversight experience).

\section{CONCLUSION}

These surveys capture two discrete moments in time describing the state of family medicine training in Canada. Many new innovations have been implemented since these surveys were completed. The WGCR recognizes that the Triple C landscape is continually evolving in this exciting period of growth for the family medicine discipline. 


\section{References}

1. Tannenbaum D, Kerr J, Konkin J, Organek A, Parsons E, Saucier D, et al. Triple C CompetencyBased Curriculum. Report of the Working Group on Postgraduate Curriculum Review - Part 1. Mississauga, ON: College of Family Physicians of Canada; 2011. Available from: www.cfpc. ca/uploadedFiles/Education/_PDFs/WGCR_TripleC_Report_English_Final_18Mar11.pdf. Accessed 2013 Apr 18.

2. College of Family Physicians of Canada, Working Group on Curriculum Review. CanMEDSFamily Medicine: A Framework of Competencies in Family Medicine. Mississauga, ON: College of Family Physicians of Canada; October 2009. Available from: www.cfpc.ca/ uploadedFiles/Education/CanMeds\%20FM\%20Eng.pdf. Accessed 2013 Apr 18.

3. College of Family Physicians of Canada. Four principles of family medicine. College of Family Physicians of Canada. 2006. www.cfpc.ca/Principles/. Accessed 2013 Apr 18.

4. Crichton T, Allen T, Bethune C, Brailovsky C, Donoff M, Laughlin T, et al. Interim Report to the Board of Examiners from the WGCP: Initial Recommendations for Changes to ITE for the Purposes of Certification. Mississauga, ON: College of Family Physicians of Canada; 2009.

5. College of Family Physicians of Canada. Standards for Accreditation of Residency Training Programs: Family Medicine; Emergency Medicine; Enhanced Skills; Palliative Medicine. Mississauga, ON: College of Family Physicians of Canada; 2006.

6. College of Family Physicians of Canada, Academic Family Medicine Department. Specific Standards for Family Medicine Residency Programs Accredited by the College of Family Physicians of Canada: The Red Book. Mississauga, ON: College of Family Physicians of Canada; 2013. www.cfpc.ca/uploadedFiles/Red\%20Book\%20English.pdf. Accessed 2013 Apr 18.

7. Dannefer E, Henson L. Diagnosing and treating barriers to implementation in competency based education. Workshop presented at: Association for Medical Education in Europe 2010 Annual Conference; September 7, 2010; Glasgow, UK.

8. Prochaska JO, DiClemente CC. Stages and processes of self-change of smoking: toward an integrative model of change. J Consult Clin Psychol 1983;51:390-395. 


\section{Appendix A: 2009 Survey}

\section{METHODOLOGY}

In September 2009, an email was sent to family medicine program directors asking them to describe via an online survey the actual state of implementation of a Triple C-aligned competency-based curriculum at their institution. A follow-up email was sent in November 2009.

The survey explored the following key curricular elements:

- Program organization and structure

- Clinical experiences

- Academic teaching

- One-on-one teaching and supervision

- Assessment of residents

Program directors were asked to engage key colleagues in the self-assessment of their programs. Every participant was asked to briefly describe individual initiatives within the institution's programs, key element by element. These responses were collated and then analyzed qualitatively by members of the WGCR, who then identified major themes among the findings.

We received an answer from 15 of the 17 programs around the country. Responses came from a variety of sources, including program directors, site directors, curriculum leads, and individual residents. This variability likely influenced the unequal level of information received, from perspectives ranging from site level to overall program level. We were looking for program-wide perspectives; Canadian residency programs are large, university-based residency programs, some of them incorporating up to 16 sites. Programs are distributed across both urban and rural communities, over distances as great as 1,000 km, with variable numbers of residents (between 100 and 250). The survey was done before the release of the Triple C report ${ }^{1}$ but after program directors had received preliminary information on the recommendations to come. It was based on self-assessment; some responses demonstrated a limited understanding of some of the Triple C concepts.

While this was not a complete compilation of all relevant curricular activities in Canada, it does represent an extensive collection of Triple C-congruent curricular elements already in place as of 2009.

\section{SURVEY DATA}

Responses from the online survey were collected, analyzed, and summarized into the five key curricular elements (program organization and structure, clinical experiences, academic teaching, one-on-one teaching and supervision, and assessments of residents).

\section{Program Organization and Structure}

As of fall 2009, only one program reported overall program planning based on a competency framework. Very few programs had competency-based program objectives, although there were some rotation-specific competency-based objectives. There were a significant number of descriptions of integrated curricula with longitudinal family medicine exposure, integration with focused areas of care, and predominant supervision by family physicians. Such curricula were often site-specific rather than program-wide. The focused clinical areas integrated with family medicine most often were emergency medicine, care of elderly, pediatrics, and perinatal care. Residents' participation in these focused activities was usually compulsory. Programs reported an associated selection of specific faculty: an intentional selection of family physicians as role models and preceptors in focused areas of care (ie, care of elderly, inpatient care), collaborative care involving family physicians with other physicians, or family medicine-friendly specialists. We were also aware of one other program that had undergone restructuring but that did not report it via the survey.

\section{Clinical Experiences}

There were many reports of family medicine-led rotations in focused areas of practice, most often in perinatal care and inpatient care, but also in emergency care, palliative care, antenatal care, and care of newborns and children. Within these clinical experiences, supervision was provided primarily by family physicians, sometimes combined with other specialists. 
Collaboration between family physicians and consultants was described in both the inpatient and outpatient settings. Collaboration between consultants and family physicians, on a daily basis in a working relationship for all domains of inhospital care, was reported as a regular feature in community or rural sites. This collaboration models the family medicinefriendly hospital. Collaborative care and teaching within the family medicine experience, with specialists or allied health professional consultants, was seen most often in mental health care.

Carefully selected family medicine-oriented specialty experiences were also described. These opportunities occurred through the use of family medicine-oriented learning activities, rotation-specific objectives, family medicine-focused content, and family medicine-friendly specialists.

Many of these experiences seemed to be site-specific, depending on local resources, as opposed to implemented program-wide.

\section{Academic Teaching}

A number of programs described systematic planning of their academic programs, based on the 99 topics and on the CanMEDS-Family Medicine (CanMEDS-FM) Roles. ${ }^{*+}$ Some of these programs had implemented program-wide academic curricula, with materials accessed by all sites through the Internet. Many programs used such strategies as either family medicine-led academic teaching sessions, co-leadership by family physicians and consultants, or selection of family medicine-oriented consultants as faculty.

Programs paid significant attention to many specific areas of competencies. Behavioural medicine/counselling/mental health was largely present. Procedural skills and ethics were given as examples of competencies being taught. There were some reports of academic sessions aimed at development of the reflective practitioner, although the formats varied greatly. There were also some reports of strategies to promote competency in lifelong learning. There were no reports of integration of domains and competencies during academic teaching sessions, although we are aware of one program that had planned its academic program with that perspective but did not respond to the survey.

\section{One-on-one Teaching and Supervision}

There were fewer positive responses to this key element, relative to the other four. Some programs described their efforts to ensure that residents developed mini-practices, with continuity for a defined group of patients, and gradual autonomy over two years. Other programs described continuity of care over two years. Some responses emphasized gradual development of autonomy and increasing levels of responsibility, based on observation and graduated levels of supervision; similar remarks applied to the teaching of procedural skills.

Some respondents mentioned direct observation and video review as competency-oriented strategies. Others mentioned preceptorship and the 1:1 learner/supervisor ratio as their strategies. One response mentioned an intentional programwide focus during supervision on residents' development of their own management strategies and practice style. There was no other mention of program-wide efforts (ie, tools and faculty development) to focus on a range of competencies during supervision, or of the explicit use of role modeling.

\section{Assessment of Residents}

A significant number of pilot projects were mentioned, as either recently started or planned. Many programs were moving toward a competency-based evaluation system, using a variety of strategies and tools: portfolios, field notes, self-assessment tools, procedure logs, and the development of learning plans based on a review of prior competencies achieved.

Some programs used systems to monitor residents' progression, with an academic advisor, progress testing, or the use of benchmarks of competencies at stages over two years. One program based its overall decision of successful completion on a portfolio of clinical experiences and academic assignments.

There was no mention of remediation planning, with additional months of training, based on a lack of achievement of competencies; however, the WGCR was aware that such planning was happening regularly in the four residency programs within the province of Quebec.

*Adapted from Frank JR, ed. The CanMEDS 2005 Physician Competency Framework. Better standards. Better physicians. Better care. Ottawa: The Royal College of Physicians and Surgeons of Canada; 2005. Available from: www.royalcollege.ca/portal/page/portal/rc/canmeds/resources/publications. Accessed 2013 Apr 18. 


\section{References}

1. Tannenbaum D, Kerr J, Konkin J, Organek A, Parsons E, Saucier D, et al. Triple C Competency-Based Curriculum. Report of the Working Group on Postgraduate Curriculum Review - Part 1. Mississauga, ON: College of Family Physicians of Canada; 2011. Available from: www.cfpc.ca/uploadedFiles/Education/_PDFs/WGCR_TripleC_ Report_English_Final_18Mar11.pdf. Accessed 2013 Apr 18.

2. College of Family Physicians of Canada, Working Group on Curriculum Review. CanMEDS-Family Medicine: A Framework of Competencies in Family Medicine. Mississauga, ON: College of Family Physicians of Canada; October 2009. Available from: www.cfpc.ca/uploadedFiles/Education/CanMeds\%20FM\%20Eng.pdf. Accessed 2013 Apr 18. 


\section{Appendix B: Survey 2010}

\section{METHODOLOGY}

We found a relevant tool, developed by Dannefer and Henson, ${ }^{1}$ by which key leaders could assess their institutional progress toward competency-based education. This short questionnaire is self-administered and based on objective facts observed within an institution. Responses correlate with one of five stages of progression toward competency-based education. Its acuity as a diagnostic tool and relevance for program self-assessment have been validated through its repeated use during faculty development workshops on this issue.

We adapted the questionnaire to the level of a single residency program, instead of a faculty-wide, undergraduate context. The same data interpretation schema was used; that is, that specific responses or groups of responses correspond to each stage of progression (Table 1). 
Table 1. Questionnaire to assess institutional progress toward competency-based education (CBE) Data interpretation:

Stage associated to

Stage 1

Resistance

Stage 2

Initiation

Stage 3

Design and development
1. Our Program director (or Department chair) has mandated CBE but almost all faculty and the curriculum committees are resistant.

Stage 4

2. Our Program director (or Department chair) has mandated CBE, and a reasonable percentage of faculty and curriculum committee members think it's a good idea but are uncertain what it means.

3. Our curriculum committee and faculty are currently engaged in a series of retreats or other activities related to CBE.

4. Our curriculum committee, with support from the Department chair, has adopted an approach to establishing competencies for the program (e.g. use of an external model vs developing our own competencies).

5. Our program has begun the process of mapping our course goals, learning objectives, and assessment methods to our competencies.

6. Our program has selected a combination of evaluation methods to provide formative and summative assessment of competencies

7. Our program has developed a way of determining student progress (promotion and graduation) based on the achievement of competencies.

8. Our program has begun the process of transforming the schedule and content of rotations into relevant learning experiences (type, context, duration, longitudinal integration), in coherence with our program's competency framework.

9. Our program has begun the process of transforming the academic teaching program (context, teaching methods, faculty) in coherence with our program's competency framework.

Implementation

Stage 5

10. Our program has implemented CBE for at least one year of the curriculum.

Maintenance and 11. We have been using CBE for a sufficient time to have adjusted our curriculum, competency standards, and assessment methods based on program evaluation. evaluation

*This data interpretation item was not included in the self-assessment questionnaire but given afterward as a key for data interpretation.

Adapted from Dannefer E, et al. Workshop presented AMEE Annual Conference. Glasgow, UK; 2010 


\section{References}

1. Dannefer E, Henson L. Diagnosing and treating barriers to implementation in competency based education. Workshop presented at: Association for Medical Education in Europe 2010 Annual Conference; September 7, 2010; Glasgow, UK. 


\title{
Reflections From \\ the Triple C Task Force
}

\author{
Authors \\ Eric Wong, \\ on behalf of the \\ Triple C Competency Based Curriculum Task Force
}

Suggested Citation:

Wong E, on behalf of the Triple C Competency Based Curriculum Task Force. Reflections from the Triple C Task Force. In: Oandasan I, Saucier D, eds. Triple C Competency-based Curriculum. Report Part 2: Advancing Implementation. Mississauga, ON: College of Family Physicians of Canada; 2013. Available from: www.cfpc.ca/uploadedFiles/Education/_PDFs/TripleC_Report_pt2.pdf. Accessed 2013 Jul 29. 


\section{THE MISSION OF THE CFPC AND TRIPLE C}

Given that the mission of the College of Family Physicians of Canada (CFPC) is "to support family physicians through certification, advocacy, leadership, research, and learning opportunities that enable them to provide high-quality health care for their patients and their communities, ${ }^{\prime 1}$ the Triple C Competency-based Curriculum (Triple C), ${ }^{2}$ along with the CFPC's vision for the Patient's Medical Home, ${ }^{3}$ is one of CFPC's highest priorities. Triple C offers a critical pathway toward the Patient's Medical Home as it will provide Canada with the best-prepared family physicians to deliver comprehensive and patient-centred care within this model of family practice. Together, Triple $\mathrm{C}$ and the Patient's Medical Home are aimed to bring enhancements to the health of Canadians.

Recognizing the importance of Triple C, the CFPC has made a substantial investment in ensuring that its implementation will be successful. The Section of Teachers Council was charged with overseeing the implementation of Triple $\mathrm{C}$ and subsequently struck the Triple C Competency Based Curriculum Task Force (Triple C Task Force) in 2010 to ensure that efforts within and outside the CFPC will be coordinated to support this national transformation of postgraduate curriculum.

As primarily an advisory committee reporting to the Section of Teachers Council, the four-year mandate of the Triple C Task Force is "to advance the successful development and implementation of a national strategy to introduce and incorporate the Triple C Competency-based Curriculum into postgraduate family medicine programs across the country" (Triple C Task Force Terms of Reference, internal document). It was asked to do so by making recommendations in five key areas:

1. Knowledge dissemination

2. Faculty development

3. Policy recommendations

4. Evaluation plan

5. Cultivation of a culture of academic excellence and collaboration

The Triple C Task Force membership forum included representation from the universities (medical education deans, chairs of family medicine, family medicine postgraduate program directors, continuing professional development experts, rural medical educators, and family medicine residents) and members from CFPC educational committees (Section of Teachers Council, Working Group on Postgraduate Curriculum Review, Working Group on Certification Process, Accreditation Committee, and Board of Examiners). It is through this Task Force that implementation issues and decisions about Triple $\mathrm{C}$ are thoroughly analyzed and optimized from various viewpoints. Additionally, the Task Force serves the important function of communicating, engaging, and liaising with key stakeholders.

\section{KEY ACCOMPLISHMENTS OF THE TRIPLE C TASK FORCE}

With guidance from principles in change management, ${ }^{4,5}$ project management, theory of communities of practice, ${ }^{6}$ and curricular change, ${ }^{7}$ the Task Force began to meet its evolving challenges with ample support from multiple departments within the CFPC: Academic Family Medicine, Information Technology, Health Policy \& Government Relations, Research, and Communications. At the time this report was published, the Triple C Task Force would have just passed the midway point of its four-year term.

Some of the major achievements as of December 2012 are summarized in Table 1. 


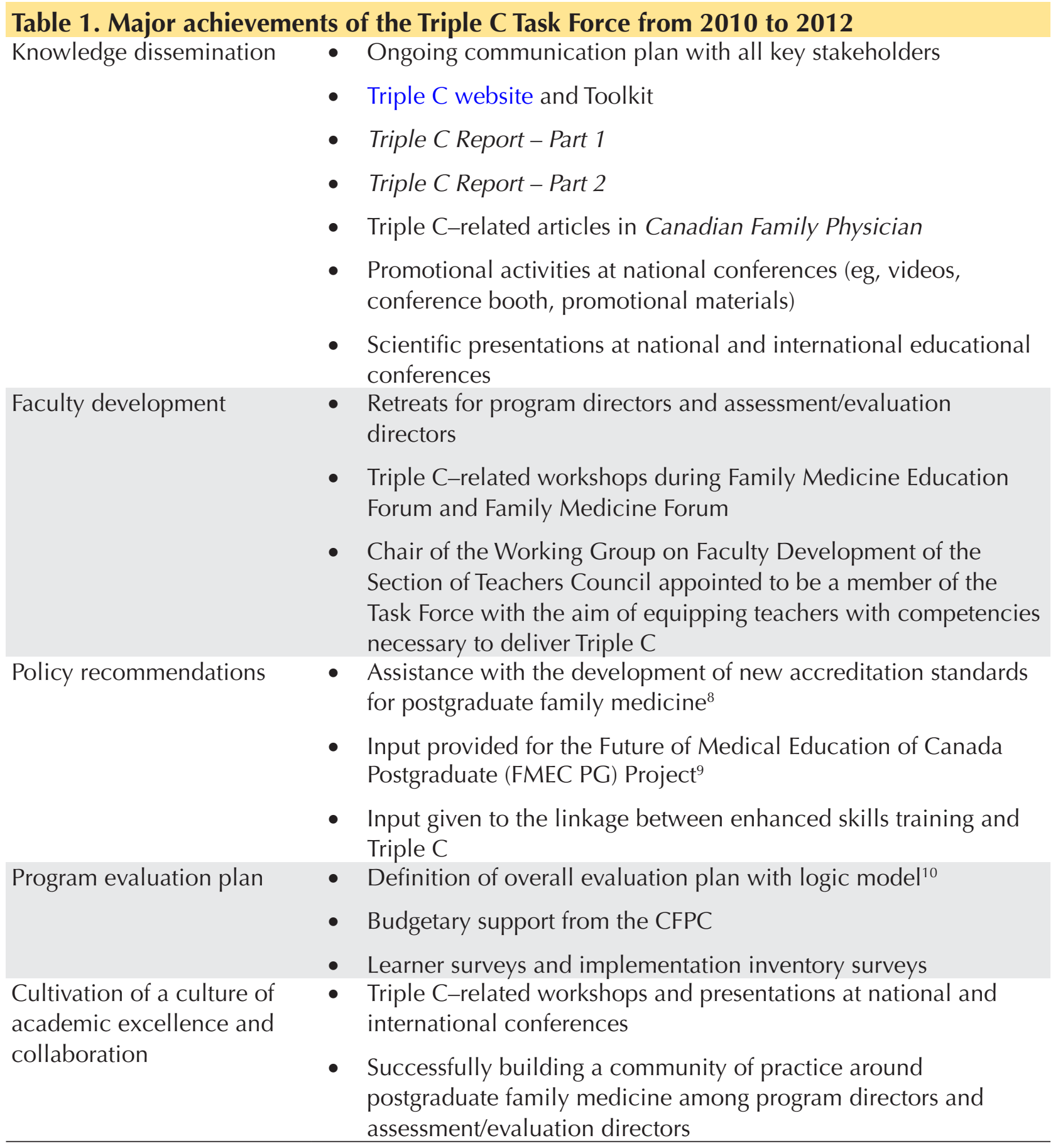

These accomplishments are leaving a lasting impact within and outside the CFPC. Within the CFPC, what was achieved required an unprecedented degree of coordination among various departments and committees, coupled with enormous commitment of human and material resources. Thus, it has become clear that the implementation of Triple $C$ necessitates a pervasive alignment of structures, policies, and processes within the CFPC. ${ }^{11}$ On the other hand, the rapidity of the adoption of Triple C by the 17 postgraduate family medicine residency programs has resulted in family medicine being the first Canadian medical specialty program to widely adopt a competency-based training system. In doing so, new frontiers are being created and the insights developed will be invaluable to the implementation phase of the FMEC PG project. $^{9}$ 


\section{EVIDENCE OF PROGRESS}

Since 2010, the Task Force has tracked progress toward a Triple C curriculum made by the family medicine residency programs with an annual survey. Data from this survey identifies a national portrait of progression toward Triple $\mathrm{C}$ and assists the Triple C Task Force in making decisions on next steps of support for training programs.

The first survey was developed by the Working Group on Postgraduate Curriculum Review, as described in "Transitioning to Triple C: Residency Program Perspectives From 2009 to 2010." 11 It was administered in December 2010, during a program directors' retreat on Triple C and was based on program directors' self-assessments. The survey offered a portrait of where the 17 family medicine residency programs stood regarding implementation prior to an intensive engagement process. The subsequent surveys were administered to program directors in November of 2011 and 2012 with a full response rate.

The Triple C Task Force has been working with family medicine residency programs to assist in implementing Triple $\mathrm{C}$ and to help it move along the stages of institutional progression toward competency-based education, as established by Dannefer and Henson (Table 2). ${ }^{12}$

\begin{tabular}{|c|c|}
\hline Stage & Description \\
\hline 1 & Resistance \\
\hline 2 & Initiation \\
\hline 3 & Design and development \\
\hline 4 & Implementation \\
\hline 5 & Maintenance and evaluation \\
\hline
\end{tabular}

Dannefer E, et al. Workshop presented at AMEE Conference. Glasgow, UK; 2010

Figure 1. Distribution of stage of progression toward a Triple $C$ competency-based curriculum, as self-assessed by program directors from 2010-2012

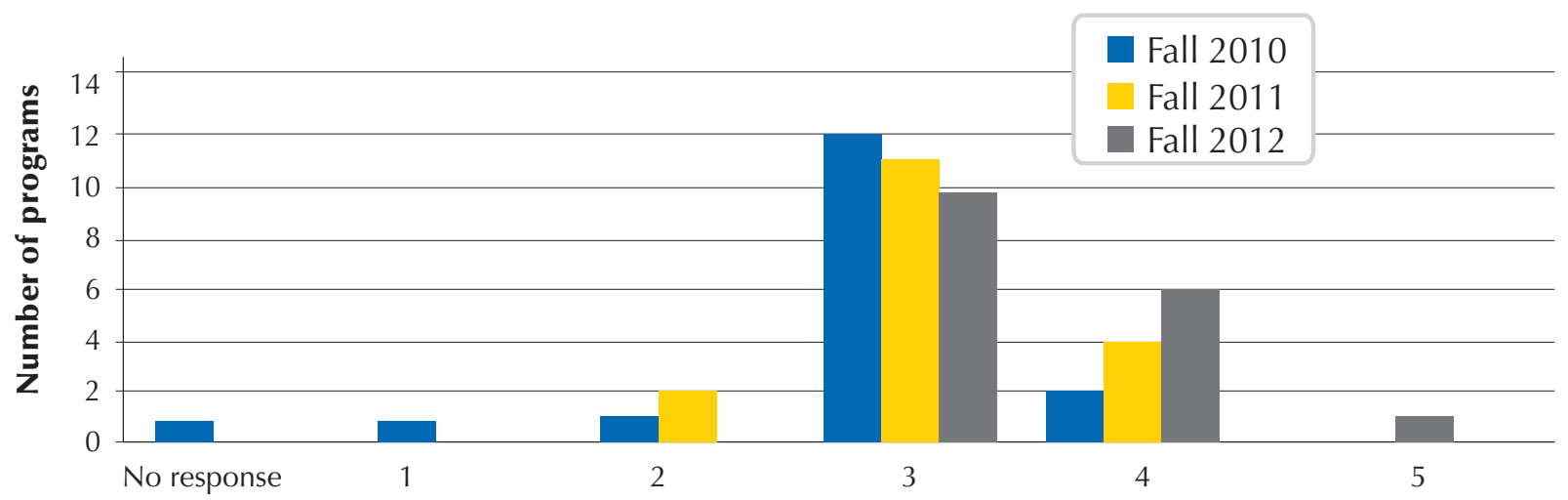

Stage of progression toward Triple C Competency-based Curriculum*

*Self-assess by program directors from 2011-2012 
Figure 1 shows incremental progression of programs on a yearly basis along the stages of institutional progression toward Triple C, building upon the work of Kerr et al. ${ }^{11}$ The Triple C Task Force identifies the following factors as critical to this successful pattern of adoption:

- Effective communication of the vision of Triple $\mathrm{C}$ by the CFPC

- Successful development of a coalition and community of practice within the CFPC for the advancement of Triple C

- Successful development of a community of practice among program directors on Triple C that enhanced the motivation and ability of program directors in making changes toward Triple $\mathrm{C}$

- Alignment of rewards and accountability with the Triple C vision through the development of the new accreditation standards

- Systematic identification and resolution of implementation challenges within a cooperative culture that focuses on human resource development

Additionally, Figure 1 provides two surprising results: 1) most programs seemed to have skipped the resistance and initiation stages and 2) two programs were already at the implementation stage in 2010 when the Task Force had just been struck. Engagement activities with program directors coordinated by the Working Group on Postgraduate Curricular Review might account for these findings. In addition, some programs had independently begun the transition to a competency-based curriculum prior to the release of the Triple C Report - Part $1,{ }^{2}$ enhanced by a long history of a culture of collaboration between the CFPC and program directors.

\section{ENSURING SUSTAINABILITY}

While the years 2010 to 2012 were characterized by the earlier steps in Kotter's model of change, ${ }^{4}$ the next phase will be focused on sustaining the ongoing change efforts and ensuring the entire postgraduate family medicine system will continue to improve and evolve under the guidelines of the Triple $\mathrm{C}$ curriculum. As discussed in Patterson et al, ${ }^{5}$ developing motivation and ability among postgraduate directors was the focus for the years 2010 to 2012. Moving forward, the concentration shifts to fostering motivation and ability in assessment and evaluation among directors, faculty developers, and frontline clinical teachers. It will also be critical to pay attention to how the overall environments and cultures in the postgraduate system, as well as the family medicine-specific postgraduate system, will support a transition toward competency-based education and Triple C. The Triple C Task Force, at their meeting in the fall of 2012, began to discuss and develop specific directions and strategies for 2013 and beyond. The Triple C Task Force foresees four critical tasks ahead:

\section{Facilitate knowledge translation about Triple $\mathbf{C}$ at the level of clinical teachers and residents}

Now that all programs are well on their way in the implementation phase, the critical question becomes whether the vital behaviours of Triple $C$ will be present at the coalface of clinical teaching and assessment. It is only when these behaviours have been clearly defined and enacted by our teachers that Triple $C$ will be anchored in the culture of postgraduate family medicine education. Part of this critical work will be taken on by the Working Group on Faculty Development, chaired by Dr Allyn Walsh. This group will define the competencies for our teachers, make recommendations on strategies to develop these competencies, and create a repository of faculty development tools that can support the acquisition of these competencies. 
The other piece of the puzzle will be the investment in a process that can support the faculty development activities within departments of family medicine. The Triple C Task Force recognizes that faculty development will be a crucial yet daunting task for programs, especially given the increased dispersion of training sites.

\section{Adopt competency-based educational methods across the continuum of medical education}

Postgraduate training stands as the critical path between undergraduate training and independent practice. Thus, undergraduate learners need to be prepared to train in a competency-based education system, and graduates of a postgraduate educational curriculum need to continue competency-based learning to maintain proficiency and enhance their patient-care abilities.

Priority has been placed on the clarification of the roles and linkages between Triple C, enhanced-skills training, and continuing professional development because there must be a clear, competency-based pathway for learning beyond core postgraduate training. Some of the critical questions in this area include: where and how do the roles and responsibilities of each of these educational curricula begin and end? How will the principles of Triple $\mathrm{C}$ be maintained so that the vision of the Patient's Medical Home can be achieved?

\section{Ensure adequate system support for family medicine to transition to Triple $\mathbf{C}$ within academic institutions}

Triple C is foremost a competency-based education curriculum that is supported by recommendation 4 of the FMEC PG project: "Integrate competency-based curricula in postgraduate programs. ${ }^{\prime \prime}$ Additionally, since family medicine is the first specialty in Canada widely implementing a complete competency-based curriculum, it will require alignment of policies and resources within the larger postgraduate education system.

In the times ahead, postgraduate medical education offices and departments of family medicine across the country will need to be engaged to a greater degree in the policy and resource implications of Triple $\mathrm{C}$ so that appropriate levels of system support can be provided. Initial discussions resulted in recommendations for attention and analyses on policies around evaluation, remediation, and cost implications so that key stakeholders at the universities will be prepared for a meaningful transition toward competency-based education.

\section{Develop appropriate structures and processes within the CFPC to continually support} postgraduate family medicine education within a continuous quality improvement model

The Task Force is currently working closely with the Section of Teachers Council to develop a proposal for a postgraduate curricular review process at the CFPC. Through the Task Force's experience with curricular implementation thus far, it has become clear that a permanent structure and process is required at the CFPC to embed the spirit of continuous evaluation and curriculum improvement in the postgraduate family medicine curriculum.

Recognizing that medical education exists to fulfill societal needs and that future recommendations for postgraduate family medicine curricular changes need to be informed by rigorous research and sound health policies, the Task Force has recommended that there be greater linkage and alignment between CFPC departments on health policy, research, and education. The comprehensive and rigorous evaluation plan for Triple $\mathrm{C}$ marks the beginning of a continuous quality improvement process that requires further support and development. 


\section{GREATER THAN TRIPLE C}

Reflection on the last two years of implementation reveals that, in addition to factors identified in the previous sections, the critical success of the Triple C Task Force has been facilitated by a diverse but likeminded group of individuals - its members! The diversity in the roles and backgrounds of the individuals serving on the Triple C Task Force enriched numerous discussions around implementation issues, while the like-minded commitment to excellence in postgraduate education consistently produced ideas and solutions that challenged the status quo and pushed the boundaries of new frontiers. The consequence of this collective wisdom has placed family medicine at the leading edge of the competency-based medical education movement in Canada.

Triple C marks an important milestone for the CFPC that has yet to be fully characterized. It has already catalyzed a critical assessment and review of the CFPC's role in postgraduate education in Canada. Additionally, it represents a unique opportunity to understand and shape the impact of postgraduate family medicine education on the delivery of primary health care to Canadians, an opportunity to fortify the foundational role of family medicine in the health care system in Canada. By reinforcing the vision of the Patient's Medical Home, ${ }^{3}$ Triple $C$ will enable the CFPC to achieve its mission "to support family physicians through certification, advocacy, leadership, research, and learning opportunities that enable them to provide high-quality health care for their patients and their communities." ${ }^{1}$ On an international front, the work surrounding the implementation of Triple $C$ will produce a unique body of knowledge and insight into competency-based medical education and, specifically, into family medicine education, which will benefit efforts of educational reforms around the world.

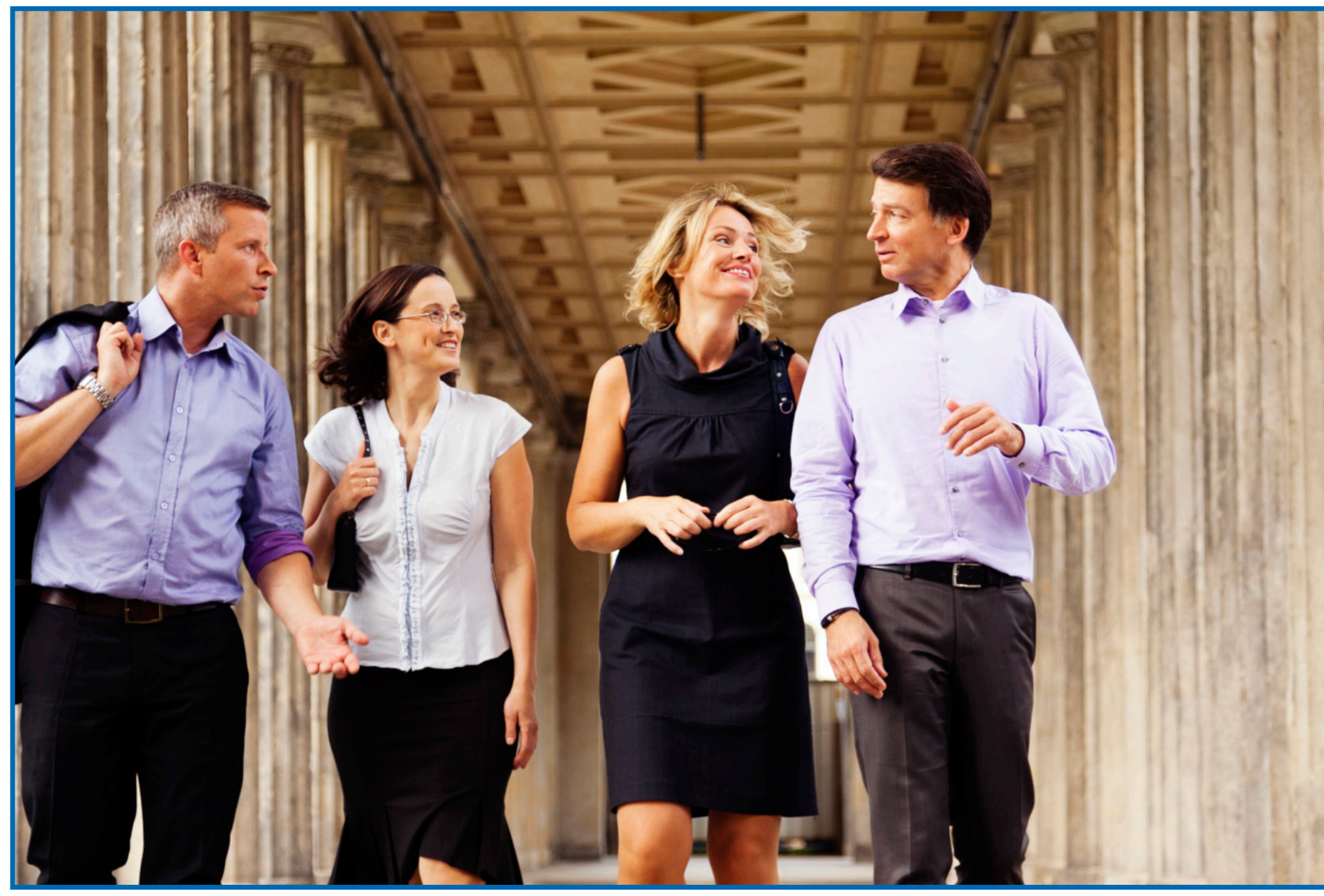




\section{References}

1. College of Family Physicians of Canada. Mission and goals. [website] 2013. www.cfpc.ca/ Mission. Accessed 2013 May 30.

2. Tannenbaum D, Kerr J, Konkin J, Organek A, Parsons E, Saucier D, et al. Triple C Competencybased Curriculum. Report of the Working Group on Postgraduate Curriculum Review - Part 1. Mississauga, ON: College of Family Physicians of Canada; 2011. Available from: www.cfpc. ca/uploadedFiles/Education/_PDFs/WGCR_TripleC_Report_English_Final_18Mar11.pdf. Accessed 2013 May 31.

3. College of Family Physicians of Canada. A Vision for Canada: Family Practice - The Patient's Medical Home. Mississauga, ON: College of Family Physicians of Canada; 2011. Available from: www.cfpc.ca/A_Vision_for_Canada_Family_Practice_2011/. Accessed 201311 Mar.

4. Kotter JP. Leading Change. Boston, MA: Harvard Business Review Press; 1996.

5. Patterson K, Grenny J, Maxfield D, McMillan R, Switzler A. Influencer: The Power to Change Anything. New York, NY: McGraw-Hill; 2007.

6. Wenger E. Communities of practice: Learning, Meaning, and Identity. New York, NY: Cambridge University Press; 1998.

7. Bland CJ, Starnaman S, Wersal L, Moorehead-Rosenberg L, Zonia S, Henry R. Curricular change in medical schools: How to succeed. Acad Med 2000;75:575-594.

8. College of Family Physicians of Canada, Academic Family Medicine Department. Specific Standards for Family Medicine Residency Programs Accredited by the College of Family Physicians of Canada: The Red Book. Mississauga, ON: College of Family Physicians of Canada; 2013. www.cfpc.ca/uploadedFiles/Red\%20Book\%20English.pdf. Accessed 2013 Mar 12.

9. Association of Faculties of Medicine of Canada. Future of Medical Education in Canada (FMEC) Postgraduate Report. A Collective Vision for Postgraduate Medical Education in Canada. Ottawa, ON: Association of Faculties of Medicine of Canada; 2012. Available from: www.afmc.ca/future-of-medical-education-in-canada/postgraduate-project/pdf/FMEC_PG_ Final-Report_EN.pdf. Accessed 2013 Mar 8.

10. Oandasan I, on behalf of the Triple C Competency Based Curriculum Task Force. A national program evaluation approach to study the impact of Triple C. In: Oandasan I, Saucier D, eds. Triple C Competency-based Curriculum Report - Part 2: Advancing Implementation. Mississauga, ON: College of Family Physicians of Canada; 2013. Available from: www.cfpc. ca/uploadedFiles/Education/_PDFs/TripleC_Report_pt2.pdf. Accessed 2013 Jul 29.

11. Kerr J, Saucier D, Wong E, Konkin J, Organek A, Parsons E, et al. Transitioning to Triple C: residency program perspectives from 2009 to 2010. In: Oandasan I, Saucier D, eds. Triple C Competency-based Curriculum Report - Part 2: Advancing Implementation. Mississauga, ON: College of Family Physicians of Canada; 2013. Available from: www.cfpc. ca/uploadedFiles/Education/_PDFs/TripleC_Report_pt2.pdf. Accessed 2013 Jul 29.

12. Dannefer E, Henson L. Diagnosing and Treating Barriers to Implementation in Competency Based Education. Workshop presented at the AMEE Annual Conference; Glasgow, UK; September 7, 2010. 


\title{
Triple C: Looking Ahead
}

Authors

\author{
Danielle Saucier and Ivy Oandasan
}

\section{Suggested Citation:}

Saucier D, Oandasan I. Triple C: looking ahead. In: Oandasan I, Saucier D, eds. Triple C Competencybased Curriculum Report - Part 2: Advancing Implementation. Mississauga, ON: College of Family Physicians of Canada; 2013. Available from: www.cfpc.ca/uploadedFiles/Education/_PDFs/ TripleC_Report_pt2.pdf. Accessed 2013 Jul 29. 
Triple C Report - Part 2 gathers a series of discussion papers, expert opinions, and tools from different committees at the College of Family Physicians of Canada (CFPC) to advance the implementation of the Triple C Competency-based Curriculum (Triple C). As the editors of this report, over a two-year period, we worked with all the authors involved in the writing of Triple C Report-Part 2. We are convinced that Triple C, with its related Triple C reports part 1 and 2, has helped to better articulate the role, identity, and competencies of future family physicians, as well as relevant curricular strategies to develop these competencies. Triple $C$ reports part 1 and 2 also reflect a general contribution to medical education through the implementation of competency-based medical education by the CFPC and the 17 university-based family medicine residency programs.

While the deliberations related to the future of family medical education at the CFPC were taking place, a large national project led by a consortium of Canadian medical education organizations was well under way. The Future of Medical Education in Canada Undergraduate (FMEC UG) and Postgraduate (FMEC PG) projects each released 10 recommendations to enhance the way medical education is to be provided in Canada. ${ }^{1,2}$ Triple $\mathrm{C}$ and its approach to competency-based curriculum design and learner assessment, faculty development, program evaluation, accreditation, and collaborative stakeholder engagement align with the 10 recommendations proposed by the FMEC PG report. $^{2}$

Triple $\mathrm{C}$ has also introduced new pedagogical language, an enhanced approach to curriculum, innovative teaching and assessment strategies, and new opportunities to leverage educational scholarship.

This final discussion paper in Triple C Report - Part 2 gathers the editors' concluding thoughts. Its aim is to stimulate conversation about the potential future of Triple C. Here, we discuss the value of Triple C, and suggest a series of critical next steps for the CFPC and its stakeholders to consider in their ongoing efforts to advance family medicine education.

\section{THE VALUE OF TRIPLE C REPORT - PART 2}

Triple C Report - Part 2 is meant to complement Triple C Report - Part 1. ${ }^{3}$ The first report presented high-level educational recommendations for a renewed curriculum for family medicine residency in Canada, based on international literature, widespread educational trends, and educational theories. The second report addresses issues related to the implementation of Triple C that affect the CFPC, the family medicine academic community, and other stakeholders in the health and educational systems. Each paper in Triple C Report - Part 2 addresses potential points of interest for different stakeholders related to Triple C. Some papers are referred to as discussion papers as they are meant to stimulate dialogue within the academic community about the potential impact of Triple C. All in all, the collective work shared in Triple C Report - Part 2, along with the collaboration that enabled its creation, provides an opportunity for the academic community to celebrate a new chapter in the history of family medicine. There are four characteristics of Triple C Report - Part 2 worth highlighting:

1. It showcases a national collective effort

2. It contributes to the affirmation of family medicine as a unique discipline

3. It is innovative, practical, and useful

4. It takes a scholarly approach 


\section{A national collective effort}

Triple C Report - Part 2 is the product of an intense national collective effort over the last few years. The papers assembled in this report have been written by a number of CFPC committees, with family medicine educators from across Canada, family medicine residents, and medical students providing key input. Many colleagues have contributed their perspectives, based on their experiences, real-life innovations, and literature. The authors of this report provide the best informed, expert opinions on different topics of concern related to the implementation process of Triple C. The discussion papers highlight issues and generate possible solutions, all in the context of enhancing family medicine education.

\section{Affirmation of family medicine as a unique discipline}

McWhinney argued in 1966 that family medicine is a unique discipline. ${ }^{4}$ Now, almost 50 years later, Triple $\mathrm{C}$ has enabled the CFPC to further affirm its uniqueness. Triple $\mathrm{C}$ reports part 1 and 2 highlight the new language being used to describe our specific competencies and the body of knowledge shared by family physicians. The family physician's unique activities and field of action have been better defined through CanMEDS-Family Medicine (CanMEDS-FM), ${ }^{*}$ the Domains of Clinical Care for residency training, ${ }^{6}$ and the Evaluation Objectives. ${ }^{7}$ Though developed for residency purposes, all three frameworks reflect the roles, tasks, and contexts of practising family physicians throughout Canada.

The new terminology and language being used will help the CFPC community better explain and affirm the discipline's uniqueness to learners, to medical colleagues from other disciplines, and to society at large. This is of particular importance for family medicine residency training, as "family medicine residents struggle to understand family physicians' unique expertise and to develop a sense of professional pride, because of their exposure to the "hidden curriculum" of the specialist consultant as the only true expert." ${ }^{3}$ Recent advances in medical education help us recognize that training involves an issue of professional identity alongside the development of competence, and therefore recommend that residency programs "include a focus on being rather than exclusively a focus on doing. ${ }^{\prime 8}$ The Triple C curriculum also empowers family medicine educators to shape the residency curriculum accordingly, to reflect the unique nature of family medicine as a discipline.

\section{Innovative, practical, and useful}

Triple C Report - Part 2 was purposefully developed for users to understand the practical and relevant aspects of Triple $\mathrm{C}$ so that they could also contribute to its implementation. Educational principles and theories were used where possible. Learned lessons from pilot projects, along with peer discussions, debates, and reviews, were also used to propose suggestions in this report. A major challenge faced by many of the Canadian family medicine educators is the little evidence available to guide the implementation, given that we are one of the first specialties to implement a competency-based curriculum at a national level. As we forge new ground, it behooves us to evaluate our progress, identify best practices, and share and disseminate our lessons learned. The ongoing national program evaluation of both process and outcomes is another Triple C-related innovation that demonstrates the CFPC's commitment to rigour and scholarship and to gathering useful information about the implementation of Triple C.

*Adapted from Frank JR, ed. The CanMEDS 2005 Physician Competency Framework. Better standards. Better physicians. Better care. Ottawa: The Royal College of Physicians and Surgeons of Canada; 2005. Available from: http://rcpsc.medical.org/canmeds/index.php. Accessed 2013 Apr 23. 


\section{Scholarly approach}

Triple C reports part 1 and 2 demonstrate our discipline's intellectually rigorous, scholarly approach to residency training. Scholarship, according to Hansen and Roberts (1992), "is demonstrated when knowledge is advanced or transformed by application of one's intellect in an informed, disciplined, and creative manner." ${ }^{\prime \prime}$ As presented by Glassick, Boyer divides scholarship into four domains: the scholarship of discovery, the scholarship of integration, the scholarship of application, and the scholarship of teaching. ${ }^{10}$ The expert opinions presented in the papers assembled in this report correspond to scholarship of integration or scholarship of application, whereas the program evaluation currently under way represents an ambitious endeavour in scholarship of discovery. The information presented in this report is based on the best evidence, experiences, teaching, and learning principles available to the authors. We believe the scholarly papers presented here can serve family medicine education well and can contribute to advancing competency-based medical education as a whole.

\section{CRITICAL NEXT STEPS FOR TRIPLE C}

This concluding paper of Triple C Report - Part 2 speculates on the steps to advance Triple C for long-term sustainability. We propose three key areas for consideration: ongoing curriculum renewal, dissemination of communication to key stakeholders, and pursuing scholarship and research.

\section{Ongoing curriculum renewal}

Education in family medicine is a dynamic process, not a static one. The CFPC should establish mechanisms for ongoing renewal of the curriculum content and process, competency-based assessment including tools and strategies, and Certification approaches for decision making that aligns with competency-based education. Ensuring that family medicine residency programs respond to the needs of the population, to changes in the structures and processes in the health care system, and to emerging pedagogies is critical if family medicine education wants to be responsive and relevant to society. Competencies expected of practising family physicians will evolve over time; therefore, what is taught and learned must be reviewed periodically. An ongoing review process would facilitate rapid adoption of relevant educational practices to better respond to the needs of Canadians in a systematic and structured manner. Various specific educational elements embedded within Triple $C$ also require ongoing review. Differences in type and scope of update requirements are detailed below.

\section{A) Core procedural skills}

The national list of core procedures residents should be competent to perform dates back to 2005. ${ }^{11,12}$ The CFPC needs to ensure that this list reflects the changing needs of communities and changing practices of family physicians. Ideally, this list of core procedures should be updated now, and should continue to be updated on a regular basis through a transparent process.

\section{B) 99 priority topics}

Priority topics (99 of them) for assessment for the purpose of Certification in Family Medicine 7,13 were derived from a systematic analysis of the results of two surveys conducted among practising family physicians. These topics should be updated periodically with a clear, repeated review mechanism in place. 


\section{C) Domains of Clinical Care for residency training}

The Domains of Clinical Care for residency training ${ }^{6}$ were determined by expert opinion in 2010. Because they are related, these Domains should be updated simultaneously with the priority topics, key features, and key themes.

\section{D) CanMEDS-FM Roles and six skill dimensions of competency frameworks}

Professional roles expressed through the CanMEDS-FM Roles ${ }^{5}$ and described in terms of observable behaviours at the end of residency through the six skill dimensions (patient-centred approach, communication skills, clinical reasoning skills, selectivity, professionalism, procedure skills) ${ }^{7}$ are expected to be refined over the coming years. The CanMEDS-FM Roles were adapted from the Royal College of Physicians and Surgeons of Canada's (RCPSC's) CanMEDS roles ${ }^{14}$ and contextualized for the specialty of family medicine. The two Colleges play a significant role in postgraduate education; it would be wise to ensure that messages and approaches related to the teaching and assessment of CanMEDS and CanMEDS-FM by the CFPC and the RCPSC are clearly articulated. Thus, ongoing collaboration between the CFPC and RCPSC is needed.

A delicate issue in this work will be to maintain the specificity of family medicine, as expressed, for example, in the definition, description, and key enabling competencies under the Family Medicine Expert role, which clearly reflect the Four Principles of Family Medicine. ${ }^{15}$ For the CFPC specifically, the CanMEDS-FM Roles should always be reviewed in relation to the assessment components expressed in the Evaluation Objectives. The relationship between curriculum and assessment in competency-based education is critical. Coherence between curriculum, in-training assessment, and assessment for the purpose of Certification needs to be maintained and further enhanced. The CFPC must ensure that the review mechanism initiated for the CanMEDS-FM Roles considers and seeks coherence with these elements.

We further recommend that a curriculum review committee be employed on an ongoing basis under the auspices of the Section of Teachers. This committee should oversee the periodic review of the aforementioned curricular elements, with a preoccupation to further overall Triple $\mathrm{C}$ curricular cohesion. The committee should also maintain an informational watch on new literature; synthesize arising evidence that might influence Triple C competency-based teaching, learning, and assessment; and highlight best practices that emerge from continued dialogue. Findings of the program evaluation and any other research conducted need to be shared with this committee so as to inform future decision making.

The review committee's mandate might include maintaining a perspective on the continuum of learning, from the undergraduate to continuing professional development levels, while working on its specific mandate in postgraduate education. An ongoing dialogue with the academic educational community would also serve well to pursue the rich multilateral exchanges that are currently very much part of the Triple $\mathrm{C}$ national implementation process. Finally, the committee should be responsible to recommend when and how to undertake the next overall curricular review, based on best judgment and taking into account new literature, evolving environment, growing needs, and opportunities.

\section{Communication with key stakeholders}

Sections of Triple C Report - Part 2 provide critical background information that will be helpful to multiple stakeholders. Residents, teachers, family physicians, educational administrators, partner medical education providers, and health care systems are all included as key stakeholders. "The Scope of Training for Family Medicine Residency $1 / 6$ is an example of a foundational paper that can inform 
the work of all those involved directly or indirectly with family medicine. It helps to further describe the meaning of comprehensiveness across the scope of family medicine. Clarification related to terms such as comprehensive care are important as the CFPC continues its implementation of the Patient's Medical Home. ${ }^{16}$ Such clarification informs discussions related to the scope of care that should be provided by family physicians.

Other papers in this report will assist educators involved across the continuum of medical education, and can help shape the collaborations needed to ease the transitions between undergraduate education postgraduate education, and continuing professional development. This report also highlights the resources, policies, structures, and practices needed to enable the move toward competency-based education. Some papers in Triple C Report - Part 2 especially guide the messaging about Triple C's resource implications for chairs, postgraduate deans, and other funders (see "Resource Implications for Departments of Family Medicine: A Discussion Paper" and "Potential Impact of Triple C on CFPC External Stakeholders: A Discussion Paper"). Triple C needs to be clearly understood such that it will be regarded as a solution that can support system change. Within the report, a number of strategies are shared that highlight the need to develop carefully crafted messaging for key partners.

Other discussion papers in Triple C Report - Part 2 can help stimulate dialogue related to policy issues facing enhanced skills, and length of training issues. Getting each paper in this report into the hands of the stakeholders for whom it was intended is paramount. To avoid uncoordinated approaches, unneeded expenditures, duplication of efforts and resources, and common mistakes, we recommend that the Triple C Competency Based Curriculum Task Force (Triple C Task Force) actively disseminate each paper to the appropriate stakeholders as part of a communications strategy to engage all those directly or indirectly involved with Triple C.

\section{Pursuing scholarship and research}

Scholarship and research are important to the successful implementation of Triple $\mathrm{C}$ as a whole. We strongly encourage the family medicine education community to see itself as the national "living laboratory" for Triple C. We envision several opportunities for advancing innovations, educational research, and scholarship by each faculty, department, and the CFPC as a whole. The CFPC and each department of family medicine could further encourage the academic community to engage in rigorous educational research locally or inter-institutionally across Canada. Exciting opportunities are presenting themselves for multisite research due to the ongoing collaborations between the residency programs in Canada, with the CFPC acting as a coordinating hub. The most urgent questions around Triple $\mathrm{C}$ relate to the practical application of theory in ways that are effective, efficient, and feasible. The impact of Triple $C$ on both human and financial resources are emerging as critical but challenging. The program evaluation plan described in "A National Program Evaluation Approach to Study the Impact of Triple $\mathrm{C}^{\prime \prime 17}$ provides an invaluable, inclusive perspective that could act as a blueprint for future research on Triple C's short-, medium-, and long-term outcomes.

The CFPC and its Section of Teachers are poised to play a key role in establishing systems that encourage members to produce quality scholarly work. The College can also act as a knowledge dissemination hub by developing a repository for best practices in competency-based curriculum and peer-reviewed assessment. It is also recommended that the CFPC continue to actively engage educational communities through different exchanges such as workshops, retreats, webinars, dedicated blogs, etc. We recommend that the CFPC continue using the Triple C website and Toolkit as a place for the community to add new national-level materials when available. The CFPC should be recognized as the main resource for Triple $\mathrm{C}$ information and tools. 
Strategies for sharing Triple C-related scholarly work will, in turn, encourage the community to disseminate Triple C-related information. More opportunities for presenting innovative "work-inprogress" opportunities could be showcased at the CFPC's Family Medicine Forum. Further, the discipline of family medicine can lead the way in building scholarly work, and can share innovations and best practices of a competency-based approach to education in family medicine on the world stage at international medical education conferences.

\section{CONCLUSION}

We are convinced that the Triple C Report - Part 2 will contribute to advancing family medicine residency education at the national level. It provides practical suggestions, strategies, and tools to help those who must make Triple C-related changes happen in their local universities, particularly program directors, chairs of family medicine departments, and postgraduate deans. It also highlights a series of issues to be addressed by the CFPC's educational committees to ensure that College policies are coherent with Triple $\mathrm{C}$. The continuation of the national collaboration between the CFPC and the academic family medicine community is key to pursuing this transformation to a competency-based curriculum, under the guidance of the Triple C Task Force.

Many countries around the world are embarking on family medicine residency programs and Canada is being looked to as a role model in postgraduate curriculum. Many learned lessons can be shared from more than 70 years of history and from a strong and dynamic educational transformation that speaks to the preoccupations of family physicians internationally. The Triple $\mathrm{C}$ project positions Canada as a leader in this area.

One of the most important potential impacts of Triple $\mathrm{C}$ lies in the practice of family medicine through the vision for the Patient's Medical Home $(\mathrm{PMH}){ }^{16}$

The $\mathrm{PMH}$ offers a way for the discipline of family medicine to respond to the present and future needs of Canadians. Triple $\mathrm{C}$ and the $\mathrm{PMH}$ share the common goal of providing comprehensive primary health care to Canadians. The PMH provides the vision of the structures, processes, practices, and policies that can support the delivery of comprehensive primary health care. Triple C provides the means by which future family physicians can gain the competencies needed to work collaboratively with patients, their families, and other health professionals within the $\mathrm{PMH}$ model. Thus, Triple $\mathrm{C}$ could be considered an intervention to develop family physicians ready to engage in practices that reflect the $\mathrm{PMH}$ model. We hope that the program evaluation will be able to shed some light on the influence Triple $\mathrm{C}$ has on the future practices of family physicians who graduate from a Triple $\mathrm{C}$ program. Triple $\mathrm{C}$ reports part 1 and 2 address issues that leverage the use of a complex systems approach to family medicine residency training. This complex approach sees family medicine education deeply intertwined with the medical education and health care systems in Canada, aimed at enhancing access and providing quality patient-centred care.

Triple C Report - Part 2 stands on its merits of being a pedagogically driven series of papers, prepared by thoughtful leaders in the discipline of family medicine who have contributed a new chapter in our discipline's history. Providing key landmarks to refer to when needed, possible directions to follow when faced with different issues, and reflective prompts to use when choosing paths to take, Triple C Report - Part 2 hopes to be one of the most picked-up resources for implementing the Triple C curriculum. It adds to our collection of scholarly work in family medicine that better describes our work as family physicians and our approach to teaching. We embark on the journey toward Triple C using the Triple C Report - Part 2 as an implementation guide to help us continue our historical quest 
to generate that "special kind of physician" — the family physician—who is a key player in the health care system. ${ }^{18}$

Triple $\mathrm{C}$ reports part 1 and 2 also provide meaningful contributions to the broader medical education community through the advancement of competency-based medical education innovations. Well aligned with the FMEC Undergraduate ${ }^{1}$ and FMEC PG projects, ${ }^{2}$ many of the suggestions and solutions discussed can serve, or be adapted to serve, throughout the continuum of education. Opportunities for the academic family medicine community to provide scholarly impact abound and must be seized. The mutual collaboration emerging from the FMEC projects enables the CFPC to help advance the future of medical education in Canada in a cohesive manner, for the good of the population.

Triple $\mathrm{C}$ was endorsed by the CFPC for its aim to enhance the delivery of family medicine residency education in Canada. The CFPC set the goal for family medicine residents to be equipped with the competencies reflective of the current and emerging needs of Canadians-to be ready to begin the practice of comprehensive family medicine in any community in Canada. Full implementation depends on the partnership between the CFPC, family medicine residency programs, external stakeholders, residents, and clinical teachers. We hope that Triple C Report - Part 2 is a resource for all those who are committed to implementing change and fostering excellence in the discipline of family medicine. 


\section{References}

1. Association of Faculties of Medicine of Canada. The Future of Medical Education in Canada (FMEC): a collective vision for MD education. Ottawa, ON: Association of Faculties of Medicine of Canada; 2010. Available from: www.afmc.ca/fmec/pdf/collective_vision.pdf. Accessed 2013 Apr 23.

2. Association of Faculties of Medicine of Canada. The Future of Medical Education in Canada (FMEC) Postgraduate Project. A Collective Vision for Postgraduate Medical Education in Canada. Ottawa, ON: Association of Faculties of Medicine of Canada; 2012. Available from: www.afmc.ca/ future-of-medical-education-in-canada/postgraduate-project/pdf/FMEC_PG_Final-Report_EN.pdf. Accessed 2013 Apr 23.

3. Tannenbaum D, Kerr J, Konkin J, Organek A, Parsons E, Saucier D, et al. Triple C CompetencyBased Curriculum. Report of the Working Group on Postgraduate Curriculum Review - Part 1. Mississauga, ON: College of Family Physicians of Canada; 2011. Available from: www.cfpc.ca/ uploadedFiles/Education/_PDFs/WGCR_TripleC_Report_English_Final_18Mar11.pdf. Accessed 2013 Apr 23.

4. McWhinney IR. General practice as an academic discipline. Reflections after a visit to the United States. Lancet 1966;1(7434):419-423.

5. College of Family Physicians of Canada, Working Group on Curriculum Review. CanMEDS-Family Medicine: A Framework of Competencies in Family Medicine. Mississauga, ON: College of Family Physicians of Canada; October 2009. Available from: www.cfpc.ca/uploadedFiles/Education/ CanMeds\%20FM\%20Eng.pdf. Accessed 2013 Apr 23.

6. Tannenbaum D, Kerr J, Konkin J, Organek A, Parsons E, Saucier D, et al. The Scope of Training for Family Medicine Residency: Report of the Working Group on Postgraduate Curriculum Review. Mississauga, ON: College of Family Physicians of Canada; 2011. Available from: www.cfpc.ca/ uploadedFiles/Education/_PDFs/8\%20The\%20Scope\%20of\%20Training\%20for\%20Family\%20 Medicine\%20Residency_Domains\%20of\%20Clinical\%20Care\%20and\%20Evolving\%20 Professional\%20Competencies.pdf. Accessed 2013 Apr 23.

7. College of Family Physicians of Canada, Working Group on the Certification Process. Defining Competence for the Purposes of Certification by the College of Family Physicians of Canada: The Evaluation Objectives in Family Medicine. Mississauga, ON: College of Family Physicians of Canada; 2010. Available from: www.cfpc.ca/uploadedFiles/Education/Definition\%20of\%20 Competence\%20Complete\%20Document\%20with\%20skills\%20and\%20phases\%20Jan\%202011. pdf. Accessed 2013

8. Jarvis-Selinger S, Pratt DD, Regehr G. Competency is not enough: integrating identity formation into the medical education discourse. Acad Med 2012;87;1185-1190.

9. Hansen PA, Roberts KB. Putting teaching back at the center. Teach Learn Med 1992;4:136-139.

10. Glassick CE. Boyer's expanded definitions of scholarship, the standards for assessing scholarship, and the elusiveness of the scholarship of teaching. Acad Med 2000;75:887-880.

11. Wetmore SW, Rivet C, Tepper J, Tatemichi S, Donoff M, Rainsberry P. Defining core procedure skills for Canadian family medicine. Can Fam Physician 2005;51:1364-1365. Available from: www.cfp.ca/content/51/10/1364.long. Accessed 2013 Apr 30. 
12. Wetmore S, Laughlin T, Lawrence K, Donoff M, Allen T, Brailovsky C, et al. Defining competencybased evaluation objectives in family medicine: procedure skills. Can Fam Physician 2012;58:775780. Available from: www.cfp.ca/content/58/7/775.full.pdf. Accessed 2013 Apr 23.

13. Allen T, Brailovsky C, Rainsberry P, Lawrence K, Crichton T, Carpentier M-P, et al. Defining competency-based evaluation objectives in family medicine: dimensions of competence and priority topics for assessment. Can Fam Physician 2011;57:e331-e340. Available from: www.cfp. ca/content/57/9/e331.full. Accessed 2013 Apr 23.

14. Frank JR, ed. The CanMEDS 2005 Physician Competency Framework. Better standards. Better physicians. Better care. Ottawa: The Royal College of Physicians and Surgeons of Canada; 2005. Available from: http://www.royalcollege.ca/portal/page/portal/rc/canmeds/resources/publications. Accessed 2013 Apr 23.

15. College of Family Physicians of Canada. Four principles of family medicine. College of Family Physicians of Canada. 2006. www.cfpc.ca/Principles/. Accessed 2013 Apr 23.

16. College of Family Physicians of Canada. A Vision for Canada: Family Practice - The Patient's Medical Home. Mississauga, ON: College of Family Physicians of Canada; 2011. Available from: www.cfpc.ca/A_Vision_for_Canada_Family_Practice_2011/. Accessed 2013 Apr 23.

17. Oandasan I, on behalf of the Triple C Competency Based Curriculum Task Force. A national program evaluation approach to study the impact of Triple C. In: Oandasan I, Saucier D, eds. Triple C Competency-based Curriculum Report - Part 2: Advancing Implementation. Mississauga, ON: College of Family Physicians of Canada; 2013. Available from: www.cfpc.ca/uploadedFiles/ Education/_PDFs/TripleC_Report_pt2.pdf. Accessed 2013 Jul 29.

18. Macinko J, Starfield B, Shi L. Quantifying the health benefits of primary care physician supply in the United States. Int J Health Serv 2007;37:111-126. 


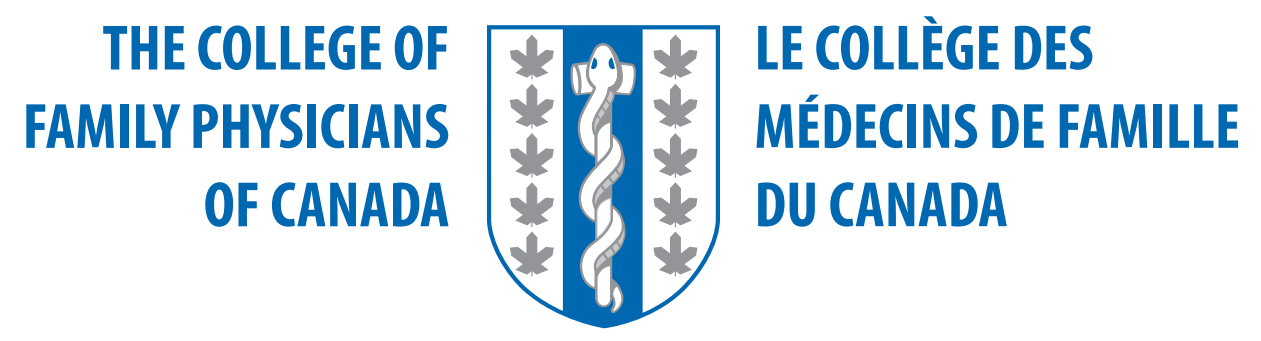

For more information, please visit $w w w+c f p c+c a / T r i p l e \_C /$

Canadian Family Medicine Curriculum

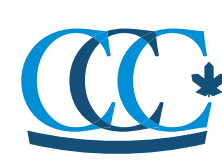

Le cursus en médecine familiale au Canada 